University of Louisville

ThinkIR: The University of Louisville's Institutional Repository

Electronic Theses and Dissertations

1946

\title{
The characteristics of Fiberglas as a column packing : III. mass transfer coefficients.
}

Charles P. Talbott 1923-2000

University of Louisville

Follow this and additional works at: https://ir.library.louisville.edu/etd

Part of the Chemical Engineering Commons

\section{Recommended Citation}

Talbott, Charles P. 1923-2000, "The characteristics of Fiberglas as a column packing : III. mass transfer coefficients." (1946). Electronic Theses and Dissertations. Paper 2180.

https://doi.org/10.18297/etd/2180

This Master's Thesis is brought to you for free and open access by ThinkIR: The University of Louisville's Institutional Repository. It has been accepted for inclusion in Electronic Theses and Dissertations by an authorized administrator of ThinkIR: The University of Louisville's Institutional Repository. This title appears here courtesy of the author, who has retained all other copyrights. For more information, please contact thinkir@louisville.edu. 
UNIVERSTTY OF LOUISVIITE

THE CHARACTERISTICS OF FIBERGIAS AS A COLUMN PACKING III MASS TRANSFER COEFFIC IENTS

\author{
A Thesis \\ Submitted to the Faculty \\ of the Graduate School \\ of the University of Louisvilie \\ in Partial Fulfiliment \\ of the Requirements \\ for the Degree of \\ MASTER OF GHEMICAL ENGINEERING
}

Department of Chemical Engineering

Charles Pa Talbott

December, 1946 
THE CHARACTERISTICS OF FIBERGLAS AS A COLUMN PACKING III MASS TRANSFER COEFFICIENTS

\author{
Charles P. Talbott
}

Approved by the Examining Committee

\begin{tabular}{|c|c|}
\hline \multirow{2}{*}{ Director } & G. C. Williams \\
\hline & R. C. Ernst \\
\hline & W. R. Barnes \\
\hline
\end{tabular}

December 1946 
The author wishes to acknowledge the kind assistance and helpful guidance of Dr. G. G. Williams who directed this research. 
CONTENTS

Page

Iist of Tables ............................ v

List of Figures $\ldots \ldots \ldots \ldots \ldots \ldots \ldots \ldots \ldots \ldots \ldots \ldots \ldots \ldots \ldots \ldots . . . \ldots 1$

Abstract $\ldots \ldots \ldots \ldots \ldots \ldots \ldots \ldots \ldots \ldots \ldots \ldots \ldots \ldots \ldots \ldots \ldots \ldots \ldots$. v11

Introduction $\ldots \ldots \ldots \ldots \ldots \ldots \ldots \ldots \ldots \ldots \ldots \ldots \ldots \ldots$

Historical $\ldots \ldots \ldots \ldots \ldots \ldots \ldots \ldots \ldots \ldots \ldots \ldots \ldots \ldots \ldots \ldots \ldots . . \ldots$

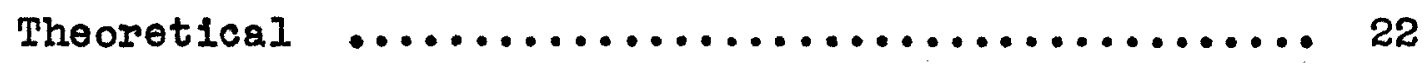

Experimental Procedure and Results ........... 43

Discussion of Results ..................... 79

Summary and Conclusions .................... 101

Iiterature cited ........................ 104

Appendix ................................. 108

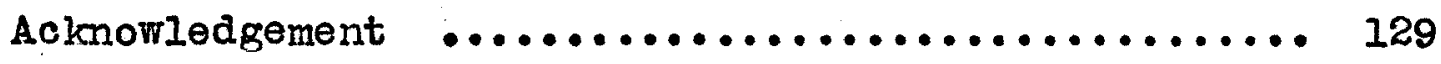

vita $\ldots \ldots \ldots \ldots \ldots \ldots \ldots \ldots \ldots \ldots \ldots \ldots \ldots \ldots \ldots \ldots \ldots \ldots \ldots \ldots \ldots \ldots . . \ldots 131$ 
IIST OF TABIES

Page

I Data of Minard, Koffolt, and Withrow ......85 85

II Data of Herman and Kaiser ............. 86

III Results of other Investigators ........... 89

IV Empirical Equations of Molstad, MoKinney,

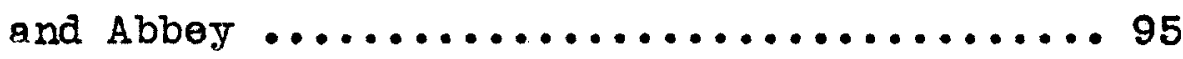

v Summary of Experimental Data ............. 119

VI Summary of Calculated Absorption Data ..... 124 


\section{LIST OF FIGURES}

Page

1. Diagram of Experimental Gas Absorber ........ 45

2. Vlew of Packed Column ....................46

3. Air Supply System to Column ................ 49

4. Blower and Humidifier Section ............ 50

5. One Inch Orifice Calibration Curve .......... 52

6. Two Inch Orifice Calibration Curve ......... 53

7. Three Inch Orifice Calibration Curve ........ 54

8. Rotameter Calibration Curve ............... 57

9. Br-Pass Rotameter Calibration Curve ......... 58

10. Ilquid Supply System and Gas Ex1t ........... 59

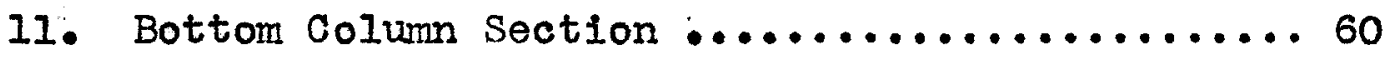

12. Sample Data Sheet ...................... 68

13. Effect of Water Rate on $\mathrm{K}_{\mathrm{g}}{ }^{\mathrm{a}} \ldots \ldots . . . \ldots . . . . . .72$

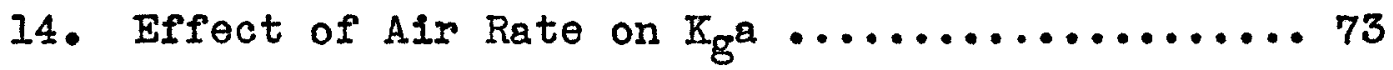

15. Effect of Air Rate on H.E.T.P. and H.T.U. .... 74

16. Effect of Water Rate on H.E.T.P. and H.T.U. ... 76

17. Correlation of H.T.J. with Reported Fiberglas

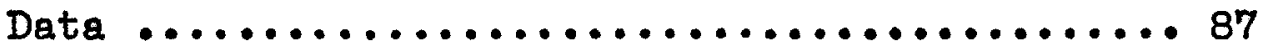

18. Comparison of Fiberglas with Other Packings ... 97 
vil

ABSTRACT 
The column that was designed, constructed, and operated to determine the mass velocity characteristics of Fiberglas packing, was continued in use for an investigation of its mass transfer efficiencies. The packed section of the tower was one foot in diameter, and absorption runs were carried out with packing heights of 6 and 10 feet. The Fiberglas was No. 800 fiber packed to a density of about 4.70 pounds per cubic foot: The absorption system, ammonia-water. was utilized in this investigation with air serving as the carrier gas. Air rates ranged from 280 to $1500 \mathrm{lbs} . / \mathrm{hr} . \mathrm{sq} . \mathrm{ft}$. With accompanying water rates varying from 1590 to $32,600 \mathrm{lbs} . / \mathrm{hr} . \mathrm{sq} . \mathrm{ft}$. The H.E.T.P.. H.T.U., and $\mathrm{K}_{\mathrm{p}}$ a values were calculated from the data of the individual runs. Graphs were prepared to demonstrate the effects of variant gas and

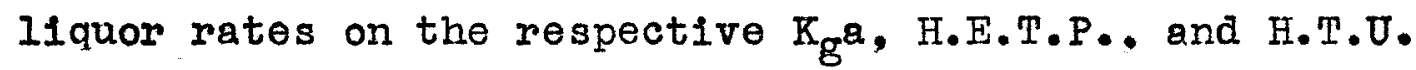
values. The results of this investigation are in excellent agreement with the accepted theory for an ammoniawater absorption process. The data are also compatible with the avallable data reported for Fiberglas in the Iiterature:

The results of this investigation indicate that Fiberglas compares favorably with the other commercially used packing materials in respect to mass transfer characteristics. The $\mathrm{K}_{\mathrm{ga}}$ values determined for Fiberglas varied 
from 0.005 to $0.023 \mathrm{lbs} . / \mathrm{min}$.cu.ft.mm.Hg. depending on the prevaling air flow rate. Design values of H.E.T.P. and H.T.U. are indicated in the ranges of 1.80 and 1.00 feet respectively for Fiberglas packing if the liquor flow rate is sufficient in quantity to wet the packing completely: 
INTRODUCTION 
The data presented in this thesis concern the third phase of the investigation of Fiberglas as a tower packing. The object of the research conducted on this recently avallable packing material was to extend the insufficient existent data pertaining to its mass velocity and ass transfer characteristics. Such data are required for the sound engineering design of packed columns as encountered in commercial absorption and distillation operations. The results of the loading and flooding tests of Fiberglas have already been reported and mass transfer coefficlent data are necessary to complete the preliminary investigation of this packing material.

Fiberglas No.800 is pure glass in a fibrous form averaging approximately 0.008 inches in diameter. The glass fibers are arranged in a jackstraw manner, and bonded together with a special temporary adhesive to give sufficlent rigidity for easy application and handing. The mechanical properties of Fiberglas as reported by the manufacturer indicate that it possesses to an exceptionaliy high degree a number of the properties necessary for a satisfactory packing medium. Such mechanical propertios will be briefly reviewed in the following section.

As an investigation of the material transfer efficiency of Fiberglas packing, an absorption process was chosen because absorption determinations are subject to very few restrictions of colum operating conditions. In carrying out experimental runs on a packed distillation column, the related operating 
variables such as feed composition, reflux ratio, available quantity of heat input, and condenser capacity inflict serlous Iimitations on the range of allowable vapor velocities and rates of down flowing liquor. In absorption procedures the only difficulties that restriet the permissible gas and liquor flows are the limiting values imposed by the column design. Flooding conditions dictate the maximum flow rates while a favorable gasIiquid absorbate balance is necessary in order to maintain a measurable amount of solute gas in the outlet gas stream. Therefore, an absorption tower was designed and constructed to carry out all three phases of this investigation, of which two have been previously reported.

The absorption system, ammonia-water, employing air as the carrier gas, was selected because there are considerable data from previous investigations of this system utilizing other, more comon tower packing materials. Thus, the ammonia-water system affords a maximum number of comparisons of Fiborglas packing with the other available column packings:

Absorption experiments permit calculations of overall material transfer coefficients $\left(K_{g} a\right)$, the height equivalent of a theoretical plate (H.E.T.P.), and the height of a transfer anit (H.T.J.) for extensive variations in operating conditions: 
HISTORICAI 
Apparatus in commercial use for gas absorption has never been standardized, and individual consideration must be alloted to the design of a column for each absorption problem. A tover packed with some solid material, over which a liquid is distributed and through which a gas rises, is the most common means of carrying out gas absorption. The desirable properties which this solid material or tower packing should possess have been listed by Badger and MCCabe (1). In the mass transfer characteristics of a packing material, a large surface per unit volume is of prime importance. Such a quality is desirable since, other factors being equal, the rate of absorption is directly proportional to the surface exposed.

That Fiberglas possesses, to an exceptionally high degree, the properties that a satisfactory tower packing medium should have is evidenced by the following facts as reported by the manufacturer (2): (1) lor weight per unit volume, (2) large surface area per unit volume, (3) large free cross section, (4) large free volume, (5) small weight of liquid retained, (6) mechanical strength, and (7) 10w cost. Part II of this investigation concerning the mass-velocity characteristics of Fiberglas as a column packing and presented by Akell (3) demonstrated that Fiberglas has high flooding velocities which lie between those of small size, large surface area packings, such as Berl saddles and Raschig rings, and those of the large size, Iow surface area packings, such as grids.

The surface area of Fiberglas ranges between 77 square 
feet per cubic foot at a packing density of 2 pounds per cubic foot, to 232 square feet per cubic foot at a packing density of 6 pounds per cubic foot. The surface areas of the other, more comnon solid packing materials as listed by Perry (4) lie between 10 and 30 square feet per cubic foot. The surface area of Raschig rings varies from 29 square feet per cublc foot for the 2 inch diameter rings to 148 square feet per cubic foot for rings $3 / 8$ inches in diameter. Berl saddles have surface area values ranging from 50 to 141 square feet per cubic foot for the $1 \frac{1}{2}$ inch and $\frac{1}{2}$ inch sizes respectively. However, one type of glass ring packing is reported to have surface areas from 131 to 283 square feet per cubic foot at densities from 18.3 to 51.6 pounds per oubic foot.

Fiberglas No.800 is pure glass in a fibrous form averaging approximately 0.008 inches in diameter. Since it Is pure glass, the individual long, thin fibers do not absorb water and are resistant to most chemicals. It is claimed to withstand weak solutions of alkalies, and most acids except hydroflouric and hot phosphoric. Being inorganic the glass packing is not subject to rot or decay.

As a packing material, Fiberglas has been utilized successfully in a number of applications in the absorption, distillation, and extraction flelds. During the war, it was well known that demands to fulfill the country's high production quotas for industrial alcohol, taxed existing distillation units to the limit of their capacities. New plate columns, which could be used to meet the demands, required non-obtainable 
strategic war materials and practically non-avallable skilled man-power to fabricate:

This condition suggested the adoption of several distillation units with fibrous glass as a packing materlal. These units were installed in large industrial alcohol plants and yielded a high-purity alcohol at a high production capacity.

In spite of the spreading applications of Fiberglas as a column packing, very few reports containing engineering data have been published. Some work in the fleld of distillation was reported by Minard, Koffolt, and Withrow (5) who presented the results of some 600 test runs on binary mixtures. Data are reported for both the enriching and stripping sections on two industrially important binary systems, ethanol-water, methanol-water, and also the enriching of acetone and water. Their column, a packed distillation unit, was 1 foot in diameter with packed helghts of both 1.5 and 6.5 feet. The Fiberglas was packed in a vertical arrangement. These investigators studied the effects of reflux ratio, vapor velocity, and feod composition on the performance of Fiberglas tower packing. Their results indicated that Fiberglas shows good rectifying performance, and a high rate of throughput combined with low pressure drop.

The ralues of (H.T.U.) or' the overall height of a transfer unit, were computed and included in the tabular data: However the tables do not include the liquid rate but simply Imply this rate by the ratio of $V / L$. The results were correlated by an extension of Colburn's method (6) which indicates 
that (H.T.U.) ov is a function of $m$, the slope of the vaporIiquid equilibrium curve, and $V / L$, the vapor-liquid ratio. The values of (H.T.U.) ov were plotted versus m. with $V / I$ as the parameter. Such plots demonstrate that a constant $V / I$ value, the (H.T.U.) ov gradually increased as the average slope of the vapor-liquid equilibrium curve became steeper. A higher V/I ratio simply displaced the curve upward. Thus, a series of curves representing different $\mathrm{V} / \mathrm{L}$ ratios was obtained for each binary system. In the case of ethanol-water, constant (H.T.U.) ov values were reached when operating in the upper regions of the equilibrium curve. The data from some of the experimental runs displayed (H.T.U.) ov values greater in height than the actual helght of packed section; that is, only fractional (H.T.U.) ov values were secured. Such data were disregarded for correlation purposes. Minard, Koffolt, and Withrow were able to obtain vapor in their column in the range of 120 to $11001 \mathrm{bs} / \mathrm{hr} . \mathrm{sq} . \mathrm{ft}$ : with a mafority of the runs being carried out at 500 lbs./hr.sq.ft. A Iimited quantity of avaliable steam prevented the achievement of higher vapor rates. Ilquid rates varied between 100 and $1150 \mathrm{lbs} \cdot / \mathrm{hr} \cdot \mathrm{sq} \cdot \mathrm{ft}$. Under conditions of total reflux, the liquor rate could logically be increased. Such flow rates are considerably lower than the throughputs under which commercial gas absorbers operate.

Another study of Fiberglas packed columns for distillation operations was conducted by Herman and Kaiser (7) to establish the H.T.U. values for Fiberglas packing when used in 
the rectification of alcohol. The work was done on a column I foot in diameter with Fiberglas in the horizontal jackstraw arrangerent packed to a helght of 5 feet 8 inches. Ethyl alcohol and water mixtures were distilled with the column being operated at total reflux and at varlous vapor velocities. H.T.U. values are presented in tabular form together with superficlal vapor velocities and $\mathrm{V} / \mathrm{L}$ ratios. These investigators correlated their results by plotting H.T.U. versus superficial vapor velocity for various fixed ethanol concentration ranges. Such plots resulted in a series of stralght lines which they interpreted to mean that H.T.U. was inversely proportional to the superficial vapor velocity. The height of a transfer unit was found to be lower when operating in the high ethanol concentration range and higher when rectifying in the low concentration range for any constant superficial vapor velocity. Such behavior indicated that in the same concentration range, the vapor velocity critically affects the H.T.U. of the packing. The vapor rates obtained by Herman and Kaiser varied from 450 and $1460 \mathrm{lbs./hr.sq.ft.} \mathrm{While} \mathrm{the} \mathrm{liquid} \mathrm{rates} \mathrm{ranged}$ from 350 to $1180 \mathrm{lbs.} / \mathrm{hr} . \mathrm{sq} . f t$. The average vapor and Iiquid rates amounted to approximately 800 and $700 \mathrm{lbs} / \mathrm{hr} . \mathrm{sq} . \mathrm{ft}$. respectively. Fractional H.T.U. values, that is, H.T.U. values exceeding the helght equivalent of the packed section were reported in some cases. Such values were included in the correlated data.

From the data avallable in the literature as mentioned 
above, the reported H.T.U. values for Fiberglas were obtained at low flow rates in conjunction with binary distillation work. These throughput rates do not approach the limiting. loading and flooding velocities as determined by Akell (3), and the mass transfer coefficient data which are essential for the sound engineering design of absorption towers are not included in the Iiterature.

The absorption system, ammonia-air-water, has been quite thoroughly studied during the past twenty-five years, and the results of numerous investigators have appeared in the Ifterature. The reported data cover the absorption of ammonia by water in wetted wall columns, packed columns, and spray towers.

Whitman and Davis ( 8 ), Monaweck and Baker $(9)$, and Hanks and McAdams (10) investigated the absorption of ammonia from air by a stirred body of water. The research performed by Haslam, Hershey, and Keen (II) was conducted in an effort to discover whether the proposed two film theory of gas absorption in a liquid would quantitatively describe the rate of absorption in given system under varying conditions for the case of liquid film controlling and gas film controling. A column of the wetted wall type, without packing, 3 inches in diameter and 3 feet in height was used, and data on the absorption of ammonia as solute gas from air by water are presented. The effects of gas velocity and temperature on the rate of absorption were studied with gas velocities ranging from 0.03 to 1.5 feet per second. The conclusions 
were that the coefficient of material transfer in absorption varies with the 0.8 power of the gas velocity and that temperature did not affect the value of the overall transfer coefficient to any great extent over the range of temperatures $10-50^{\circ} \mathrm{C}$. It was also concluded that the gas film coefficient decreased as the 1.4 power of the absolute temperature; whereas the liquid film coefficlent increases as the fourth power of the temperature.

Cogan and Cogan (12). Hanks and McAdams (10), and Hollings and Silver (13), as reported by Dwyer and Dodge (14), also absorbed ammonia from air by water in a wetted-wall tower. Hanks and McAdams also utilized hydrogen and butane as a carrier gas, while Hollings and silver used city gas as well as air. Hollings and Silver found no effect of liquor rate on ammonia absorption.

The work conducted on wetted-wall towers indicated that practically all the resistance to absorption was in the gas film even at high gas velocities. Most of the investigators who have studied absorption of ammonia in spray towers, in single drops of liquid, and in stirred or quiescent batches of liquid have either assumed that the gas film was controlling or interpreted their results as indicating that such was the case. Practically the only dissenting voice to such a theory was that of Whitman and Davis (8) whose experiments exhibited that there was an appreciable resistance in the liquid film.

of the early investigators in the field of ammonia 
absorption, the work of Kowalke, Hougen, and Watson (15) is most significant. These researchers were in first to present data on the mass transfer coefficients of ammonia in packed absorption towers. Haterials such as stoneware, quartz, and wood grids were packed to a height of approximately 3.5 feet in a sheet steel cylinder 16 inches in diameter. The variance In gas rate was from 48 to $240 \mathrm{lbs./hr.sq.ft.} \mathrm{with} \mathrm{water} \mathrm{flow}$ rates ranging between 60 and $820 \mathrm{lbs.} / \mathrm{hr} . \mathrm{sq} . \mathrm{ft}$. The ammonia concentration in the entering gas stream was varied, but the pressure of ammonia in the incoming gas amounted to about 10 millimeters of mercury for the majority of the experimental runs.

For each of the packings, a plot of overall transfer coefficients versus both gas and water flow was constructed. Br keeping one flow rate fixed while varying the other, a series of curves was procured from the data for a particular packing materlal. Empirical equations were derived expressing the overall transfer coefficient as a function of both the gas and Iiquid rates. Later investigators have shown that their data suitably fit an equation of the type in which $\mathrm{K}_{\mathrm{g}} \mathrm{a}$ is directly proportional to the 0.8 power of the gas rate. Three dimensional graphs were also prepared showing the combined effects of varlant $a i r$ and liquor rates on $\mathrm{K}_{\mathrm{g}} \mathrm{a}$.

From the results of their work Kowalke, Hougen, and Watson concluded that, for all practical purposes, the resistance offered to the transfer of ammonia by the liquid film is negligible as compared to that of the air film. Their data also demonstrated that the variation of the overall transfer 
coefficients with vapor pressure of ammonia in the entering gas stream and temperature is very slight.

Sherwood and kilgore (16) carried out an investigation to determine the relation between the rates of diffusion of amonia gas to and from a dilute aqueous amonia solution in a coke packed column. In other words, both absorption and desorption runs were performed. The column consisted of an iron plpe with an inside diameter of 4.02 inches packed for 42.1 inches of its length with 0.35 to 0.63 inch diameter household coke. The feed liquor was water for the absorption runs and the feed liquor rate was maintained constant at $324 \mathrm{lbs} . / \mathrm{hr}$.sq.ft: with an average temperature of $23^{\circ} \mathrm{C}$. Air was used as the carrier gas, and the gas velocity ranged from 150 to $510 \mathrm{lbs.} / \mathrm{hr} . \mathrm{sq} . \mathrm{ft}$. , at an approcimate temperature of $32^{\circ} \mathrm{C}$. The partial pressure of ammonia in the entering gas stream was approximately 30 millimeters of mercury while the partial pressure of ammonia in the outlet gas amounted to about 7 millimeters of mercury. The overall transfer coefficient was found to increase Inearly with an increasing gas velocity. At a gas rate of $507 \mathrm{lbs./hr.sq.ft.} \mathrm{the} \mathrm{re-}$ ported $\mathrm{K}_{\mathrm{G}}$ a value amounted to $201 \mathrm{lbs} / \mathrm{hr}$.cu.ft.atm. whlle a gas rate of $148 \mathrm{lbs} . / \mathrm{hr} . \mathrm{sq} . \mathrm{ft}$. presented a $\mathrm{K}_{\mathrm{g}} \mathrm{a}$ value of $102 \mathrm{Ibs} \cdot / \mathrm{hr} \cdot \mathrm{cu} \cdot \mathrm{ft} \cdot \mathrm{atm}$.

Comparison of these data with that of Kowalke, Hougen, and Watson shows that the overall coefficient at a given gas velocity is considerably greater in the case of the 
quartz packing. To explain such comparative results, it was concluded that the most important factor in comparing. the coke and quartz packings is the nature of the surface, as the liquor layers will be thicker and slower-moving on the rougher surface.

In the course of a general investigation on the efficiency of packed towers, experiments were undertaken to determine the comparative efficlency of packing materials for the absorption of gases using towers of several sizes. Results are reported by Chilton. Duffey, and Vernon (17) for the absorption of ammonia from air by water employing $3 / 4,1 / 2$ and $1 / 4$ Inch crushed stone and $1 / 2.3 / 4$, and 1 inch clay spheres in columns 3,6 , and 11.3 inches in diameter with packed heights of 4 and 8 feet. Water used as the scrubbing liquid flowed at a constant rate of $500 \mathrm{lbs} / \mathrm{hr} . \mathrm{sq} . \mathrm{ft}$. An air flow

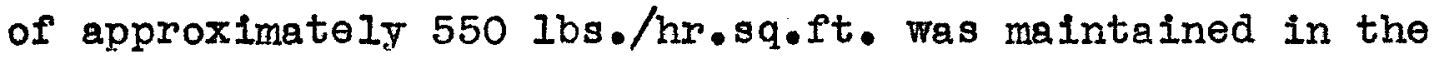
majority of the tests with the carrier air being saturated by means of a humidifier. The ammonia concentration in the inlet gas stream was approximately 5 per cent by volume for all the absorption runs. The natural logarithmic mean of the inlet and exit driving force was used in calculating the H.T.U. and $\mathrm{K}_{\mathrm{g}} \mathrm{a}$ values. The reported values of the overall transfer coefficient were normaliy in the range of $204 \mathrm{lbs} / \mathrm{hr} . \mathrm{cu} . \mathrm{ft} . \mathrm{atm}$., and the average height of a transfer unit was 1.5 feet. From the results of their experimental data Chilton, Duffey, and Vernon derived the following conclusions: Adequate initial water distribution is necessary to 
secure maximum absorption efficienoy.

(2) There is no definite effect of depth in the range of 8 to 16 tower diameters.

(3) There is no effect of tower diameter on the absorption efficiency of the packings tested when the ratio of tower diameter to packing diameter exceeds 8 to 1 . (4) For a given type of packing, the increase in absorption coefficlent is proportional to some fractional power of the increase in surface.

The data of Chilton, Duffey, and Vernon are in agreement with extrapolated $\mathrm{K}_{\mathrm{g}}$ a values of Sherwood and Kilgore.

Sherwood and Holloway (18) reviewed the available data presented by previous investigators on the absorption of ammonia by water. The data of Kowalke, Hougen, and Watson and of Chilton, Duffey, and Vernon were shown to follow the empirical question: $\quad K_{g} a=\gamma \quad G^{0.8}$ where $K_{g^{a}}$ is expressed in lb.mols./hr.cu.ft.atm. Sherwood and Holloway also report on the data for I inch carbon Raschig rings obtained by Borden and Squires (19) using a 10 inch diameter column packed to depths of 19 and 31 inches. The inlet gas mixtures contained from 0.3 to 6.5 mol per cent ammonia in air and 67 to 97 per cent of the enterIng ammonia was absorbed. Over the range of gas rates from 55 to $530 \mathrm{lbs./hr.sq.ft.} \mathrm{and} \mathrm{liquid} \mathrm{rates} \mathrm{from} 440$ to 2050 lbs./hr.sq.ft. the data were fitted by the empirical equation: 


$$
K_{g^{a}}=0.046 G^{0.5} 5_{L} 0.4
$$

At the intermediate values of $I$ and $G$ of 500 and 200 , respectively these results correspond to a value of $\gamma$ of 0.114 in the equation:

$$
K_{g} a=\gamma \quad G^{0.8}
$$

The values of $\gamma$, based on the data of previous investigators $(15,15)$ as computed by Sherwood and Holloway at $I=500 \mathrm{lbs}: /$ hr.sq.ft:, varies from 0.057 for 1 inch solld balls to 0.147 for $1-1 / 4$ and 1-3/4 inch broken quartz. Except for the difference in the exponent on $G(0.5$ in place of 0.8$)$, the data fall in line with the previous results on other packings. The tower constructed by Borden and Squires was used subsequently by Doherty and Johnson (20) who first repeated much of the work done by Borden and Squires. Employing a packing height of 16 inches of 1 inch carbon rings they absorbed ammonia from air by water in the range of $G$ and $I$ of 67-670 and 657-4,020 respectively. A comparison of their date with the previous data of Borden and Squire demonstrated that their $K_{g}$ values were from 10 to 20 percent higher than the $K_{B^{a}}$ values reported by Borden and Squires. The explanation may be that Borden and Squires used water at approximately $25^{\circ} \mathrm{C}$; Whereas Doherty and Johnson's mans were performed with water at about $12^{\circ} \mathrm{C}$. The effect of temperature on solubility would make $\mathrm{K}_{\mathrm{g}}$ a larger at the lower temparature. Borden and Squire's data for both 19 and 31 inch packed heights agreed well with the data of Doherty and Johnson who report a value 
of 0.36 for the exponent associated with $L$. The value of 0.4 was employed by Borden and Squire in the equation:

$$
K_{\mathrm{g}} \mathrm{a}=\gamma \quad \mathrm{G}^{\mathrm{n}} \mathrm{L}^{\mathrm{m}}
$$

Doherty and Johnson continued their investigation in the same apparatus, but using dilute aqueous solutions of sulfuric acid in place of water as absorbent. The acid normality was measured at the base of the tower although the acid rates were large enough so that the inlet and outlet normalities were essentially the same. It was established that $\mathrm{K}_{\mathrm{q}}$ e increased with acid strength and becomes a constant at 23.5 lh.mols./hr.cu.ft.atn, at a acld concentration of 3 normal. From such data Doherty and Johnson calculated that 77 percent of the resistance was due to the gas film while the liquid film represents 23 per cent of the overall resistance.

Dwyer and Dodge (14) carried out an investigation in order to furnish data on the ammonia-air system using Raschig ring packing. The packing consisted of $1 / 2,1,1-1 / 2$ inch carbon Raschig rings, and 48 inch depth of packing was utilized in all runs. The column was fabricated of 16-gage Iron with an inside diameter of 12 inches. The gas flow rate varied from 100 to $1000 \mathrm{lbs} / \mathrm{hr} . \mathrm{sq}$.ft. at a constant liquor rate of $500 \mathrm{lbs.} / \mathrm{hr} . \mathrm{sq} . \mathrm{ft}$. While the liquor rate ranged from 100 to $1000 \mathrm{lbs} / \mathrm{hr} . \mathrm{sq} . \mathrm{ft}$. at a constant gas rate of approximately $500 \mathrm{lbs.} / \mathrm{hr} . \mathrm{sq} . \mathrm{ft}$. For $\mathrm{I-I} / 2$ inch carbon Raschig rings, $G$ and $I$ values of 1000 and $480 \mathrm{lbs} . / \mathrm{hr}$. sq.ft. resulted in 
a $\mathrm{K}_{\mathrm{g}} \mathrm{a}$ of $13.7 \mathrm{lb} \cdot \mathrm{mols.} / \mathrm{hr}$.cu.ft.atm. whereas a $\mathrm{K}_{\mathrm{g}} \mathrm{a}$ value of $5.5 \mathrm{lb} . \operatorname{mols} . / \mathrm{hr} . c u . f t . a t m$. Was reported at $a \mathrm{G}$ and $I$ of 525 and $150 \mathrm{Ibs./hr.sq.ft.} \mathrm{respectively.}$

The effect of the humidity of the entering gas on the overall coefficient was found to be quite small, and in most cases, within the experimental error. The overall transfer coefficient was observed to decrease slightly as the temperatuer increased. This fact was already confirmed by the results of previous investigators.

Empirical equations were derived relating the separate dependence of $\mathbb{K}_{\mathrm{p}}$ en both $G$ and $I$ in such mathematical forms as the following:

For 1 inch rings

$$
\begin{aligned}
& K_{c^{a}}=0.29 G^{0.57} \\
& K_{g} a=0.77 L^{0.41}
\end{aligned}
$$

Assuming that the effects of gas and liquor rates are entirely independent, the two ma be combined in one equation.

$$
K_{g^{a}}=0.0225 G^{0.57} I^{0.4 I}
$$

This equation displays satisfactory agreement with the empirical equation established by Borden and Squires for 1 inch Carbon Raschig rings.

Dwver and Dodge also reported that the overall transfer coefficient was found to increase as the 0.45 power of the surface area. This coefficient agrees reasonably well with the conclusions of Chilton, Duffey, and Vernon who found an exponent of about 0.55 from their results on sold packings: 
an exponent of about 0.55 from their results on sold packings: The performance of several types of Drip-point grid tower packings were studied together with the other more common packing mediums by Molstad, McKinney, and Abbey (21) for the absorption of ammonia by water. The column was constructed of sheet metal, 12-1/8 Inches square, with a packing depth of 27 inches. The tower packings consisted of one inch Rasohig rings and Berl saddles, wood grids with and without legs, several varities of spiral tile, and three types of Drip-point grid tile. At a constant water rate of 3000 lbs./ hr.sq.ft;, the gas rate was varied between the limits of 100 and $1100 \mathrm{lbs} . / \mathrm{hr} . \mathrm{sq} . \mathrm{ft}$. Water rates were fluctuated for the operating range of 1800 to 18000 lbs./hr.sq.ft. at a constant gas throughput of $500 \mathrm{lbs} / \mathrm{hr} . \mathrm{sq} . \mathrm{ft}$. The ammonia concentration in the inlet gas stream was maintalned at approrimately 3.0 per cent by volume during all runs. Tabular data are presented which includes the H.T.U. values.

The data obtained for each packing material are fitted to an empirical equation expressing $K_{g}$ as an exponential function of the gas and liquid rates. These equations are of the famillar form,

$$
K_{g^{2}}=\beta a^{n} L^{m}
$$

where $\beta, n^{\prime}$, and in' are constants for each individual colum packing. Such constants were calculated and presented in tabular form for the various packings: 
The data of Molstad, McKinney, and Abbey showed that the overall transfer coefficlent increased with an increase in elther the gas or water rates, and in more cases can be represented by straight lines on a double logarithmic scale plot. The variation of $K_{g}$ with gas rate ranged from the 0.40 to the 0.90 power of the gas rate depending on the packing. This variation indicated that a single value such as 0.8 cannot be taken for all packings and that the exponent for any packing may depend on the relative importance of laminar diffusion and transfor due to gas turbulence:

Whitman, Long, and Wang (22); Hatta, Veda, and Baba (23); and Johnstone and Williams (24), as mentioned by Dwyer and Dodge (14), reported on the absorption of ammonia from alr by single drops of water. Johnstone and Williams also used sulfuric acid as absorbent in place of the water. Overall transfer coefficients for the absorption of ammonia and sulfur dioxide in a water spray and the absorption of benzene vapors from air into an oll spray were determined from an inner "wall free" section of a spray type absorption tower by Hixson and Scott (25). The effects of varlable fluid flows at three tower heights were investigated. The spray tower was fabricated of galvanized iron tubing with an inside diameter of $2-7 / 8$ inches. The tower height varied from 19 to 54 inches. The spray nozzles produced rather large drops which ranged from 1.5 to 2.0 millimeters 
In diameter. Ilquid velocity from the nozzle varied from 0.23 to 1.58 feet per second. The incoming gas stream contained ammonia in concentrations ranging from 1 to 2 per cent by volume:

Core and total $\mathrm{K}_{\mathrm{g}}$ values were reported. The core $\mathrm{K}_{\mathrm{g}} \mathrm{a}$ values discounted the ammonia abrorbed by the water running down the inside surface of the column walls: The relation of $K_{\mathrm{g}}$ and the variables, such as flow rates and tower height, was expressed by the derived equation

$$
K_{g^{a}}=\frac{C G^{0.8}}{H^{0.5}}
$$

where $\mathrm{K}_{\mathrm{g}} \mathrm{a}=$ overall transfer coefficient in the united of

$$
\text { Ibs./min.cu.ft: mm.Hg. }
$$

$G$ and $I=$ gas and liquid rates respectively in

$$
\begin{aligned}
& \text { Ibs./sq.ft.min: } \\
& H=\text { tower height in foet } \\
& C=\text { a constant }=2.5 \times 10^{-5} \text { approximately: }
\end{aligned}
$$


22

THEORET ICAI 
Gas absorption in the usual sense involves the transfer of material from the gas phase into a liquid, in which it is more or less soluble. While gas absorption has been practiced in one form or another for a considerable period of time, there still remains mach to be learned about the theory of gas absorption and the equipment most suitable for a specific application. It will be necessary here to treat this subject in the light of the present accepted theory, which may be quite incomplete with respect to both theory and practice.

Gas absorption has been properly designated as one of the diffusional operations. Sinoe it is a diffusional process, the general mechanism of the absorption of a constituent from a gas phase by a liquid must be analyzed from the twofold polnt of view of equilibrium and reaction rate.

The so-called "two-film" theory has proved quite useful in predicting or explaining the change in absorption rate which results from a change in condition. Although it is still only a theory, it is plausible and in fair agreoment with the existing data. Whitman (26, 27) suggested the two-film theory In 1923, and sinoe then several other investigators have extended and elaborated on 1t. The film concept has been of inestimable service in provialng a mental picture of the surface resistances encountered in interphase transfer of materials, and of heat. The word "film" is somewhat misleading, however, since it is frequentiy inferred that the resistance is offered wholly by a layer of absolutely stationary fluid at the inter- 
phase boundary. The error of such a conclusion has been demonstrated by Black and Monroe (28) who show the moisture gradients in an air stream flowing through a wetted-wall column at a Reynolds number in the turbulent flow region as reported by Sherwood (29). It is possible, however, to imagine a purely stagnent fluid film of such a thickness that It would offer the same resistance as is usually encountered in transfer between the phases. The thickness of such a fictitious film is best termed the "effective film thickness". In concluding the qualitative discussion of the film concept, It should be emphasized that whereas the principal resistance to interphase transfer of heat or material is encountered in a narrow zone very near the interface, an appreclable resistance is also present in the main turbulent fluid stream.

The flrst requirement of engineering equipment for gas absorption is that it be designed to bring two separate phases into intimate contact. Since the gas to be treated, and the liquid solvent, are both fluids, the materlal at the interface or surface of contact between the phases is not fixed but may itself be in motion. Owing to free or forced connection currents, the main body of each fluid is invariably in motion with respect to the interface. There is,consequently, a fluid "film" adjolning the interface in each f1lm, and the principal resistance to interphase diffusion is this double film. The relative resistances of the liquid and gas films depend primarily on the nature of the fluids, their 
relative motion, and the solubility of the solute gas in the absorbing liquid.

The analytical treatment of the diffusion through each of the two films has been quite thoroughly described by Sherwood (30). Since the films are sufficiently thin so that the solute retained by them may be neglected, it is possible to equate the rates of diffusion through the gas and liquid Pilns.

$$
N_{A}=\frac{D P}{R N_{g}} \frac{\left(p_{g}-p_{I}\right)}{p_{B M}}=\frac{D_{I}\left(C_{A}+C_{B}\right)\left(C_{I}-C_{I}\right)}{\psi_{I} C_{B M}}
$$

There appears to be no evidence of an appreciable diffusional resistance at the actual interface, and it seems only reasonable, but in accord with the avallable data, to assume that there exists no resistance of such a character. It follows, therefore, that the gas and Ilquid phases at the actual interface are in equilibrium and that the relation between $p_{1}$ and $c_{1}$ is the equilibrium relation between the two phases for the system involved. The overall resistance to interphase diffusion is evidently the sum of the individual gas and IIquid "film resistances":

For purposes of engineering computations, many of the terms of Eq. (1) may be grouped in the form of individual "film coefficients" and the expression rewritten.

$$
N_{A}=k_{g}\left(p_{g}-p_{I}\right)=k_{L}\left(c_{1}-c_{I}\right)
$$


Where $k_{g}$ is the gas film coefficient and $k_{L}$ is the Iiquid-film coefficient: Obviously $\mathrm{k}_{\mathrm{g}}$ is a function of temperature, total pressure, and mean pressure of inert as well as of the varlous factors which determine the value of $D$ and of the effective gas-film thiokness. Similarly, $k_{L}$ is a function of solute concentration and $D_{\mathrm{L}}$ and of those factors governing $\psi_{L}$. For these reasons the extrapolation of experimental values of $k_{g}$ and $k_{L}$ is usually somewhat hazardous:

Equation (2) states that the weight rate of diffusion through each film is proportional to the driving force applioable to the particular phase. In the case of the gas film the driving force is expressed in terms of partial pressures, while in the liquid film it is expressed in terms of solute concentrations. The ratio of the driving forco $\left(p_{g}-p_{1}\right)$ to the driving force $\left(C_{1}-C_{L}\right)$ is determined by the ratio of $k_{L}$ to $k_{g}$, but the actual values of $p_{1}$ and $C_{1}$ are determined by the equilibrium or solubility relation. For example, if $k_{g}=k_{L}$ then

$$
\left(p_{g}-p_{1}\right)=\left(c_{1}-c_{L}\right)
$$

If the case in question is that of a very soluble gas, then the only way for the driving forces to be equal would be for $p_{1}$ to be nearly as small as $p_{g}$, the equilibrium value corresponding to $C_{I}$, since with a large value of $p_{I}$ the concentration $C_{1}$ would be very large and the difference $\left(C_{1}-C_{L}\right)$ too great. Actually, if $k_{I}$ and $k_{g}$ are of the same order of 
magnitude in the units employed, then for a liquid and a very soluble gas, such as water and ammonia, $p_{1}$ will necessarily be practically equal to $p_{\theta}$ and equation (2) may be written

$$
N_{A}=k_{g}\left(p_{G}-p_{e}\right)
$$

It follows that the rate of diffusion is nearly the same as though the liquid film were absent, and the gas film resistance is sald to be controlling. This conclusion is supported by experlence with industrial absorption equipment, in whioh it is found that the factors influencing the Ifquid film resistance are of negligible consequence when handing liquids and highly soluble gases:

Pursuing a similar line of reasoning, it follows that for liquids and relatively insoluble gases, $p_{1}$ becomes nearly equal to $\mathrm{p}_{g}$ and $\mathrm{C}_{1}$ nearly equal to $\mathrm{C}_{e}$, the equilibrium value corresponding to $\mathrm{pg}_{\mathrm{g}}$. The diffusion equation becomes

$$
\mathrm{N}_{\mathrm{A}}=\mathrm{k}_{\mathrm{L}}\left(\mathrm{C}_{\theta}-\mathrm{C}_{I}\right)
$$

The gas film is eliminated from consideration, and the liquid f1lm resistance is sald to be controlling. For gases of intermediate solubility, the resistance of each film must be taken into account.

Where allowable, it is convenient to employ a single overall coeffielent, in place of the two film coefficient, $k_{g}$ and $k_{L}$ : The two overall coefficlents, $K_{g}$ and $K_{L}$ are defined by the equation.

$$
N_{A}=K_{B}\left(p_{g}-p_{\theta}\right)=K_{L}\left(C_{\theta}-C_{L}\right)
$$

where $p_{e}$ is the pressure in equilibrium with the concentration 
$C_{L}$, and $C_{e}$ is the concentration in equilibrium with the pressure $\mathrm{p}_{\mathrm{g}}$. $K_{g}$ is the overall coeffiolent in terms of pressures, and $K_{L}$ is the overall coefficient in terms of concentrations:

It is Important to realize that the overall coefflcient should be employed only when $\left(p_{g}-p_{\theta}\right)$ remains proportioned to $\left(C_{e}-C_{L}\right)$ as pressure and concentration are varied. If this proportion ceases to hold, it is evident from Eq.(6) that as the concentration changes, $K_{L}$ or $K_{g}$ will vary. In order for the proportion to hold, it is necessary that Henry's law should apply; that is;

$$
\mathrm{C}=\mathrm{H}_{\mathrm{p}}
$$

For systems which do not follow Henry's law, the overall coefficients are frequently found to vary widely with concentration, and should be used with the utmost caution.

Where Henry's law does apply, the relation between the overall and the individual film coefficients may be obtained by eliminating $c_{1}$ and $p_{1}$ from Eqs. (2) and (6):

$$
\begin{aligned}
& 1 / K_{\mathrm{L}}= 1 / \mathrm{k}_{\mathrm{g}} \quad 1 / \mathrm{E}_{\mathrm{L}} \\
& \text { and } \\
& I / \mathrm{K}_{\mathrm{L}}=1 / \mathrm{K}_{\mathrm{L}} \quad \mathrm{H} / \mathrm{k}_{\mathrm{g}}
\end{aligned}
$$

It is evident from Eqs. (8) and (9) that as $I$ becomes high In value, the gas $11 \mathrm{~m}$ resistance approaches the overall resistance, and $\mathrm{k}_{\mathrm{g}}$ approaches $\mathrm{K}_{\mathrm{g}}$ in the limit. Similariy if H Is made very small, the liquid $\mathrm{fl} I \mathrm{~m}$ and overall resistances 
become practically equal in magnitude. Since a large H corresponds to high solubility, these considerations verify the previous general conclusions that gas-film resistance becomes controlling for highly soluble gases, but that in the case of a gas of low solubility the controling resistance is sponsored by the liquid film.

The overall coefficlent $\mathrm{K}_{\mathrm{g}}$ was defined by Eq. (6) to be the rate of interphase diffusion as mols per unit time per unit area per unit of driving force expressed in terms of pressures. The superficlal surface area of the ordinary packed tower is difficult, if not impossible, to evaluate: It is usualiy possible to calculate the total surface of the dry packing material, but this is somewhat greater than the Interfacial ares, because the circulated solvent tends to collect at the points of contact of the lumps of paciring. Then, too, the effect of column channeling may prevent the solvent from being distributed over all the packing surface. At low solvent throughput rates, the solvent may not be sufflolent in quantity to completely wet all the surface area of the packing. For such reasons it is convenient to introduce a new variable $a$, which represents the interfaclal area per unit of tower volume. Since both $a$ and $K_{g}$ depend primarily on the nature of the packing, they may be combined as a product $\mathrm{K}_{\mathrm{g}}$, which represents the overall capacity coefficlent on a volume basis for any particular paoking. Thus $\mathrm{K}_{\mathrm{g}}$ a represents 
rate of interphase diffusion expressed as mols per unit time per unit volume, per unit of driving force in terms of pressures: It can be defined by the equation

$$
\mathrm{H}_{\mathrm{A}} \mathrm{aV}=\pi_{\mathrm{g}} \mathrm{a} \mathrm{V}\left(\mathrm{p}_{\mathrm{g}}-\mathrm{p}_{\theta}\right)
$$

where $V$ represents the volume of packed section. $K_{L^{a}}$ is similariy defined by the equation

$$
N_{A} a V=K_{L} a \quad V\left(C_{\theta}-C_{I}\right)
$$

as the rate of diffusion as mols por unit time per unit volume, per unit of driving force in terms of concentrations:

In the application of the various rate equations the conditions of a comercial absorption tower, it is necessary to allow for the fact that both gas and Ilquid concentrations vary throughout the apparatus. Walker, Lowls; McAdams, and Gllilland $(6)$ developed and described a graphical method to allow for these variables. The present treatment w1Il follow these authors closely in method and nomenclature, but w1Il employ partial pressures instead of stolchiometric units for sascentrations:

In considering amy countercurrent absorption equipment, such as a packed tower, the absorbent enters at the top containing I pounds per hour of solute froe liquid per square foot of tower cross section with $\mathrm{X}_{2}$ pounds of solute per pound of solvent. In passing down the column the solute concentration increased to $x_{1}$ in the solvent. The gas to be treated enters at the bottom, with $G$ pounds per hour per 
square foot of tower cross section of solute free or inert gas, and with a partial pressure of the solute gas equal to $p_{1}$ atmospheres. At the top the partial pressure of the solute in the outlet gas has been reduced to $p_{2}$. If the colum pressure drop is assumed to be negligible in comparison with the total pressure $P$, the overall material balance may be written as

$$
\frac{L}{M_{A}}\left(x_{1}-X_{2}\right)=\frac{G}{M_{B}}\left[\frac{p_{1}}{P-p_{1}}-\frac{p_{2}}{P-p_{2}}\right]
$$

For the case of solute gas highly soluble in the absorbent, such as the absorption of amonia by water, the I1quid-film resistance may be assumed to be negligible in comparison with the resistance of the gas film. Under such conditions the concentration drop across the liquid film may be combined with the other film pressure drops, and the partial pressure of the solute at the gas-11quid interface may thus be taken as the equilibrium pressure corresponding to the main body of the solution. The driving force across the gas film is considered, therefore, as the difference between the pressures read from the operating and equilibrium curves, respectively, at any concentration $C$ in the main body of the liquid. Similarly, the mean inert gas pressure pBM at any point becomes the mean of $P-p$ and $P-p_{e}$, where $p$ is the partial pressure of solute in the gas phase, and $p_{\theta}$ is the equilibrium pressure over the solution. For the case of gasfilm resistance controlling, Sherwood ( 7$)$ has derived the 
following equation:

$$
h=\frac{G P}{K_{B}} \int_{p_{2}}^{p_{1}} \frac{x}{k_{Q}} \frac{p_{B M}}{(P-p)^{2}\left(p-p_{e}\right)} d p
$$

where $h$ is the required helght of packing. The capacity coefficient $\mathrm{ka} / \psi$ is defined by Sherrood as

$$
\frac{k_{Q}}{\gamma}=k_{g} p_{B M}
$$

Equation (13) then becomes

$$
h=\frac{G P}{M_{B}} \int_{p_{2}}^{p_{1} \frac{1}{k_{g}}} \frac{d p}{(P-p)^{2}\left(p-p_{\theta}\right)}
$$

For the resistance of a gas phase controlling system, Walker, Lewis, McAdams, and Gilliland (31) have expressed the variables affecting packing height in the nomenclature employed by Sherwood as

$$
\int_{J_{2}}^{y_{1}} \frac{d Y}{\left(Y-Y_{\theta}\right)}=\frac{K_{R} a s h M_{B}}{G}
$$

where $Y$, the solute concentration in the gas strean, is expressed in molal units:

Equations similar in form to Eqs. (14) and (15) can be derived for the situation when the liquid film represents the controlling resistance.

Sherwood (32) has pointed out that although the graphical' procedure as previously outlined must be employed in many practical design problems, it is erequentiy posibie to use a single mean driving force or potential and so obviate 
the graphical integration. Where it is possible to assume that the equilibrium curve is linear over the operating range, it can be shown that the logarithmic mean of the terminal potentials is theoretically correct. When the gas-film resistance is controlling, the calculation then reduces to the solution of the equation

$$
\begin{aligned}
& I\left(X_{1}-X_{2}\right)=G\left(Y_{1}-Y_{2}\right)=M \propto \text { avg } K_{g^{2}} h\left(Y-Y_{\theta}\right)_{\text {aVR }} \\
& \left(Y-Y_{\theta}\right)_{\text {avg }}=\frac{\left(Y-Y_{\theta}\right)_{1}-\left(Y-Y_{\theta}\right)_{2}}{\ln \frac{\left(Y-Y_{\theta}\right)_{1}}{\left(Y-I_{\theta}\right)_{2}}}
\end{aligned}
$$

where the subscripts, 1 and 2, refer to entrance and exit gas conditions respectively. It may be noted that with the gas f1lm controlling. It is necessary that the equilibrium curve be linear between $X_{2}$ and $X_{1}$ if the logarithmic mean potential is to be used. With liquid flim controlling, the logarithmic mean driving force applies if the equilibrium curve is linear over the range $Y_{2}$ to $Y_{1}$ :

In determing the value of the overall transfer coefficlent experimentally, previous investigators (14, 15) studying the absorption of ammonia by water have used equations similar to Eq. (16) but differing in that partial pressures were employed instead of stolchiometric units for gas concentrations. In this investigation of Fiberglas packing the experimental $\mathrm{K}_{\mathrm{p}}$ a values were determined by the equation: 
(18)

$$
K_{g} a=\frac{N_{A}}{\left(p-p_{\theta}\right)_{Q V G}}
$$

where

$$
\left(p-p_{\theta}\right)_{\text {avg }}=\frac{\left(p-p_{\theta}\right)_{1}-\left(p-p_{\theta}\right)_{2}}{\ln \frac{\left(p-p_{\theta}\right)_{1}}{\left(p-p_{\theta}\right)_{2}}}
$$

In this equation the weight of ammonia absorbed per unit time is expressed in pounds per minute, and the logarithmic mean driving force has the units of millimeters of mercury. Thus the overall transfer coefficient as calculated from this equation will be expressed as pounds per minute per cubic foot per millimeter of mercury driving force. Ammonia is highly soluble in water, and has been shown to obey Henry's law in the low concentration range. The operating conditions Imposed on the Fiberglas packed column in this investigation were such that the quantity of water in comparison with the amount of amonia input was sufficlent to produce a discharge Ilquor whose ammonla concentration was low. The equilibilum curve over the operating range is therefore s straight line, and the logarithmic mean potential can be applied. Equation (18) is equivalent to Eq. (16) as given by Sherwood except for the difference in units employed. In Eq. (16) the product of either $L\left(X_{1}-X_{2}\right)$ or $G\left(Y_{1}-Y_{2}\right)$ is equal to the weight of solute absorbed per unit time. Since

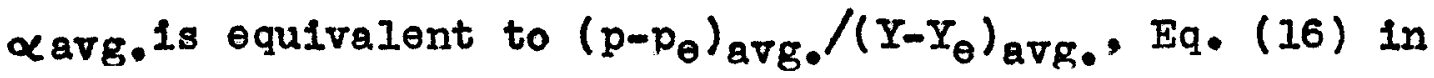


molal units becomes

$$
K_{R^{2}}=\frac{\frac{I\left(X_{1}-X_{2}\right)}{M_{A}}}{h\left(Y-Y_{\theta}\right)_{\text {avg. }}}
$$

since $L$ is expressed in pounds per hour per square foot of cross section, and $h$ term in $\mathrm{Eq} .(20)$ can replace the $\mathrm{V}$ term in Eq. (18), and the two equations are identical:

In order to apply theoretical plate concept to a packed tower, a certain helght of packing has been regarded as accomplishing the same separation as one theoretical plate. The "height of packing equivalent to one theoretical plate" has been termed by Peters (33) the "H.E.T.P.". The numerical value of the H.E.T.P. is an indication of the capacity of the apparatus, as are the capacity coefficients $K_{\mathrm{g}} a$ and $K_{L^{a}}$. It should be noted, however, that large values of $\mathrm{K}_{\mathrm{g}}$ and $\mathrm{K}_{L^{\beta}}$ correspond to smell values of H.E.T.P:

Theoretically, the H.I.T.P. is a section of packing of a helght such that the vapor leaving the top of the section will have the same composition as the vapor in equilibrium with the Ilquid leaving the bottom of the section. Sherwood (34) has shown that whon the gas film controls, (2I)

$$
\text { H.E.T.P. }=\frac{2 a T}{M_{A} \propto K_{g}{ }^{2}(I+m G)}
$$

where $m$ represents the slope of the equilibrium curve over the range of concentration in question. For a very dilute 
gas, in which the partial pressure of solute gas, $\mathrm{p}_{\mathrm{g}}$, is negligible compared with the total operating pressure, the conversion factor becomes equal to $P M_{B} / M_{A}$ and the relation simplifies further to

$$
\text { H.E.T.P. }=\frac{2 G L}{\mathrm{PM}_{\mathrm{B}} \mathrm{K}_{\mathrm{B}}{ }^{2}(L+m G)}
$$

The equation in this form will be used to calculate the experimental H.E.T.P. values for Fiberglas when used as a packing in the absorption of ammonia by water.

For the sake of ease and simplicity in computing the experimental H.E.T.P. values, an equation was desired which related H.E.T.P. to the operating varlables considered in this investigation. An equation which expressed the variables affecting the H.E.T.P. in the units in which the experimental quantities were measured would be very advantageous. To achieve such ends, an H.E.T.P. equation was derived combining the several constants of Eq. (22) for the particular absorption system, amonia-rater, and expressed the variables in the experimentaliy measured units:

To To convert $G$ from the units, pounds per hour per square foot of cross section, as required by Eq. (22), to cuble feet of saturated air at 700F, the normal operating temperature, a constant was worked out mathematically such that, $G=\left(C . F_{0} M_{0}\right)(5.66)$. A similar constant, $I=(637)$ (G.P.M.), was obtained for converting the I term of Eq.(22) 
to gallons of water per minute. To convert the $\mathrm{K}_{\mathrm{g}}$ from the units of Eq. (22) to pounds per minute per cubic foot per milimeter of mercury driving force, it was necessary to multiply the $K_{g}$ a in the units of Eq. (22) by 2685. The average slope of the equilibrium curve for ammonia-water in the range from 0 to 2 per cent ammonia by we ight in the discharge I1quor was found to be 0.275. Assuming a total pressure of one atmosphere and taking the molecular welght of air as 28.85, Eq. (22) after applying the conversion factors was reduced to

$$
\text { H.E.T.P. }=\frac{0.093}{K_{B} a\left[\frac{637}{C . F_{. M}}+\frac{1.56}{G . P . M \bullet_{\bullet}}\right]}
$$

where $\mathrm{K}_{\mathrm{g}}$ a has the units of pounds per minute per cublc foot per millimeter of mercury driving force.

Equation (21) beings out the important point that the ratio of slopes of operating and equilibrium curves is involved in the relation between $\mathrm{K}_{\mathrm{g}} \mathrm{a}$ and the H.E.T.P. Therefore the H.E.T.P. is clearly not so fundamental as the overall coefficient $\mathrm{K}_{\mathrm{g}}{ }^{a}$, and it is quite possible for the H.E.T.P. to vary widely over the range of concentrations Involved in a comnercial absorption tower. The overall transfer coefficient is generaliz not affected by variances in concentrations, but variations in temperature or pressure will influence it. Theoretically, the use of the H.E.T.P: 
Is unsound because it substitutes a stepwise calculation for integration. However, where the operation is such that the number of theoretical plates is large and the change in concentration per plate smell, the error is well within the accuracy with which such columns can be designed.

An alternative design method possessing many of the advantages of the plate concept, but not subject to the Iimitations outlined in the last paragraph has been desoribed by Chilton and Colburn (35). A quantity which represents a measure of the difficulty of the desired separation has been defined by Chilton and Colburn as the number of transfer units. The height of calumn corresponding to one transfer unit has been properly designated as the "height of a transfer unit" or "H.T.U", A low value of H.T.U. is associated with a high $K_{g}$ value as is also true for the H.E.T.P. The numerical value of the H.T.U. Increases with Increasing gas velocity through the column, provided $\mathrm{K}_{\mathrm{g}}$ increases as less than the first power of G. Since the H.T.U. concept is based on an integration of the basic diffusion equation,

(24) H.T.U. = Number of Transfer UnIts $=\frac{\mathrm{packing} \mathrm{Height}}{\int_{p_{2}}^{p_{1}} \frac{d p}{\left(p-p_{\theta}\right)} \frac{p_{B M}}{(P-p)}}$ the H.T.U. should not vary with solute concentration in the gas stream, as does the H.E.T.P. Although this method is 
basically the same as the use of overall coefficients such as $\mathrm{K}_{\mathrm{g} a}$, it has the advantage that the H.T.U. has only one dimension (length), and does not vary widely with change in gas velocity.

For the case of gas-film controlling, and if the gas contains very littlo solute, that is, $\mathrm{pg}_{\mathrm{g}}$ is small compared with $P$, Sherwood (34) has derived an equation expressIng H.T.U. as the function

$$
\text { H.T. U. }=\frac{Q}{\mathrm{~K}_{\mathrm{g}} \mathrm{P}_{\mathrm{B}}}
$$

Applying the conversion factors as was done in the case of the H.E.T.P. relation, Eq. (25) simplifies to

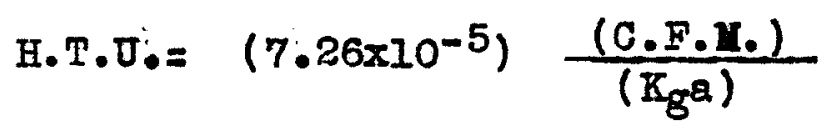

where $\mathrm{K}_{\mathrm{g}}$ is again expressed in pounds per minute per cubic foot per milimeter of mercury driving force. A similar treatment is possible for the casos when the liquid film controls.

The H.T.J. and the H.E.T.P. differ appreclably only when operating and equilibrium lines are far from parallel. Thus, when operating and equilibrium lines are parallel and the gas dilute, the H.E.T.P., and H.T.J. become almost identical:

The foregoing discussion has assumed isothermal operation, an assumption that is usually satisfactory where 
dilute gases and liquid are being handled. However, in cases such as the absorption of hydrogen chloride gas in water, the heat evolution is sufficient to raise the temperature in the tower appreclably. The changes in temperature may be sufficient to alter the equilibrium conditions to the extent of raising the equilibrium curve with respect to both coordinates. Since the temperature effects are usually such as to kinder the desired separation, the capacity of the operation may be seriously limited. In most cases it is a relatively simple matter to correct for the changes in temperature because of the heat of solution or condensation of the vapor. This correction is possible because the heat liberated is a function of the change in composition of the liquid, so if the heat capacity of the solvent is known, the relation between temperature rise and concentration may be calculated quite easily. An equilibrium curve that no longer represents isothermal conditions and that takes into account the temperature variation through the colum may then be constructed.

The operating conditions under which the absorption of ammonia by water was performed in this investigation were such that the inlet gas mixture was always very dilute and the resulting exit liquor very weak in respect to ammonia content. Therefore, the heat of solution of ammonia could be neglected and isothermal operation assumed.

It is important to note the manner in which the 
solvents flows down or is distributed over the surface area of the packing material in absorption columns. The type of flow through a particular packing should be studied in order to determine whether the liquid absorbent flows in continuous or pulsating sheots, the relative amount of turbulence, and the directional fluctuation in the liquid stream. The effect of liquor rate has been previously interpreted as influencing the liquid film coefficlent, and to a lesser extent the gas film coefficient: This condition may sanetimes be due to an effect on the distribution over the packing and hence on the active interfacial surface of the packing. The nature of the flow over the packing surface could also influence the relative amount of utilized surface area. In investigating the mass-velocity characteristics of Fiberglas as reported by Akell (3) it was observed that Ilquid flow in a Flberglas packed column was closely related to free fall in an empty tower. The presence of the packing seomed only to retard this free fall. At low liquid rates the flow resembled the surface of film type, that is, the Ilquid tended to roll down over the surface area of the individual fibers. For the intermediate liquid flow rates, somewhere between loading and flooding conditions, the flow was of the hindered dropwise or retarded free-fall type. Flow in the flooding region of Fiberglas packing consisted of quickly dissipated layers of liquid-gas froth within the 
packing producing a decreasing surface effect. This is somewhat analogous to Ilquid flow over wire helices as indicated by Bain and Hougen (36): 
EXPERTMENTAL PROCEDLRE AND RESULTS 
The absorption column employed in determing the mass-transfer characteristics of Fiberglas consisted of five section fabricated of Pyrex glass, each with a height of 2 feet and an inside diameter of 1 foot. This same colum was used by Akell (3) in investigating the mass-velocity characteristics of Fiberglas. A complete description of the column and auxillary apparatus has been presented in his thesis. The individual glass sections were packed to a height of 24 inches wth Fiberglas in the vertical jack-straw arrangement. At the top of each section was a small opening through which water distribution was observed. Thus an overall height of packing of 120 inches was secured at an average packing density of 4.70 pounds per cublc foot. A detalled account of the method of inserting the Fiberglas and other packing data has been previously reported by Akell (3). The experimental absorption column plus all the required auxillary apparatus is diagramatically listed in Fig. I: Figure 2 gives a view of the packed sections:

The surface area of the packing was computed from an adaptation of the empirical formula supplied by the manufacturer, using the density of the glass as 155 pounds per cubic foot and the diameter of the fiber as 0.008 inches or 0.00067 feet:

$$
s^{\prime}=\frac{4 G}{d B}
$$

The surface area for the packing density of 4.70 pounds per 


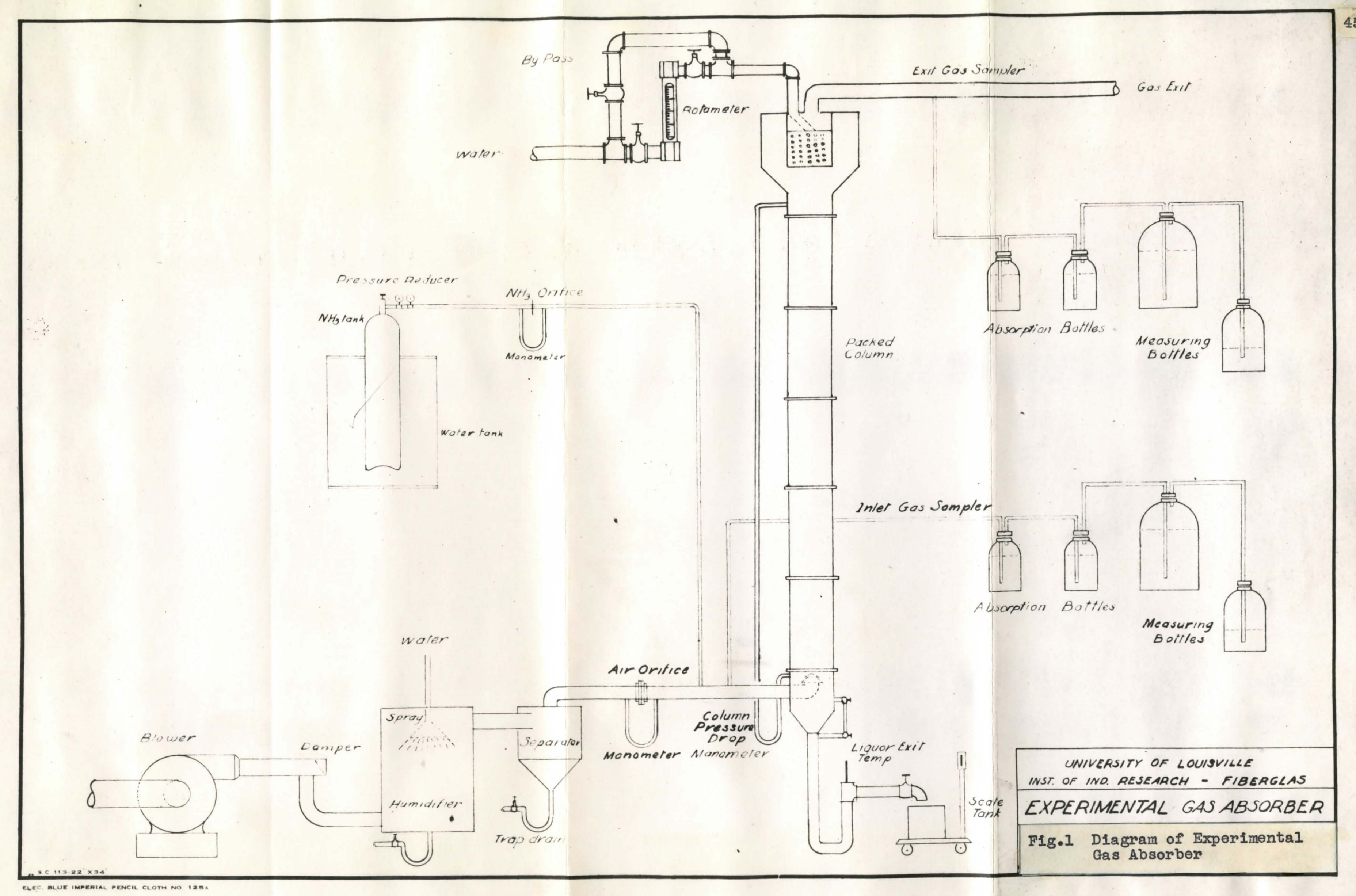




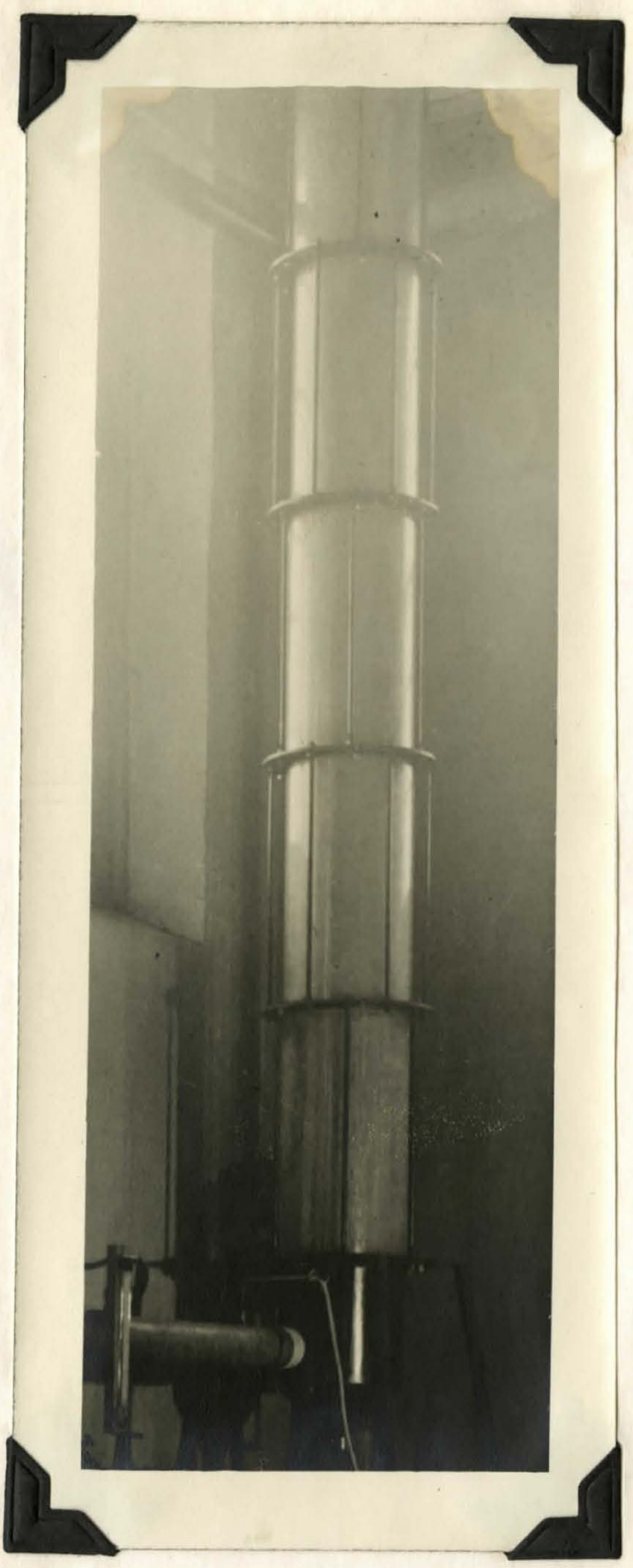

Fig. 2 View of Packed Column 
cublo foot is 181 square foet per cublc foot:

The data obtained from the initial absorption runs demonstrated that almost complete absorption of the ammonia from alr was being achieved. There was considerable doubt whether a measurable quantity of ammonia was remaining in the outlet gas. Therefore, to reduce the percentage of ammonia being absorbed two of the column sections were removed. In this manner the overall height of packing was shortened to 72 inches and the effective absorbing surface area decreased by approximately 40\%. As a result, a greater concentration of ammonia was allowed to remain in the outlet gas, and the precision of the determination of amonia in the outlet air stream was increased. The first 24 absorption runs were carried out with Fiberglas packed to a height of 10 feet while the remainIng 31 runs utilized a packing height of 6 feet. The carrier gas for the ammonia was humidified alr. The alr was supplied by a Buffalo Forge Blower Model No. 5E designed to deliver a maximum of 500 cublc feet per minute at 14.9 inches of water pressure. The blower may be seen in Figs. 3 and 4. Alr from the blower walivered to a humidifler of the wooden grid type where it was brought into contact with a water spray. The saturated air was discharged from the humidifier and was conducted to a ter separator. Air entered the separator tangentially, and the entrained water was removed by the ensuing centrifugal action, The exit air was found to be 
essentially free of entrained water and could be assumed to be completely saturated with water vapor. The humidifier and separator may be seen in Figs. 3 and 4.

In order to increase the rate of throughput air for the later runs, it was necessary to eliminate a large portion of the resistance to air flow by removing the humidifier and separator from the system. Thus, the carrier air no longer saturated, but was air of the same relative humldity as that determined by room conditions usually about $60 \%$ R.H. Dwyer and Dodge (14) have previously shown that the effect of humidity of entering gas on the overall coefficient is quite small and within the limits of experimental error. The air rates employed by the operating conditions of the early absorption runs (Runs 1 - 24) permitted the use of the humidifier and separator. The removal of the humidifier and separator together with the reduction of packing height were accomplished simultaneously:

The volume of carrier alr supplied to the base of the column per unit time was measured by means of a sharp edge orifice inserted in the line entering the bottom section of the tower. Because a wide range of a ir flow was required, three different orifice plates each of a different size and covering a definite range of flows were used. It was calculated that no single orifice size could cover the range without reaching elther pressure differentials that could not be accurately read or pressures that would exceed the pressure rating of the 


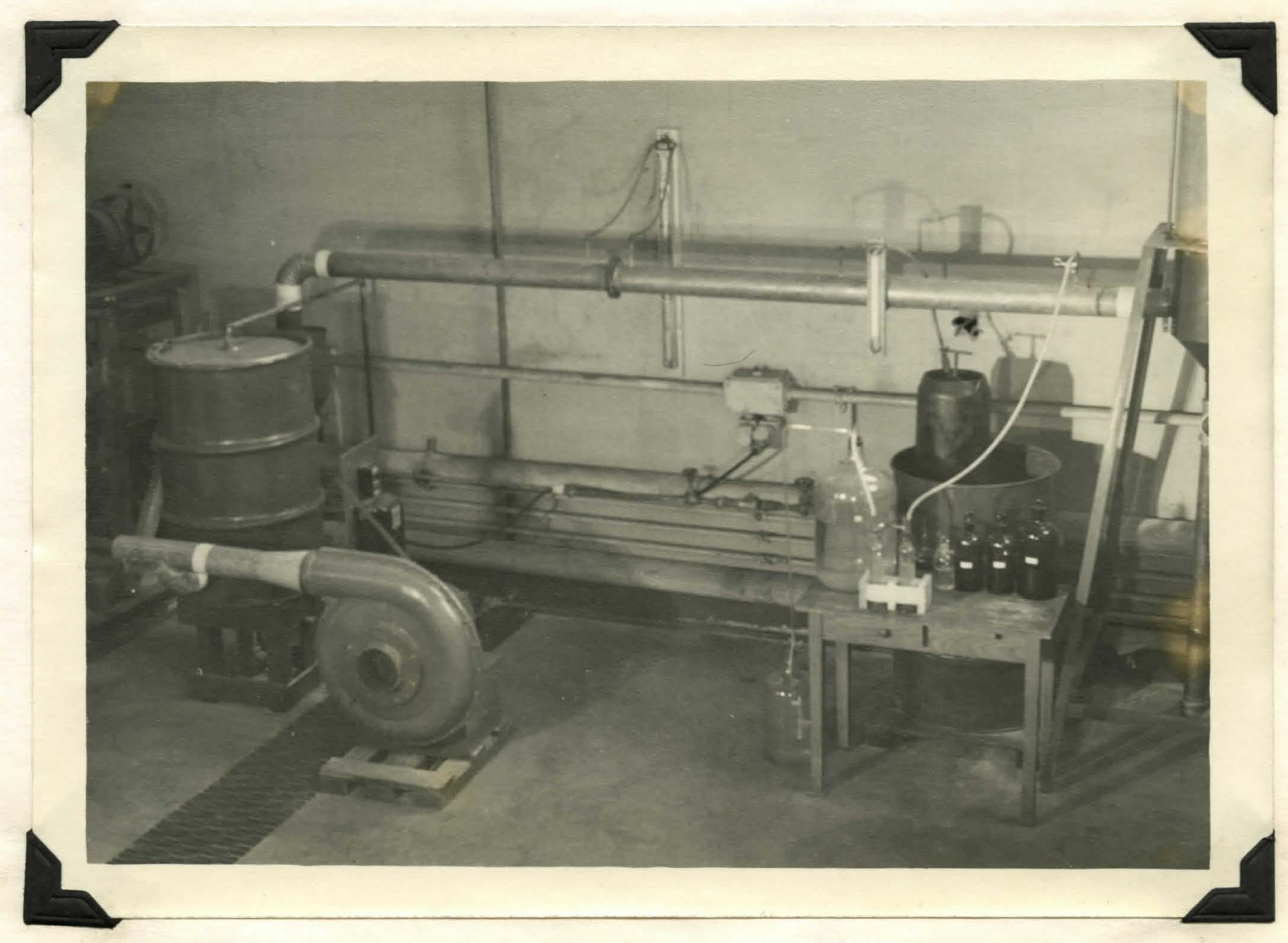

Fig. 3 Alr Supply System to Column 


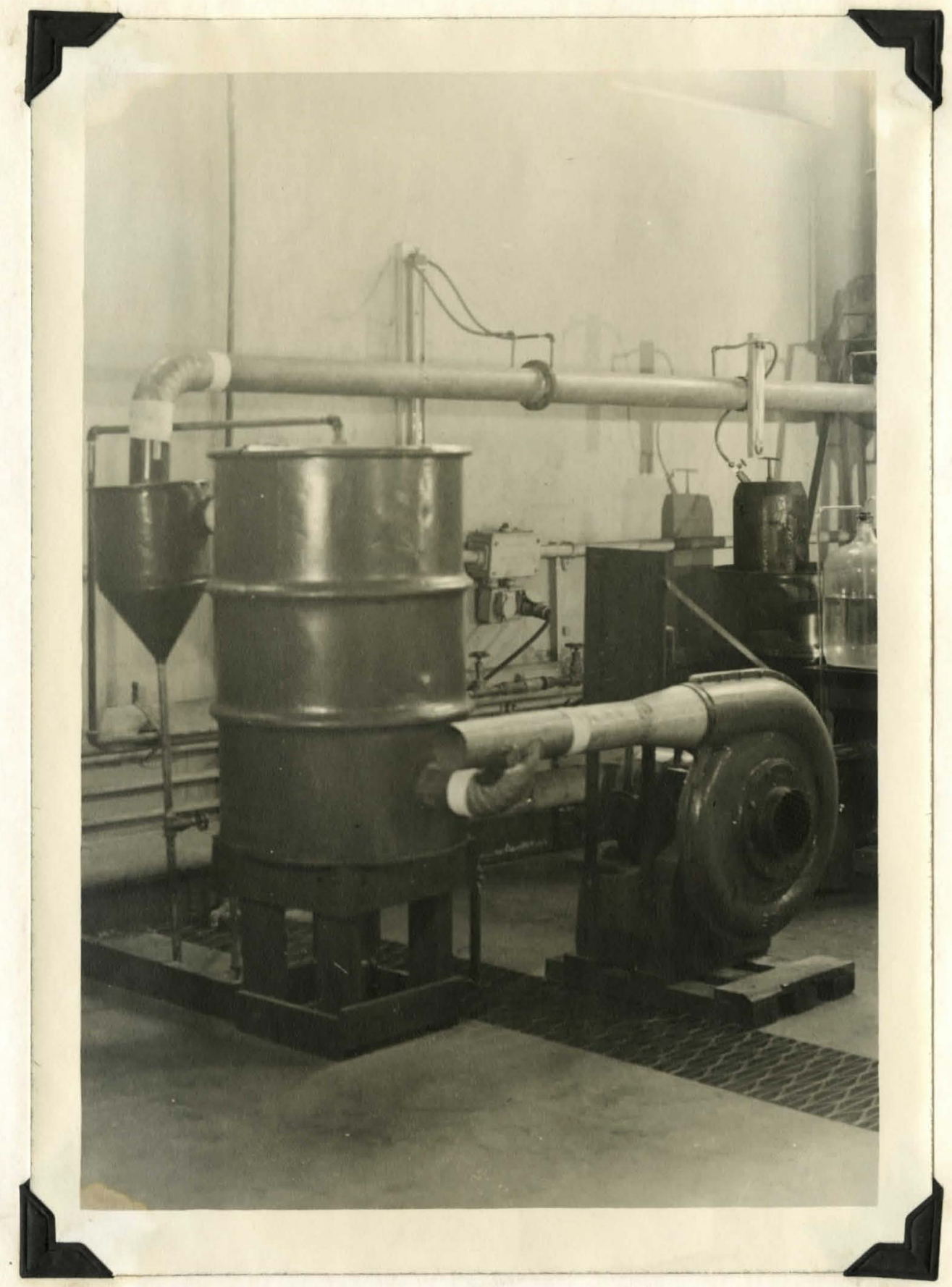

Fig. 4 Blower and Humidifier Section 
blower. This arrangement permitted a reasonable reading on the manometers and a reasonable pressure recovery for any range up to blower capacity. The orifice plates were fabricated of stainless steel with accurate openings of 1.000 , $2.000,3.000$ inches:

The rate of flow through the $I$ inch orifice was computed from the gas flow equation given by Rhodes (37) with orifice coefficients taken from the same source:

$$
Q=C^{\prime} D_{p}^{2} H^{\prime} P^{\prime} T^{\prime} S^{\prime} M B^{\prime}
$$

The results of this calculation are presented in Fig. 5 showing the air flow rate versus orffice pressure differential. The I inch orifice was used in the range of flow of 0 to 50 cubic feet per minute:

The 2 inch orifice was calibrated by calculation and checked by anemometer readings. The 3 inch orifice was calibrated against the 2 inch orifice by making the assumption that any given air flow will produce the same column pressure. drop regardless of which orifice is used to measure the flow, and was rechecked by calculation from accepted formulae. Such calibration work was performed while conducting the massvelocity tests of Fiberglas as reported by Akell (3). The 2 inch orifice was utilized in the range of 80 to 180 cubic feet per minute and the 3 inch from 120 to 260 cublc feet per minute. The calibration curves for the 2 inch and 3 inch orifice are presented in Figs. 6 and $\eta$ respectively. 

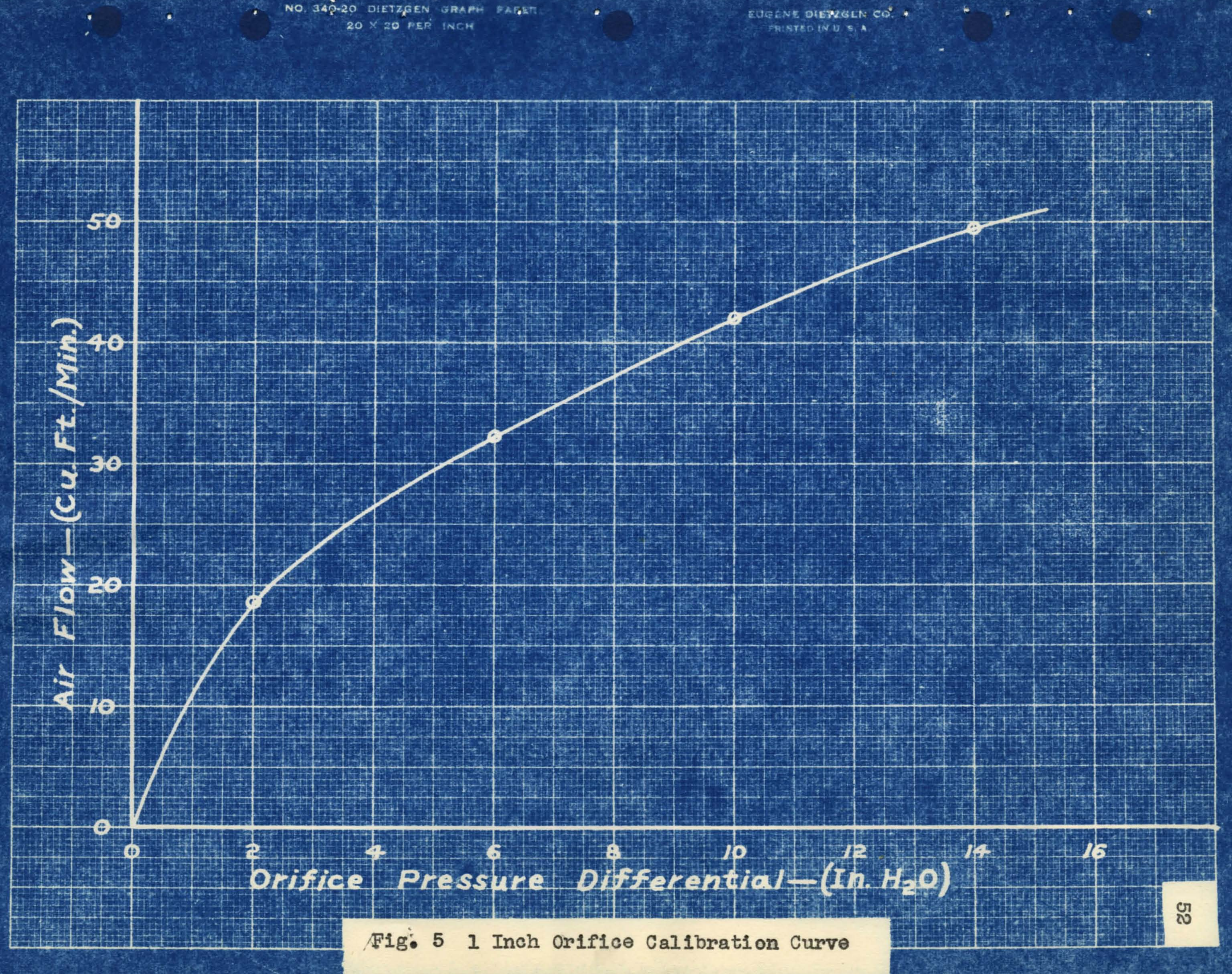


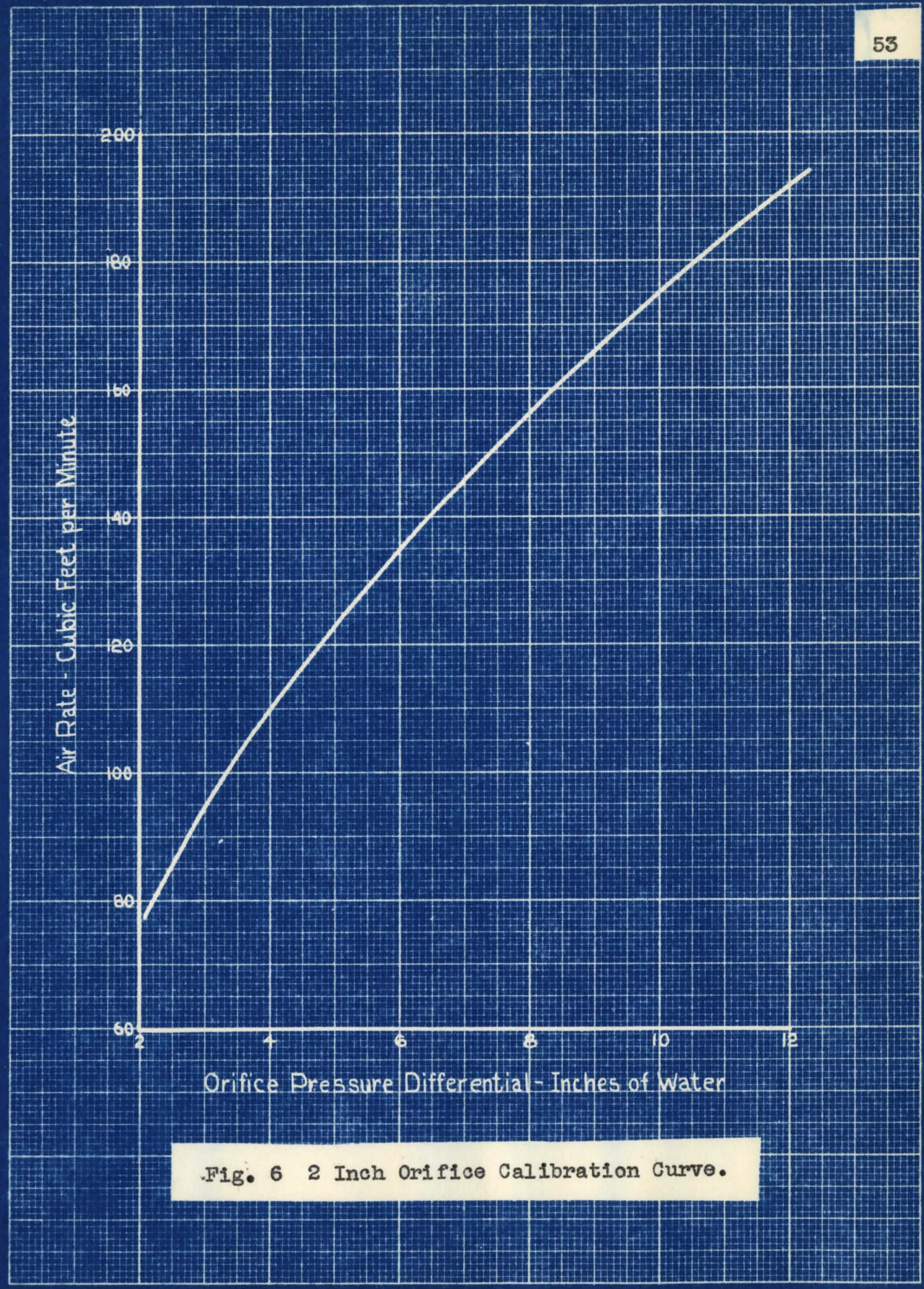




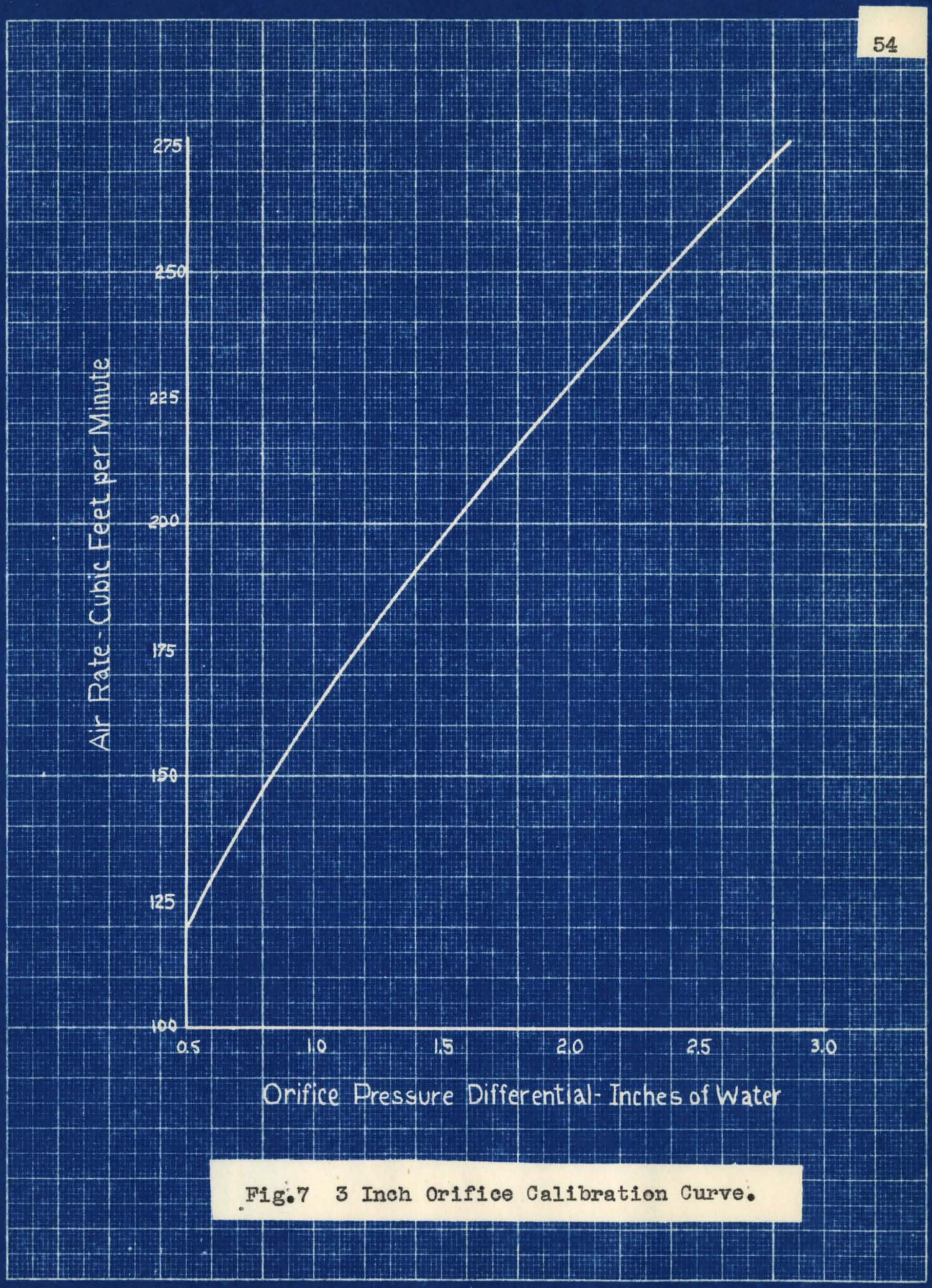


A view of the orifice installtion and manometer can be seen in Figs. 3 and 4 :

The absorbable gas, amonia, was supplied from a commerctal 50 pound cylinder. A neөdle valve in conjunction with the cylinder cock was used to regulate the flow of input armonia. Since the expansion of a gas produces a cooling effect, the ammonia cylinder was placed in a 55 gallon drum into which water was circulated: The water was to heat the cylinder in order to compensate for the cooling effect, and thus prevent freezing.

The ammonia input was measured approximately by means of a $1 / 4$ inch orif1ce, and a U-tube gage with ammonium hydroxide which served as the manometer. This orifice arrangement was not calibrated accurately, but an approximate curve was estabIished from the manometer settings in the early absorption runs. It was not necessary to measure accurately the rate of input ammonia by means of this orifice since this value was determined from an ammia balance over the column.

The solute gas, anmonia, entered the alr line downstream from the air flow orifice through a $1 / 8$ inch pipe bent so that the end inside the pipe discharged along the axis of the air pipe, heading downstream. The end of the ammonia inlet pipe was placed inside a "hat" mixer, a cylinder with slots open at one end. The construction details and dimensions of the "hat" mixer have been previously presented by Akell (3): Air flowed through the air pipe around the outside of the cylinder and through the slots producing high turbulence: The 
turbulent air mixed with the ammonia and discharged from the mixer. The ammonia supply system may be seen in Fig. 3.

Samples of the inlet and outlet gas were withdrawn for analysis by means of sampling tubes installed across a diameter in the Inlet and exit gas lines. These sampling tubes consisted of $1 / 8$ inch pipe having one end sealed, with 5 equidistant $1 / 8$ inch holes passing through one side of the pipe only, and drilled over a length of 4 inches facing opposite to the direction of gas flow.

The water supplied to the column was measured with a rotameter and by-pass arrangement. The rotameter had a capacity of 18.25 gallons per minute and was calibrated by the manufacturer. For water rates above 18.25 gallons per minute a by-pass valve was opened and water was allowed to pass through both the rotameter and by-pass. Flows in this range were previously calibrated by weighing the discharge water, and the data for this calibration have been given by Akell (3). A plot of the rotameter calibration as furnished was used in the range of 0 to 18.25 gallons per minute and is shown in Fig. 8. A second plot showing the position of the rotameter float when the by-pass valve is fully open and covering the range of 18 to 55 gallons per minute is presented In Fig. 9. The maximum water throughput rate employed in the experimental absorption mans was 51.2 gallons per minute. The rotameter and by-pass are shown in Fig. 10:

Samples of the inlet and exit gas stream were drawn 


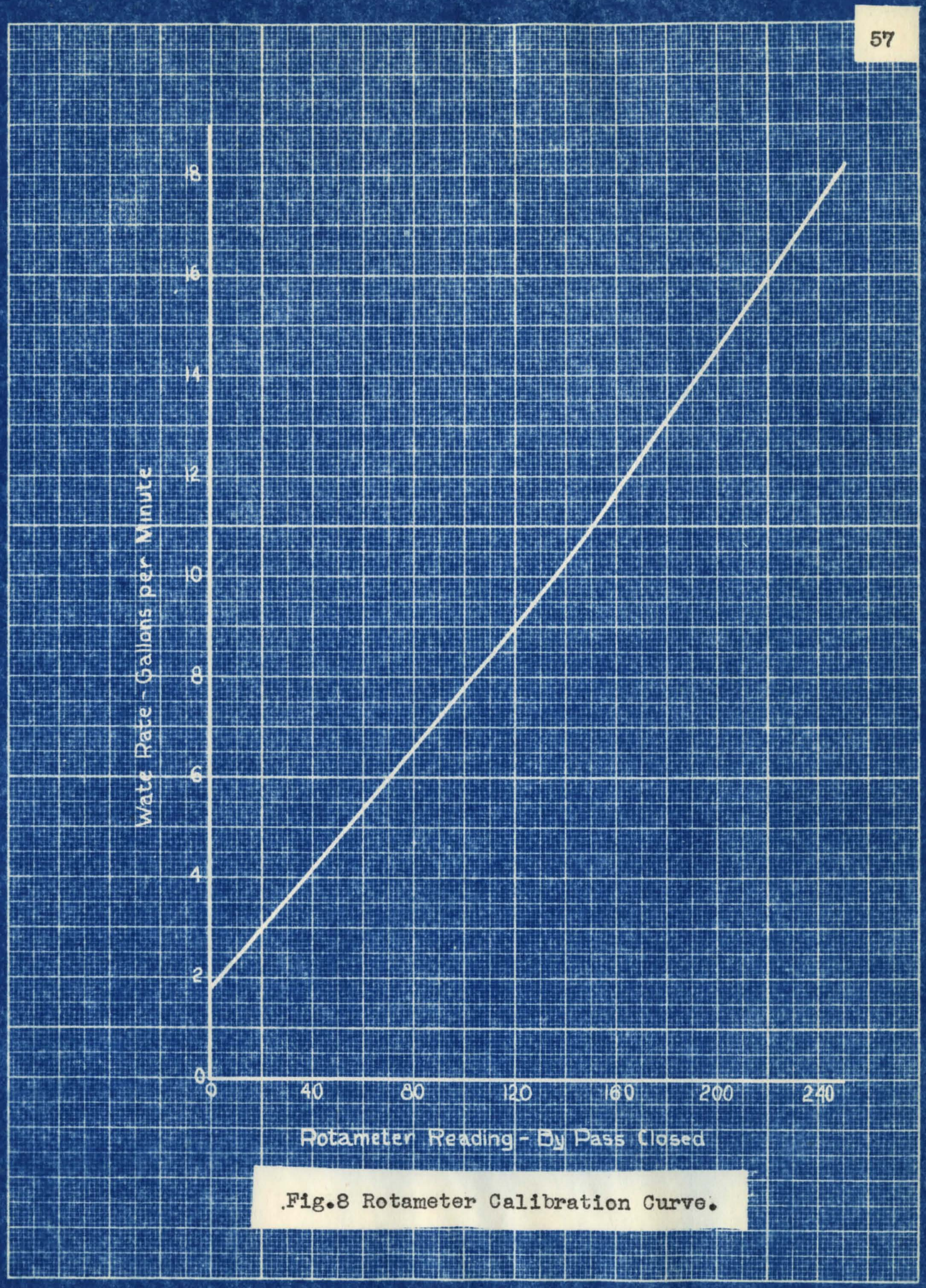




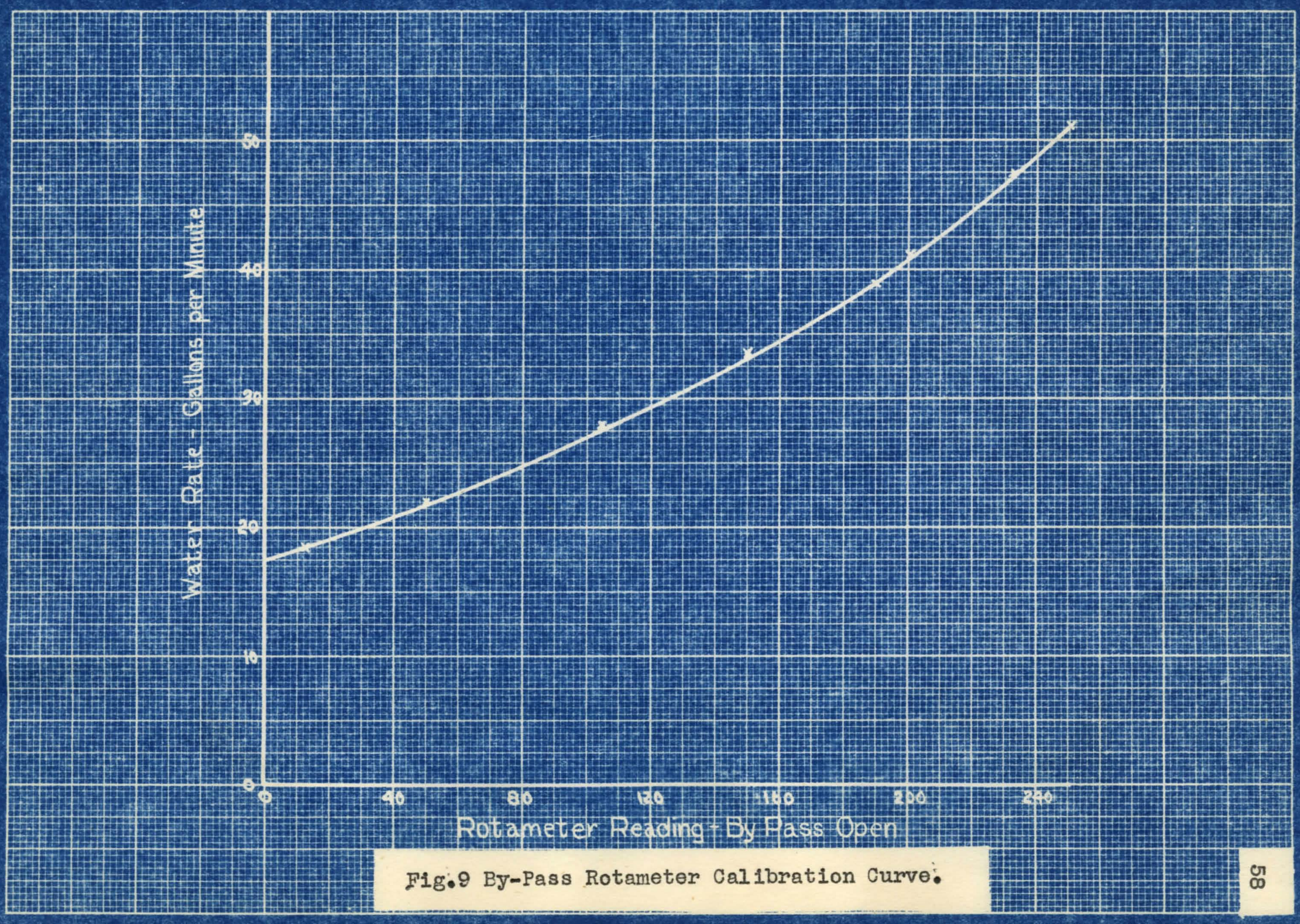




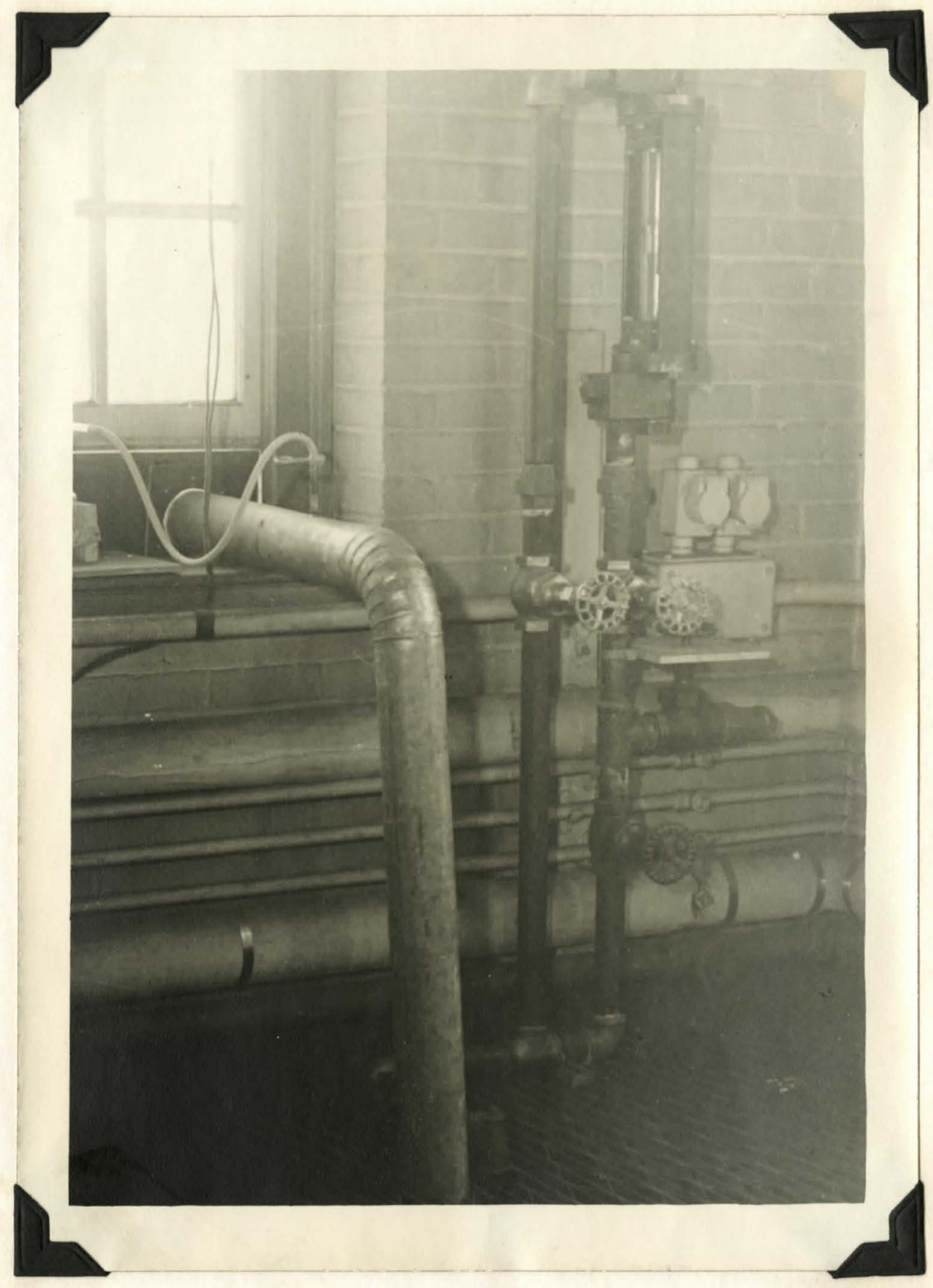

Fig.10 Iiquid Supply System and

Gas Exit 


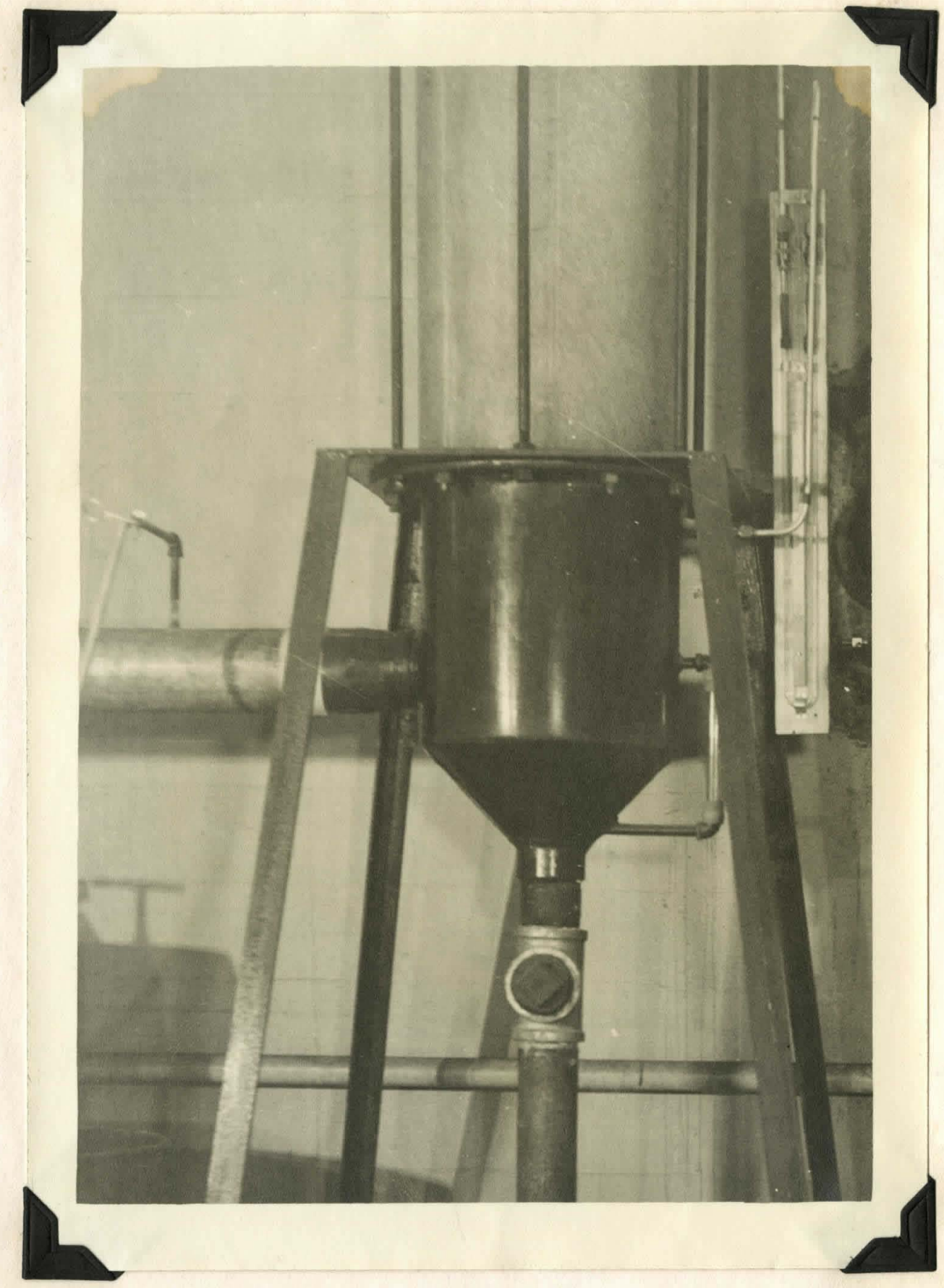

Fig. 11 Bottom Column Section 
through the sampling tubes provided in the respective inlet and outlet gas lines by means of vacuum furnished by a siphon bottle: The siphon bottles were 5 gallon glass bottles filled with water. From the weight of water displaced, the volume of the collected gas sample could be computed. Preceding the siphon bottles in the gas sampling apparatus, two gas absorption bottles were supplied. The absorption bottles were provided with bubbling tubes of the Folin improved absorption bell type. Glass tubing connected one bottle with another, and rubber tubing was used to seal the respective glass tubes. In this manner the gas sample first passed through two gas absorbing bottles where all the amonia was recovered and only alr was actually drawn into the siphon bottle. The gas sampling apparatus can be seen in Figs. 3 and 10.

For the inlet gas sample a varying volume of approxImately $0.1 \mathrm{~N}$ sulfuric acid was placed in the first gas absorption bottle, and the required volume of distilled water was then added to give a total volume of solution amounting to $250 \mathrm{ml}$. The quantity of $0.1 \mathrm{~N}$ sulfuric acid was varied according to the amonia concentration of the entering gas stream for each particular run. Such a compensation was necessary in order to maintain the resulting solution just slightiy basic at the completion of the gas collection period. The sulfuric acid was required in order to neutralize the major portion of the absorbed amonia and thus insure a complete recovery of ammonia. It was desired to produce a resulting 
solution that contained amonia in excess because a back titration could then be performed using sulfuric acid. A sulfuric acid solution of known concentration can be stored for a considerable length of time without undergoing any serious changes in strength. The resulting basic solution contained in the first absorption bottle of the inlet gas sampling apparatus was then back titrated with 0.1 N sulfuric acid. If the solution in the first bottle remained acid at the completion of the gas collection period, the amount of excess sulfuric acid was determined by titration with a $0.01 N$ solution of standara base:

In the event that the first bottle failed to accomplish a complete absorption of ammonia, a second gas absorbing bottle was provided into which $250 \mathrm{ml}$ of distilled water were placed. The quantity of ammonia absorbed by the water of the second bottle was slight during all of the runs, and the resulting solution was satisfactorily titrated with $0.01 N$ sulfuric acid solution.

Since the amonia concentration of the outlet gas stream was slight at all times, the second gas absorbing bottle of the outlet gas sampling apparatus contalned only $250 \mathrm{ml}$ of distilled water. Titration with $0.01 \mathrm{~N}$ sulfuric acid could then be successfully applied to the resulting solution after the gas sample had been collected. The first bottle of the exit gas collection setup served merely as a gas trap during the inftial runs and then was removed from 
the apparatus since it served no useful purpose.

Samples of the discharge water from the column were collected for each of the experimental absorption runs. A $25 \mathrm{ml}$. protion of the discharge liquor to which $225 \mathrm{ml}$. of distilled water were added was titrated with $0.1 \mathrm{~N}$ sulfuric acid in order to determine the ammonia content. The results from all the analytical determinations are shown in Table $\mathrm{V}$ given in the appendix.

The selection of the proper indicator for an ammoniasulfuric ac1d titration was based upon the $p H$ range of this system at the stoichiometric point. Several suitable indications with respect to $\mathrm{pH}$ range were listed by Lange (38), but methyl red was found experimentaliy to exhibit the most distinguishable color change at the end point. Methyl red was subsequently employed as the indicator for all the required titrations.

The data from the first few absorption runs demonstrated that the slight akalinity of the inlet water to the column could serfously affect the analytical determination of the ammonia concentration of the discharge liquor. The alkaline quality of the water would have increased the analyticaliy determined ammonia content of the water flowing from the column. To correct for this effect a sample of the water supplied to the column was titrated with $0.01 \mathrm{~N}$ sulfuric ac1d in order to determine the actual number of milliequivafents of sulfuric acid required to neutrelize only the ammonia 
absorbed by the water. The basic nature of the distilled rater used in gas sampling absorption bottles could also seriousiy affect the accuracy of determing the ammonia concentration of the incoming and outgoing gas stream by anelytical means. Therefore, a similar correction was achieved by titrating the available distilled water with $0.01 N$ sulfuric acid: This slight basic quality of the distilled water could hate augmented the resolved exit gas ammonia content to a considerable extent:

The temperature of the discharge IIquor from the absorption tower was measured by immersing a thermometer into a sample portion of the discharge liquor immediately after being procured. The temperature of the outlet gas stream was also found to be equivalent approximately to the temperature of the outflowing water and isothermal absorption conditions were approximated. The entering gas stream was essentially at room temperature for the majority of the runs, and room temperature was approximately $70^{\circ} \mathrm{F}$ at all times. In executIng the early absorption runs when the humidifier and extrainment separator were still connected to the system, the incoming air was subsequently cooled a few degrees below room temperature due to the action of the water sprays while passing through the humidifier.

The procedure established and adhered to for operating the absorption oolumn was as follows:

1. The rotameter arrangement was adjusted to allow a 
water flow of about 30 gallons per minute to pass down the column to thoroughly wet the Fiberglas packing. The blower was then set into operation, and a maximum flow of air was blown up the column. This wetting technique was continued for at least ten minutes.

2. The manometer in conjunction with the orifice measuring air throughput was set to the required pressure differential reading in order to deliver a specific air flow by adjusting the air by-pass valve. The rotameter vas then regulated to permit the desired quantity of water to flow down the column. The respective manometer and rotameter readings were checked periodically for 15 minutes in order to allow the flow rates to become steady and free from serious fluctuations.

3. During the time interval conceded for obtaining steady flow rates the respective gas absorbing bottles of the inlet and outlet gas sampling apparatus were being filled with the proper volumes of distilled water and sulfurlc acid. The required quantities of water and acid were measured with pipettes and graduated cylinders. The various absorption bottles were then connected in series with the siphon bottles.

4. The cock of the ammonia cylinder ses then opened and the needle valve adjusted in order to give the desired reading on the manometer in connection with the orifice determining the approximate ammonia input. Thus the ammonia concentration of the incoming gas stream was set within the limits of the 
desired concentration range. A five minute period was allowed for the column to attain equilibrium with respect to operating conditions.

5. Water was then allowed to drain from the respective siphon bottles into previously weighed containers and samples of the inlet and outlet gas stream were drawn through the gas absorbing bottles of each gas sampling apparatus. A sample of exit water was now collected from the liquor discharge pipe.

6. While the gas samples were being collected simultaneousiy, the Immediate readings of the rotameter, and both manometers were recorded, column pressure drop and the static pressure at the base of the column were both determined from the same manometer and recorded. The existing barometric pressure was then read from an aneroid barometer.

7. When the containers receiving the water flowing from the siphon bottles were filled, the siphoning action was immediately checked. A second sample of the discharge liquor was then obtained and a therometer was instantly immersed in the sample to determine its temperature. The input of ammonia to the column was then ceased and the supply of air and water discontinued:

8. The quantity of water withdrawn from each of the two siphon bottles was weighed on a beam balance. All the required titrations were then immediately performed:

A sample data sheet will be presented on the follorIng page which lists all of the items recorded on an original 
data sheet: 
Absorption Run Number 49

Observers = R. B. Akell and C. P. Talbott

Air Orifice Differential Pressure ( $3^{\prime \prime}$ orifice) $=2.6^{\prime \prime} \mathrm{H}_{2} \mathrm{O}$

Rotameter Reading 134.5. By-Pass Valve Closed

Ammonia Orifice Differential Pressure= $1.90^{\prime \prime} \mathrm{NH}_{4} \mathrm{OH}$

Barometric Pressure = $745 \mathrm{~mm}$.Hg.

Column Pressure Drop= 5.1" $\mathrm{H}_{2} \mathrm{O}$

Static Pressure at Base $=5.2^{n} \mathrm{H}_{2} \mathrm{O}$

Temperature of Discharge Iiquor $=640 \mathrm{~F}$.

Titer for $25 \mathrm{ml}$. Top $\mathrm{H}_{2} \mathrm{O} 225 \mathrm{ml}$ Distilled $\mathrm{H}_{2} \mathrm{O}=2.90 \mathrm{ml}$ : of

Titer for $250 \mathrm{ml} \cdot \mathrm{Distilled} \mathrm{H} 2 \mathrm{O}=0.30 \mathrm{ml}$ : of $0.0123 \mathrm{~N} \cdot \mathrm{H}_{2} \mathrm{SO}_{4}$

\section{INIET GAS SAMPIE}

Weight of Siphoned Water Container = 23 1bs: $121 / 4$ oz: Weight of Container $\quad 7$ Ibs: $21 / 4$ oz: Weight of Siphoned Water $=161 \mathrm{bs} \cdot 10 \quad 0 z$ :

First Bottie

Contents = $25 \mathrm{ml}$ : of $0.0968 \mathrm{~N} \cdot \mathrm{H}_{2} \mathrm{SO}_{4}$ Contents $=250 \mathrm{ml} \cdot \mathrm{Dist} \cdot \mathrm{H}_{2} \mathrm{O}$ $225 \mathrm{ml}: \mathrm{Dlst} \cdot \mathrm{H}_{2} \mathrm{O}$

Titer

$$
\begin{aligned}
-16.95 \mathrm{ml} \cdot \mathrm{of}_{0.0968 \mathrm{~N} \cdot \mathrm{H}_{2} \mathrm{SO}_{4}} & \text { Titer }= \\
0.95 \mathrm{ml} \cdot \text { of } & 0.0123 \mathrm{~N} \cdot \mathrm{H}_{2} \mathrm{SO}_{4}
\end{aligned}
$$

\section{OUTIET GAS SAMPIE}

Weight of Siphoned Water Container $=231 \mathrm{bs} .123 / 4$ oz: Weight of Container $=7$ lbs. $2 \mathrm{oz}$ Welght of siphoned Waterm 16 1bs: $103 / 4$ oz: First Bottle

Use Discontinued

Contents $=250 \mathrm{ml}:$ of Dist: $\mathrm{H}_{2} \mathrm{O}$

Piter $=2.1 \mathrm{ml}:$ of $0.0123 \mathrm{~N} \cdot \mathrm{H}_{2} \mathrm{SO}_{4}$

Titer for lst $25 \mathrm{ml}$. of Discharge Liquor $225 \mathrm{ml}$. Dist. $\mathrm{H}_{2} \mathrm{Om}$ $27.95 \mathrm{ml}$. of $0.0968 \mathrm{~N} \cdot \mathrm{H}_{2} \mathrm{SO}_{4}$

Titer for 2nd $25 \mathrm{ml}$. of Discharge Iiquor $225 \mathrm{ml}$. Dist. $\mathrm{H}_{2} \mathrm{O}=$ $28.15 \mathrm{ml}$. of $0.0968 \mathrm{~N} \cdot \mathrm{H}_{2} \mathrm{SO}_{4}$

F18. 12 Sample Data Sheet 
The Fiberglas packed absorption was operated under varying conditions with respect to carrier air, solvent water, and absorbate ammonia concentrations: The variance in throughput air ranged from 279 to $1496 \mathrm{lbs./hr.sq.ft.,}$ ( 7 to $5.5 \mathrm{ft} / \mathrm{sec}$ ), while the supply of input water varied from 1590 to $32,600 \mathrm{lbs} / \mathrm{hr} .3 q . f t$. The ammonia concentration of the incoming gas deviated between the limits of 5 to $28 \times 10^{-3}$ Ibs. $\mathrm{NH}_{3} / \mathrm{Lb}$. dry air. Such a variance on a weight basis corresponded to a variation in partial pressure of amonia for the entering gas stream from 6 to 33 millimeters of mercury. A large number of runs were made at ammonia concentration of around $8 \times 10^{-3}$ Ibs. $\mathrm{NH}_{3} / \mathrm{Ib}$.dry air, and the related points are correlated in four graphs. Table $V$ in the appendix is a complete summary of experimental data obtained in amonia absorption runs with water in a Fiberglas packed tower. Table VI presents a summary of calculated data including overall $\mathrm{K}_{\mathrm{g}}$ a values, H.E.T.P., and H.T.U. Values:

An examination of the data of the early runs (Runs I to 24) demonstrates that the absorption values were high at all times, a recovery of $99.6 \%$ ammia in the rich liquor being the lowest found, and the usual value was about $99.9 \%$ for the runs. The quantity of ammonia remaining in the exit gas stream was extremely low. Such data showed excellent absorption being accomplished, al though probably too much 
for discriminative calculations of $\mathrm{K}_{\mathrm{g}}$. $\mathrm{I}_{\mathrm{n}}$ an atempt to remedy this situation, it was decided to decrease the surface area of the Fiberglas packing and increase the input of carrier air. A decrease in the packing surface area reduced the avallable amount of active absarbing surface area and thus permitted more ammonia to remain in the outflowing gas. Increasing the rate of throughput air increased the superficial velocity of the gas stream through the column and allowed more ammonia to escape from the column:

These effects were achleved by removing two glass sections from the existing column and by-passing the humldifier and entrainment separator in the experimental absorption setup. The helght of packing was thus decreased from an original height of about 10 feet to a height of about 6 feet, and the resistance to gas flow was greatly reduced. As previously mentioned, the humidity of the carrier air has been found to exert little influence on the $\mathrm{K}_{\mathrm{g}}$ v value. The results from this modification were favorable as higher gas rates were secured, and more ammonia remained in the exit gas stream:

Graphs were constructed to illustrate the effect of varient water and air rates at a constant inlet gas ammonia concentration of the $K_{g} a, H . E . T . P .$, and H.T.U.values. The ammonia concentration of the Inlet gas for all plotted data was approximately $8 \times 10^{-3} \mathrm{lbs}$. $\mathrm{NH}_{3} / \mathrm{lb}$. dry a ir. 
An inspection of the plot relating to $\mathrm{K}_{\mathrm{g}}$ value with the water rate, as shown in Fig. 13, reveals that the oterall transfer coefficient increases until the water rate 1s above about $10,000 \mathrm{lbs} . / \mathrm{hr} . \mathrm{sq} . \mathrm{ft}$. If a packing is completely wetted, the overall transfer coefficlent should remain essentially constant for gas film controlling systems. The graph exhlbits the same trend for two different air rates; however, the higher alr rate jields a greater $\mathrm{K}_{\mathrm{g}}$ a value. A higher $\mathrm{K}_{\mathrm{g}}$ a value for the higher air rate should be expected since a higher air flow causes a more intimate mixing of the ammonia and water, and the system has previously been shown to be gas film controlling:

The plot expressing $K_{\mathrm{g}}$ as a function of the carrier air at a constant water rate below that necessary for constant values, as present in Fig. 14, shows that the overall coefficient increases Iinearly with the alr rate. Water rates of 3180 and $6360 \mathrm{lbs} / \mathrm{hr}$.sq.ft. both give similar curves. Again, the higher water rate produc es higher $\mathrm{K}_{\mathrm{g} a}$ values because of the more complete and unfform wetting of the packing. The output capacity of the blower prevented the attainment of higher air flows up to the flooding values for these water rates:

The effect of a variant rate of carrier air throughput on the H.E.T.P. and H.T.U. values with a fixed water rate is shown in Fig. 15. This plot indicated the almost negli- 


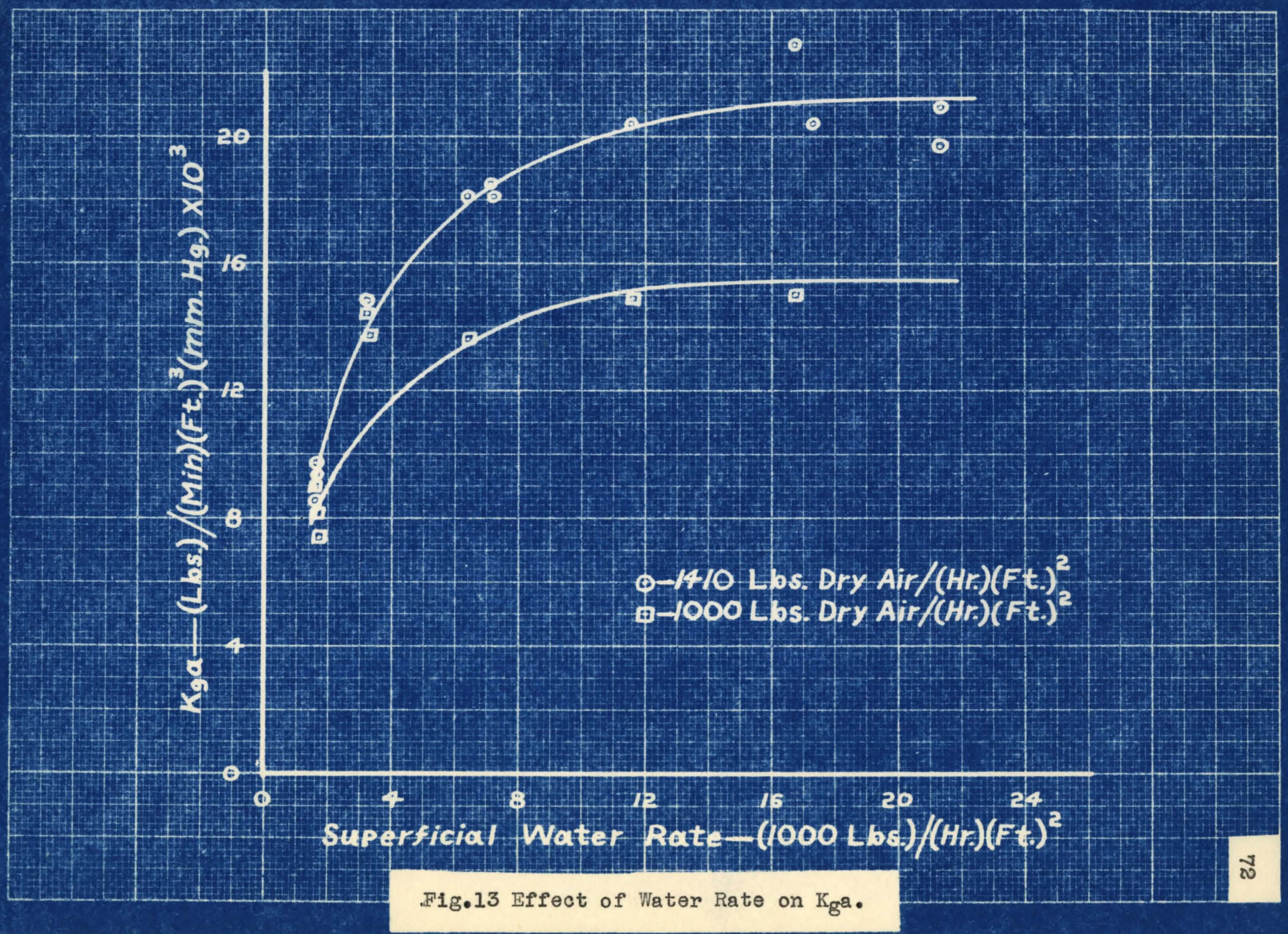









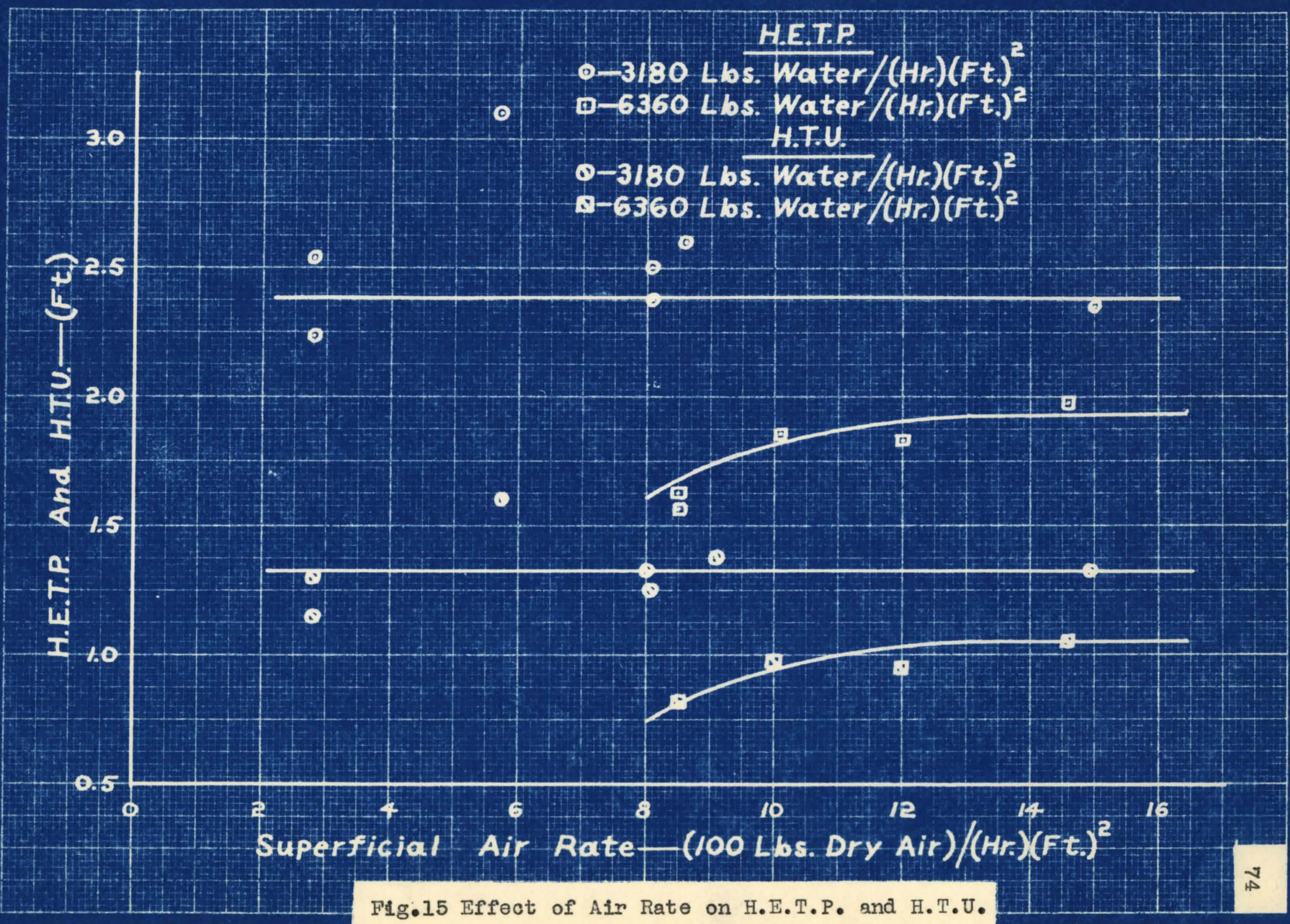


gible effect of the air rate on these two quantities. An H.E.T.P. value of $2.38 \mathrm{ft.}$ and an H.T.U. value of $1.33 \mathrm{ft}$. appears reasonable at a water rate of $3180 \mathrm{lbs} / \mathrm{hr.sq.ft.,}$ while a water rate of $6360 \mathrm{lbs} / \mathrm{hr} . \mathrm{sq}$.ft. gives indication that an air rate of $1,300 \mathrm{lbs} . / \mathrm{hr}$. sq.ft. is required before constant values for the H.E.T.P. and H.T.J. of 1.95 ft. and 1:05 ft: respectively can be obtained. At an a1r rate below l,300 Ibs./hr.sq.ft, the H.E.T.P. and H.T.U. values are increasing slightly with increasing alr rate until the constant values are reached. The lowest air rate shown on the graph was the lowest permissible air rate for a water rate of $6,360 \mathrm{lbs} / \mathrm{hr} .3 q . f t$. If any measurable quantity of ammonia were to be present in the exit gas. Because of the nature of the H.E.T.P. and H.T.U. equation, a high $\mathrm{K}_{\mathrm{g}}$ value is necessary for low H.E.T.P. and H.T.U. values. Since a water rate of 3,180 lbs./hr.sq.ft. will yield a lower $\mathrm{K}_{\mathrm{g}}$ value than a water rate of $6,360 \mathrm{lbs} / \mathrm{hr} . \mathrm{sq}$.ft:, the reason for a higher water rate resulting in a lower H.E.T.P. and H.T.U. is evident: When H.E.T.P. and H.T.J. are plotted against the water rate at a constant air rate as given in Fig. 16, the curves illustrate that the water flowing down the column must be adequate in quantity to wet the packing completely before constant values of H.E.T.P. and H.T.J. can be attained. At air rates of 1,410 and $1,000 \mathrm{lbs} . / \mathrm{hr} .3 q . \mathrm{ft}$ and low water flows the lesser air rate accords a lower H.E.T.P. and H.T.U: because of the mathematical arrangement of the equation relat- 

ing these terms with the air rate. However, when the water completely wets the Fiberglas packing, the H.E.T.P. and H.T.U. remain constant and demonstrate that they are only slightly influenced by the mount of carrier air input. A water throughput of $10,0001 \mathrm{bs} \cdot / \mathrm{hr} \cdot \mathrm{sq} \cdot \mathrm{ft}$. Is required before the essentially constant values of $1.65 \mathrm{ft}$ and $0.97 \mathrm{ft}$. for the H.E.T.P. and H.T.J. respectively can be obtained:

It is interesting to note that when the overall ammonia transfer coefficient, the H.E.T.P. and the H.T.U. approached a constant value, the air and water flows were sufficient for the column to be operating actually above the loading point. Reference to the previous work of this investigation as reported by Akell (3) determining the loading and flooding characteristics of Fiberglas packing will substantlate this fact. The column when operating above the loading point had a small column pressure drop of only 0.3 in $\mathrm{H}_{2} \mathrm{O} / \mathrm{ft}$. of packing.

Absorption determinations were carried out with the column operating under flooding conditions Imposed by the water rates of Runs 34,36 , and 39 . In general, normal $\mathrm{K}_{\mathrm{g}}$. values were obtained although the H.E.T.P. and H.T.U. values were somewhat lower than the normal expected values. For example. Run 34 with the column operating with an air rate of $949 \mathrm{Ibs} \cdot / \mathrm{hr} \cdot \mathrm{sq} \cdot \mathrm{ft}$. and a water rate of $32,600 \mathrm{lbs} . / \mathrm{hr} \cdot \mathrm{sq} \cdot \mathrm{ft}$. presented the lowest H.E.T.P. and H.T.U. values of the experimental absorption muns. The H.E.T.P. amount to $1.43 \mathrm{ft}$. 
while the H.T.U. was $0.71 \mathrm{ft}$. These operating conditions would not be practical and little significance should be given to such data since the amount of ammonia in the exit gas stream is extremely small and experimental values are in some doubt:

Examination of the data at varying ammonia concentrations indicates that the overall transfer coefficient increases slightly with an increasing ammonia content in the Inlet gas; however, at low air rates the trend is not perceptible. The data are not sufficiently consistent nor accurate enough to demonstrate the effect of ammonia concentration by means of graphs: 
DISCUSSION OF RESUITS 
An examination of Figs. 13 and 14 showing the effects of water and air rate on the overall transfer coefficient reveals that the data are in good agreement with the accepted theory governing the ammonia-water absorption process. The plot relating $\mathrm{K}_{\mathrm{g}}$ with the superficial air rate resulting in practically two parallel straight lines for two different flows of water input is in agreement, and the trend at two water rates is essentially the same with the more ample water throughput $\mathrm{yielding} \mathrm{K}_{\mathrm{g}}$ a values of an increased magnitude through an increase in the active absorbing surface area of the packing. In other words, the $\mathrm{K}_{\mathrm{g}}$ value, if measured independently. would probably remaln constant for any water rate. But the increase in the wetted surface area of the packIng Imposed by an increased supply of downflowing water augments the surface area term in the $\mathrm{K}_{\mathrm{g}}$ a factor.

As was previously noted, the water rate influences the $\mathrm{K}_{\mathrm{g}}$ a value to only a slight extent after the packing has been completely wetted, and this is a generally accepted conclusion. The flow rate of the input water must provide a sufficlent quantity of water in order to wet the Fiberglas In a complete and uniform manner before the independence of $\mathrm{K}_{\mathrm{g}} \mathrm{a}$ with respect to liquor rate can be assumed. The greater supply of carrier air results in higher $\mathrm{K}_{\mathrm{g}}$ a values in this case because of the increasing tendency of $\mathrm{K}_{\mathrm{g}} \mathrm{a}$ with an increasing superficial air rate: 
Numerous investigators $(11,14,15,16,17,21)$ have previously examined the characteristics of an ammonia absorption by water, and have drawn practically indentical conclusions. There is canplete agreement in regard to the overall transfer coefficient being predominately controlled by the gas rate, and only slightly influenced by the liquor rate. The variation of $\mathrm{K}_{\mathrm{g}}$ a with gas flow has been previously expressed as proportional to the gas rate raised to an exponential power less than unfty depending on the type of packing material, and the effect of liquor rate on the $\mathrm{K}_{\mathrm{g}}$ value has been formulated in a similar manner. Chilton, Duffey, and Vernon (17) have concluded that for a given tyge of packing the increase in the overall absorption coefficient is proportional to some fractional power of the increase in surface. Kowalke, Hougen, and Watson (15) noted that an increase in the ammonia concentration of the inlet gas promoted a slight increase in the value of the overall transfer coefficient. This slight increasing tendency of $K_{\mathrm{g}}$ with ammonia concentration was also demonstrated from the results of this investigation. A few investigators $(11,14,15)$ ascertained that $\mathrm{K}_{\mathrm{g}}$ a decreased to a slight extent as the temperature increased, but no attempt was undertaken to determine the fefet of temperature on the absorption coefficients in carrying out the investigation of Fiberglas tower packing.

From the above mentioned statements it can be 
realized that the results of this investigation are substantially in agreement with the deductions of the foregoing investigators studying the absorption of amonia by water. In general, the flow rates employed in this investigation greatly exceed the throughput rates imposed by the previous investigators. The size of the column, however, compares favorably with the experimental colurms used in ammonia absorption runs reported in the literature. The conformity of the results of this investigation with the accepted theory lends credence to the basic soundness of the experimentally determined $\mathrm{K}_{\mathrm{g}}$ a values.

A review of the literature concerning the previous work on the ammonia-water system reveals that only a few investigators $(17,21)$ have presented experimental H.T.U. values for a limited number of packing materials. No attempts have been made by the previous investigators to relate H.T.U. data with the respective gas and water throughput rates by means of plots.

An examination of Figs. 15 and 16 indicates that the trends of the H.E.T.P. under the influence of varying gas and liquid flow rates parallel the trends of the H.T.D. under similar conditions. This is logical for the H.E.T.P. and H.T.U. values are calculated from equations which bear a considerable resemblance to one another. The mathematical setup of the respective H.E.T.P. and H.T.U. equations is responsible for the H.E.T.P. value exceeding the H.T.U. value in an approximate twofold manner for the individual absorption runs. 
No H.E.T.P. values are available in the literature for the absorption of ammonia by water.

In evaluating the H.E.T.P. and H.T.U. values obtained from the data of this investigation, it should be remembered that these quantities were computed from the $\mathrm{K}_{\mathrm{g}}$ a values. Such values are secondary quantities; therefore, the H.E.T.P. and H.T.U. values are influenced also by the factors that affect the overall transfer coefficient. Such factors can sometimes exert their influence in an indeterminable manner.

It has been previously stated that there are only two literature references to Fiberglas packing; that of Minard, Koffolt, and Withrow and that of Herman and Kalser. It is to be understood that nelther of these articles deals with absorption as such, but both are specifically for rem porting distillation investigations. In the field of distillation, conditions of liquid and gas flow are materlally different, for although the gas rates may be quite high, the liquid rate is tied in with in through the reflux ratio, and it cannot be large in proportion. An examination of both articles indicates that the liquid rates at no time exceeded $1500 \mathrm{lbs} . / \mathrm{hr} . \mathrm{sq} . \mathrm{ft}$. , which is below the minimum water rate in this investigation and far below the value which, by visual observation, afforded an even and uniform liquid distribution pver the Fiberglas packing:

Caloulations were necessary to determine the re- 
sulting liquor rates from these two previous investigations of Fiberglas packing. The calculations for the respective Ilquid rates in these columns were based on the vapor rate and the ratio, V/I, as reported. Several runs from each of the systems, methanol-water and ethanol-water, were selected from the data of Minard, Koffolt, and Withrow on the basis of representing their widest range of variables: These are tabulated in Table I. Their data from the runs conducted on the column with a height of 1.45 feet presented H.T.U. values that were too low with respect to their assoclated liquor rates to be adequate for correlation purposes. Such data were neglected, and only data from the runs carried out with a colum helght of 6.5 feet were consldered. All the liquid rates were computed for the runs performed by Herman and Kaiser in rectifying ethanol-water mixtures with a colum packed with Fiberglas to a helght of 5.67 feet. Their data are shown in tabular form in Table II:

Fig. 17 is a plot showing a representative portion of the data of Minard, Koffolt, and Withrow together with all the date reported by Herman and Kaiser along with the range of values obtained in this investigation for liquid rates below $8000 \mathrm{lbs} / \mathrm{hr} . \mathrm{sq} . \mathrm{ft}$, while the values for flows above this figure are constant within the plotting accuracy of this graph. This plot demonstrates the good agreement of the data of this investigation with that previously reported for Fiberglas. The variations are within experimental 
TABLE I - DATA OF MINARD, KOFFOLT AND WITHROW

\begin{tabular}{|c|c|c|c|c|c|c|c|}
\hline & $\begin{array}{l}\text { Run } \\
\text { No. }\end{array}$ & $\frac{\text { Avg: }}{Y}$ & $\begin{array}{l}x \\
\text { at } \\
\text { Avre: } \\
Y\end{array}$ & $\begin{array}{c}\text { Vapor- } \\
\text { Iiquid } \\
\text { Ratio } \\
\text { (V.I) } \\
\text { (Ib-MoIs }\end{array}$ & $\begin{array}{r}\text { Vapor } \\
\text { Flow } \\
(\mathrm{V}) \\
\text { Ibs } \\
\text { (hr.) (It }\end{array}$ & $\begin{array}{c}\text { IIquid } \\
\text { Flow } \\
\text { (I) } \\
\text { Ibs: } \\
\left(\mathrm{hr}_{\mathrm{r}}\right)(\mathrm{ft})\end{array}$ & $\begin{array}{l}\text { H.T.U. } \\
\text { (ft. })\end{array}$ \\
\hline $\begin{array}{l}\text { Serles C } \\
\text { Methanol- } \\
\text { Water }\end{array}$ & $\begin{array}{l}2 \\
6 \\
7 \\
10 \\
12 \\
13 \\
14 \\
18 \\
19 \\
20\end{array}$ & $\begin{array}{l}0.774 \\
0.121 \\
0.098 \\
0.312 \\
0.430 \\
0.413 \\
0.107 \\
0.253 \\
0.502 \\
0.087\end{array}$ & $\begin{array}{l}0.492 \\
0.019 \\
0.015 \\
0.063 \\
0.107 \\
0.098 \\
0.017 \\
0.047 \\
0.143 \\
0.013\end{array}$ & $\begin{array}{l}1.21 \\
1.20 \\
1.20 \\
1.48 \\
1.50 \\
1.50 \\
1.48 \\
1.73 \\
1.68 \\
1.75\end{array}$ & $\begin{array}{l}868 \\
402 \\
489 \\
523 \\
834 \\
834 \\
436 \\
485 \\
713 \\
478\end{array}$ & $\begin{array}{l}616 \\
310 \\
380 \\
297 \\
450 \\
453 \\
276 \\
242 \\
338 \\
312\end{array}$ & $\begin{array}{r}1.56 \\
6.40 \\
6.00 \\
5.09 \\
3.69 \\
3.63 \\
8.80 \\
7.40 \\
10.90 \\
10.90\end{array}$ \\
\hline $\begin{array}{l}\text { Series D } \\
\text { Methanol- } \\
\text { Water }\end{array}$ & $\begin{array}{r}3 \\
5 \\
6 \\
10\end{array}$ & $\begin{array}{l}0.338 \\
0.581 \\
0.221 \\
0.578\end{array}$ & $\begin{array}{l}0.071 \\
0.214 \\
0.038 \\
0.202\end{array}$ & $\begin{array}{l}1.50 \\
1.51 \\
1.50 \\
1.50\end{array}$ & $\begin{array}{l}255 \\
438 \\
498 \\
932\end{array}$ & $\begin{array}{l}142 \\
232 \\
292 \\
497\end{array}$ & $\begin{array}{l}4.84 \\
2.64 \\
6.31 \\
2.76\end{array}$ \\
\hline $\begin{array}{l}\text { Series E } \\
\text { Ethanol- } \\
\text { Water }\end{array}$ & $\begin{array}{r}8 \\
9 \\
10 \\
12 \\
14 \\
17\end{array}$ & $\begin{array}{l}0.378 \\
0.283 \\
0.260 \\
0.201 \\
0.496 \\
0.492\end{array}$ & $\begin{array}{l}0.068 \\
0.041 \\
0.035 \\
0.024 \\
0.149 \\
0.142\end{array}$ & $\begin{array}{l}1.49 \\
1.62 \\
1.50 \\
1.77 \\
1.86 \\
1.86\end{array}$ & $\begin{array}{l}400 \\
221 \\
387 \\
451 \\
915 \\
909\end{array}$ & $\begin{array}{l}187 \\
101 \\
195 \\
201 \\
342 \\
338\end{array}$ & $\begin{array}{l}3.13 \\
5.32 \\
5.41 \\
9.12 \\
2.58 \\
2.66\end{array}$ \\
\hline $\begin{array}{l}\text { Series F } \\
\text { Ethanol- } \\
\text { Water }\end{array}$ & $\begin{array}{l}5 \\
6 \\
7 \\
8 \\
9\end{array}$ & $\begin{array}{l}0.392 \\
0.281 \\
0.254 \\
0.220 \\
0.387\end{array}$ & $\begin{array}{l}0.072 \\
0.040 \\
0.035 \\
0.028 \\
0.070\end{array}$ & $\begin{array}{l}1.58 \\
1.50 \\
1.50 \\
1.40 \\
1.58\end{array}$ & $\begin{array}{l}498 \\
387 \\
400 \\
689 \\
500\end{array}$ & $\begin{array}{l}217 \\
189 \\
201 \\
382 \\
220\end{array}$ & $\begin{array}{l}3.15 \\
5.22 \\
5.46 \\
6.05 \\
3.13\end{array}$ \\
\hline $\begin{array}{l}\text { Series H } \\
\text { Hethanol- } \\
\text { Water }\end{array}$ & $\begin{array}{r}1 \\
5 \\
6 \\
7 \\
9 \\
13\end{array}$ & $\begin{array}{l}0.414 \\
0.525 \\
0.163 \\
0.155 \\
0.224 \\
0.430\end{array}$ & $\begin{array}{l}0.100 \\
0.159 \\
0.027 \\
0.025 \\
0.040 \\
0.106\end{array}$ & $\begin{array}{l}0.85 \\
0.65 \\
0.69 \\
0.69 \\
0.53 \\
0.47\end{array}$ & $\begin{array}{l}357 \\
827 \\
461 \\
501 \\
629 \\
485\end{array}$ & $\begin{array}{r}342 \\
1020 \\
606 \\
662 \\
1045 \\
834\end{array}$ & $\begin{array}{l}3.94 \\
2.00 \\
4.14 \\
3.78 \\
3.03 \\
2.35\end{array}$ \\
\hline $\begin{array}{l}\text { Series I } \\
\text { Ethano1- } \\
\text { Teber }\end{array}$ & $\begin{array}{r}7 \\
8 \\
9 \\
10 \\
13 \\
19 \\
20 \\
21\end{array}$ & $\begin{array}{l}0.255 \\
0.295 \\
0.235 \\
0.225 \\
0.350 \\
0.450 \\
0.280 \\
0.170\end{array}$ & $\begin{array}{l}0.035 \\
0.045 \\
0.030 \\
0.029 \\
0.058 \\
0.1 .00 \\
0.040 \\
0.020\end{array}$ & $\begin{array}{l}0.37 \\
0.38 \\
0.38 \\
0.36 \\
0.63 \\
0.61 \\
0.64 \\
0.70\end{array}$ & $\begin{array}{l}443 \\
451 \\
536 \\
536 \\
581 \\
572 \\
555 \\
657\end{array}$ & $\begin{array}{r}903 \\
869 \\
1080 \\
1150 \\
655 \\
638 \\
643 \\
762\end{array}$ & $\begin{array}{l}2.32 \\
2.37 \\
2.69 \\
2.86 \\
2.29 \\
2.77 \\
3.56 \\
4.39\end{array}$ \\
\hline
\end{tabular}




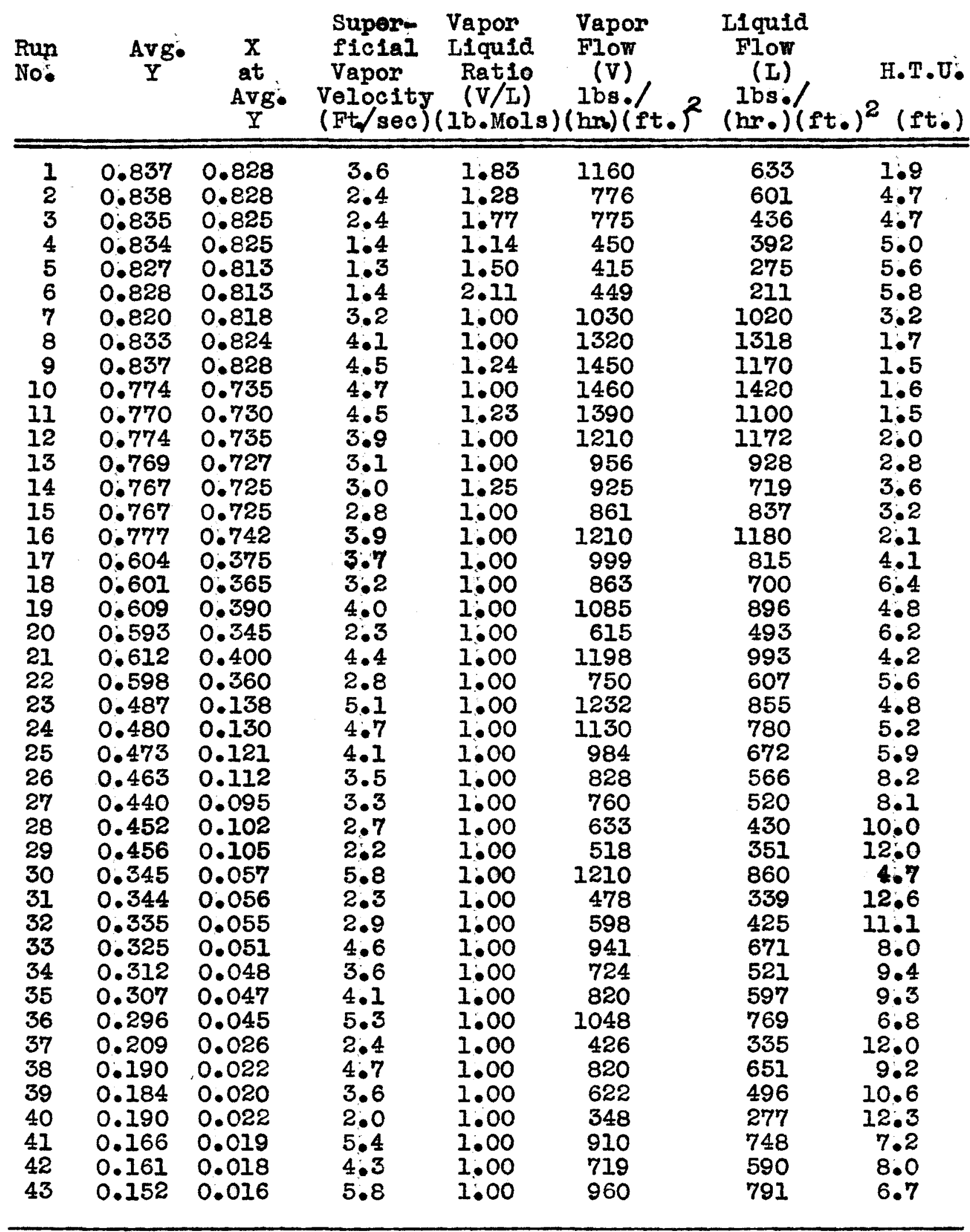


accuracies for systems of different materials. The plot also displays that the H.T.U. values obtained by Minard, Koffolt, and Withrow are intrinsically in good alignment with the values presented by Herman and Kalser. The previous available data further substantiate that extremely high H.T.U. values result when a Flberglas packed column is operated under the conditions of a low liquid rate. As the Iiquor rate is increased, the corresponding H.T.U. values are reduced accordingly. The H.T.U. values of this investigation were much lower than the previously reported values because absorption determinations allowed considerably higher down-flow Iiquid rates in the column.

This plot points out that the quantity of Iiquid actually flowing down the Fiberglas packed columns of these two former groups of investigators was not adequate to wet the packing in a complete and uniform manner. The resulting high H. T. $U$. values can be attributed to this condition. In Table III a representative summary of the data of previous investigators reporting on experimental studies conducted on ammonla-water absorption is presented. The $\mathrm{K}_{\mathrm{g}}$ a values with the accompanying gas and liquid flow rates are given, and the H.T.U. values are included if available. In some cases, the units associated with $\mathrm{K}_{\mathrm{g}}$ a values and flow rates had to be converted to the units of this investigation in order to maintain consistency for comparative needs. This table reveals that the gas flows in the previous 
TABIE III - RESULTS OF OTHER INVESTIGATORS

\begin{tabular}{|c|c|c|c|c|c|c|}
\hline Investigators & & $\begin{array}{l}\text { Packing } \\
\text { Material }\end{array}$ & $\begin{array}{l}\text { Gas } \\
\text { Rate } \\
\text { (G) } \\
\text { Ibs. } \\
(\mathrm{hn})(\mathrm{ft})^{2} \\
\end{array}$ & 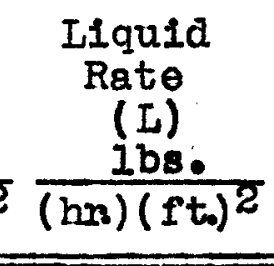 & $\begin{array}{c}\mathrm{K}_{\mathrm{g}} \mathrm{a} \\
\text { Ibs./ } \\
\text { (min) ( ft.) } \\
\text { (mm.Hg. }\end{array}$ & $\begin{array}{l}\text { H.T.U: } \\
\text { (ft. ) }\end{array}$ \\
\hline \multirow{11}{*}{$\begin{array}{l}\text { Sherwood } \\
\text { and } \\
\mathrm{K} 1 \text { lgore }\end{array}$} & $9-16$ & mm: Coke & 507 & 323 & 0.0044 & \\
\hline & & & 459 & $\begin{array}{l}\text { Constant } \\
\text { For all }\end{array}$ & 0.0040 & \\
\hline & & & 400 & Runs & $0: 0035$ & \\
\hline & & & 338 & & 0.0030 & \\
\hline & & & 303 & & 0.0029 & \\
\hline & & & 246 & & 0.0027 & \\
\hline & & & 148 & & 0.0023 & \\
\hline & & & 120 & & $0: 00258$ & \\
\hline & & & 459 & & $0: 0047$ & \\
\hline & & & 348 & & 0.0041 & \\
\hline & & & 490 & & 0.0050 & \\
\hline \multirow{11}{*}{$\begin{array}{l}\text { Chilton, } \\
\text { Duffey, and } \\
\text { Vernon }\end{array}$} & $3 / 4^{n}$ & Stone & 544 & 497 & 0.0042 & $1: 76$ \\
\hline & & & 543 & 494 & $0: 0059$ & 1.24 \\
\hline & & & 561 & 490 & 0.0046 & 1.65 \\
\hline & & & 565 & 493 & 0.0046 & 1.68 \\
\hline & & & 567 & 491 & 0,0047 & 1.62 \\
\hline & & & 562 & 509 & $0: 0029$ & 2,62 \\
\hline & & & 565 & 484 & 0.0047 & $1: 64$ \\
\hline & & & 564 & 504 & 0.0038 & $2: 00$ \\
\hline & & & 550 & 488 & 0.0052 & 1.44 \\
\hline & $1 / 2^{n}$ & Stone & 570 & 502 & 0.0056 & 1.35 \\
\hline & & & 546 & 530 & 0.0046 & 1.60 \\
\hline
\end{tabular}


TABLE III (continued) -RESULTS OF OTHER INVESTIGATORS

\begin{tabular}{|c|c|c|c|c|c|}
\hline InvestIgators & $\begin{array}{l}\text { Packing } \\
\text { Material }\end{array}$ & $\begin{array}{l}\text { Gas } \\
\text { Rate } \\
\text { (G) } \\
\text { Ibs: } \\
(\mathrm{hn})(\mathrm{ft})^{2}\end{array}$ & $\begin{array}{c}\text { Liquid } \\
\text { Rate } \\
\text { (I) } \\
\text { Ibs: } \\
\left.(\mathrm{hr})_{0}\right)(\mathrm{ft})^{2}\end{array}$ & $\begin{array}{c}\mathrm{K}_{\mathrm{p}} \\
\mathrm{lbs} \cdot / \\
(\mathrm{min})(\mathrm{ft}) \\
(\mathrm{mm} \cdot \mathrm{Hg} \cdot)\end{array}$ & $\begin{array}{l}\text { H.T.U: } \\
\text { (ft.) }\end{array}$ \\
\hline & $1 / 4^{\prime \prime}$ Stone & 388 & 510 & 0.0054 & 0.95 \\
\hline & Clo.y & 563 & 510 & 0.0036 & 2.13 \\
\hline & Spheres & 553 & 485 & 0.0033 & 2.27 \\
\hline & & 561 & 540 & 0.0041 & $1: 84$ \\
\hline & & 546 & 585 & 0.0036 & 2.06 \\
\hline & $3 / 4^{\prime \prime}$ Clay & 562 & 507 & 0.0039 & 1.92 \\
\hline & Spheres & 547 & 535 & 0.0038 & 1.92 \\
\hline . & & 553 & 531 & 0.0050 & 1.47 \\
\hline \multirow{4}{*}{$\begin{array}{l}\text { Chilton, } \\
\text { Duffey, and } \\
\text { Vernon }\end{array}$} & $\begin{array}{l}3 / 4^{\prime \prime} \text { Clay } \\
\text { Spheres }\end{array}$ & 520 & 575 & 0.0048 & 1.47 \\
\hline & $1 / 2^{\prime \prime}$ Clay & 382 & 497 & $0: 0048$ & $1: 07$ \\
\hline & का & 386 & 571 & 0.0045 & 1.17 \\
\hline & & 556 & 584 & 0.0058 & $1: 28$ \\
\hline \multirow{4}{*}{$\begin{array}{l}\text { Dwyer and } \\
\text { Doder }\end{array}$} & I年" Carbon & 1000 & 480 & 0.0051 & \\
\hline & Raschig Rings & 970 & 480 & $0: 0052$ & \\
\hline & & 516 & 150 & $0: 0021$ & \\
\hline & & 525 & 150 & $0: 0020$ & \\
\hline \multirow{5}{*}{$\begin{array}{l}\text { Molstad, } \\
\text { McKinney and } \\
\text { Abbey }\end{array}$} & 6295 Drip - & 485 & 1850 & 0.0038 & $1: 71$ \\
\hline & Point Grid & 950 & 3000 & 0.0075 & 1.65 \\
\hline & & 485 & 11500 & 0.0064 & $1: 00$ \\
\hline & & 485 & 18500 & 0.0055 & 1.15 \\
\hline & $1^{\prime \prime}$ Raschif & 915 & 3000 & 0.0177 & 0.67 \\
\hline
\end{tabular}


TABLE III (continued) -RESULTS OF OTHER INWESTIGATORS

\begin{tabular}{|c|c|c|c|c|c|}
\hline Investigators & $\begin{array}{l}\text { Packing } \\
\text { Material }\end{array}$ & $\begin{array}{c}\text { Gas } \\
\text { Rate } \\
\text { (G) } \\
\text { Ibs: } \\
(n n)(e+12\end{array}$ & $\begin{array}{c}\text { Liquid } \\
\text { Rate } \\
\text { (I) } \\
\text { Ibs. } \\
(h+1)+12\end{array}$ & $\begin{array}{c}K_{\mathrm{g}} \mathrm{a} \\
\mathrm{lbs} \\
(\mathrm{min})\left(\mathrm{ft} \mathrm{t}_{0}\right) \\
(\mathrm{mm} \cdot \mathrm{Hg} .\end{array}$ & $\begin{array}{l}\text { H.T.U: } \\
\left(f t_{\bullet}\right)\end{array}$ \\
\hline & & 515 & 3000 & 0.0083 & 0.76 \\
\hline & & 515 & 5000 & 0.0087 & 0.75 \\
\hline & & 530 & 10000 & $0: 0089$ & 0.73 \\
\hline & & 515 & 14200 & 0.0081 & 0.81 \\
\hline & I" Berl & 695 & 3000 & 0.0092 & 0.97 \\
\hline & & 870 & 3000 & 0.0106 & $1: 05$ \\
\hline & & 540 & 5000 & 0.0099 & $0: 66$ \\
\hline & & 525 & 12900 & $0: 0114$ & 0.57 \\
\hline
\end{tabular}


experimental work of no time exceed $1000 \mathrm{lbs} / \mathrm{hr} . \mathrm{sq} . \mathrm{ft}$ : This figure saken as the minimum air rate to be held constant for correlation purposes in this investigation. The previous studies of amonia absorption reported in the literature were for the most part carried out with a prevaling liquor rate in the neighborhood of $500 \mathrm{lbs} / \mathrm{hr} . \mathrm{sq} . \mathrm{ft}$. However, Molstad, McKinney, and Abbey reported liquor rates in the high range from 1850 to $18,500 \mathrm{lbs} / \mathrm{hr.sq.ft}$. The rate of input water was varled from 1,590 to 32,600 lbs./hr.sq.ft: for this investigation of Fiberglas packing. The data obtained by Kowalke, Hougen, and Watson in their early determinations of the transfer coefficlents of ammonia in absorption towers were not included in this table. Their flow rates were extremely low with a maximum gas flow of 240 lbs./hr.sq.ft:, and a liquid rate which never exceeded 820 lbs./hr.sq.ft: Then too, their data can be considered as preliminary values, and the results of their work served primarily as a guide for the later investigators in firmly establishing the characterlstics of this system for engineering design purposes.

Since the flow rates of the previous investigators did not represent a sufficient range of variation, a correlation of the data obtained from this investigation with the actual data of previous investigators vas omitted. The transfer efficlencies of the commercial packing materials are generally compared by means of the established empirical equations: Such empirferl equations express $K_{g} a$ as an ex- 
ponential function of gas and liquor flow rates with the required exponents and constants varying for each particular packing material. The derivation of such an empirical equation to represent the material transfer characteristics of Fiberglas was not possible from the results of this investigation because the mass of requisite data was not essential to the problem.

The values of the overall transfer coefficient determined by the previous investigators for other column packings as shown in Table III cannot be directly compared with the $K_{g}$ values obtained from this investigation at similar air throughput rates. Table VI in the appendix gives the $\mathrm{K}_{\mathrm{g}} \mathrm{a}$ values for Fiberglas at considerably higher gas rates, and the $\mathrm{K}_{\mathrm{g}}$ a values are above those reported for the other packing materials. This condition may be expected, however, because of the increased gas flows. The maximum $\mathrm{K}_{\mathrm{g}}$ value given in Table III is 0.0177 at an air and water flow of 915 and $3000 \mathrm{lbs./hr.sq.ft:} \mathrm{respectively,} \mathrm{as} \mathrm{reported} \mathrm{by} \mathrm{Molstad,}$ McKinney, and Abbey for one inch Raschig Rings. The highest experimentaliy determined $\mathrm{K}_{\mathrm{g}} \mathrm{a}$ value for Fiberglas amounted to 0.0229 with the accompanying flow rates of 1400 and 16,700 lbs./hr.sq.ft. for the air and water. The $K_{g}$ values determined for Fiberglas exceed those reported by Kowalke, Hougen, and Watson for packings of quartz and stoneware by factors ranging from 4 to 10 :

It already has been mentloned that empirical equations have been previously established to relate $K_{\text {ga }}$ with 
the gas and liquid rates for some packing materials. Molstad, McKinney, and Abbey (2I) were a group of investigators who, although chiefly concerned with determining the characterietics of the various types of Drip Point Grid packing, derived such equations for eight other packing materials. Their empirical equations were developed so as to express $\mathrm{K}_{\mathrm{g}}$ a as an exponential function of the respective gas and liquor rates in the following manner:

$$
\mathrm{K}_{\mathrm{g}}{ }^{a}=\beta^{\prime} \mathrm{a}^{\prime} \mathrm{L}^{\mathrm{m}}
$$

The individual exponents together with the constant of proportionality varied in magnitude depending on the particular packing. The values designated for these exponents and constants are presented in Table IV for nine individual column packing materials:

Since it was not possible to correlate the results of this investigation directly with the actual data of previous investigators it was decided to utilize the empirical equations available as a means of correlation. The equations of Molstad, McKinney, and Abbey were chosen because their empirical relationships expressed $K_{g}$ as a function of both the ges and liquid flow rates. Of course, the gas rate is principally controlling, but the equations do permit the liquor rate to exert its slight influence. With such equations it would be concelvable to affect a correlation with Fiberglas in comparison with other tower packings. A cor- 
TABLE IV - EMPIRICAL EQUATIONS OF MOLSTAD, MCKINNEY, AND ABBEY

$$
K_{g^{2}}=\beta^{i} G^{n} I^{m^{\prime}}
$$

\begin{tabular}{|c|c|c|c|}
\hline PACKING & $\underline{B}$ & $\underline{n}$ & m \\
\hline 1- Inch Raschig Rings & 0.0207 & 0.90 & 0.18 \\
\hline I- Inch Berl Saddles & $0: 0132$ & 0.66 & $0: 40$ \\
\hline Staggered 3-inch Single Spiral Tile & 0.0178 & 0.59 & 0.31 \\
\hline Staggered 3-1nch Triple Spiral Tile & 0.0101 & 0.54 & 0.46 \\
\hline Staggered 3-Inch Partition TIle & 0.000036 & 0.40 & 1.10 \\
\hline Continuous 3-inch Triple Spiral Tile & 0.00179 & $0: 73$ & 0.47 \\
\hline Wood Grids without legs & $0: 00215$ & 0.63 & 0.59 \\
\hline Wood Grids with legs* & 0.0110 & 0.57 & 0.26 \\
\hline Various Types of Drip* & 0.188 & 0.49 & 0.14 \\
\hline Point Grid Tile & to & to & to \\
\hline Packing Materials & $0: 0052$ & 0.87 & 0.52 \\
\hline
\end{tabular}

* Not used for correlation purposes. 
relation plot illustrating the effect of a varying a ir throughput rate with a fixed water rate on $\mathrm{K}_{\mathrm{ga}}$ for various other packings together with Fiberglas was then constructed. In constructing this correlation plot a constant water rate of $3180 \mathrm{lbs} / \mathrm{hr} . \mathrm{sq}$.ft. was maintained, while the carrier gas was permitted to vary between the limits of 200 and $1600 \mathrm{lbs} / \mathrm{hr} . \mathrm{sq} . \mathrm{ft}$. BV employing this set of flow conditions, the resulting stralght line for Fiberglas obtained under ldentical conditions as shown in Fig. 18 represents the characteristics of Fiberglas on this graph. Six packings were then selected on the basis of representing the most diverging tendencies in packing characteristics. For each packing a $\mathrm{K}_{\mathrm{g}}$ value was computed at every $200 \mathrm{lbs} . /$ hr.sq.ft. Interval for an air rate increasing from 200 to 1600 lbs./hr.sq.ft. BV keeping the water rate fixed at $3180 \mathrm{lbs} / \mathrm{hr} . \mathrm{sq} . \mathrm{ft}_{.}$, the Im term becomes a constant which can be combined with the constant of proportionality, , and the empirical equation is reduced to the more familiar form

$$
\mathrm{K}_{\mathrm{g}} \mathrm{a}=\gamma \quad \mathrm{G}^{\mathrm{n}}
$$

However, in this case the value of the constant of proportionality is affected by the rate of liquor flow. It is evident that $\gamma$ bears no direct relation to the packing surface per cublc foot. Such empirical equations also neglect the effect of ammonia concentration in the raw feed gas. The results from such calculation together with the 


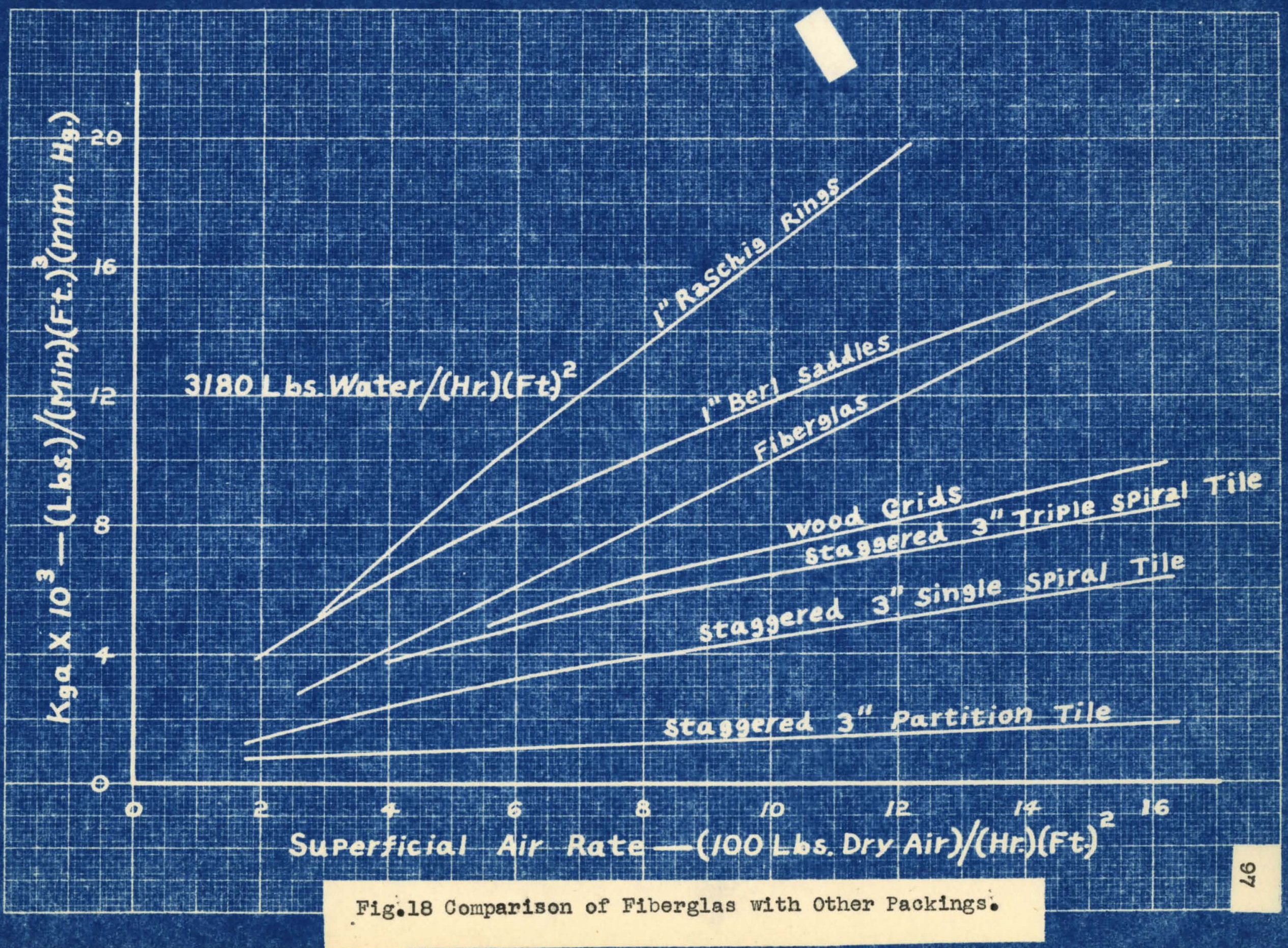


Fiberglas data are shown by the series of curves in Fig.18. All calculated points together with the points obtained for Fiberglas were omitted from this plot for the sake of clarity. This plot indicates that the resulting straight Iine exhibited by Fiberglas under these conditions compares favorably with the accepted theory for the absorption of ammonia by water. In the general expression for $\mathrm{K}_{\mathrm{g}} \mathrm{a}$, the previous investigators agree that the value of $n$, the exponent for $G$, is in the neighborhood of 0.8 . But as this exponent approaches unity in value, the resulting parabolic curve will gradually assume the form of a stralght line. The Iimited number of absorption runs conducted on the Fiberglas packed colum failed to produce the necessary number of points to demonstrate any slight curving tendencies. The empirical equations themselves under these conditions resulted in curves whose curving nature is difficult to distinguish:

Such a correlation also provides an excellent means for comparing the transfer efficiency of Fiberglas with that of other packing materials at identical flow rates. The empirical equations of Molstad, McKinney, and Abbey indicate that Raschig Rings and Berl Saddles yield higher $K_{g}$ a values than Fiberglas under the same conditions of flow. But it can be seen that the $K_{\text {ga }}$ values of Fiberglas approach those of Berl Saddles at the increased superficial air rates. The effect of a continually increasing air flow would favor 
Raschig Rings with a more pronounced increase in $\mathrm{K}_{\mathrm{g}}$ a than Fiberglas. The slopes of the respective lines also indicate that the reverse would be true with respect to Berl Saddles. In general, this plot displays that the transfer efficiency of Fiberglas exceeds that of the other packing materials possessing the desirable property of high allowable flow rates such as wood grids and spiral tile. The resulting curves for these packing materials lie beneath the Fiberglas line and are of a lesser slope.

The available H.T.U. values reported in the Iiterature given along with the $\mathrm{K}_{\mathrm{g}}$ a values in Table III for various column packings compare favorably with those determined for Fiberglas in this investigation. The H.T.U.values reported by Chilton, Duffey, and Vernon for coke, stone, and clay sphere packings are considerably higher than the values reported herein, but the low flow rates associated with such values mast be considered. The H.T.U. values for these packing materials varied from 0.95 to 2.60 feet with the average value amounting to 1.6 feet, but the gas and liquid flow rates at no time surpassed $600 \mathrm{lbs} / \mathrm{hr} . \mathrm{sq} . \mathrm{ft}$. The H.T.U. values determined by Molstand, MoKinney, and Abbey ranged from 0.66 to 105 feet for Raschig Rings and Berl Saddles; however, although their liquid throughput rates were $\mathrm{hlgh}$, the gas rate never exceeded $1000 \mathrm{lbs} . /$ hr.sq.ft. It would be safe to assume a H.T.U. of 1.00 feet for Fiberglas if the rate of down flowing liquid is suffi- 
clent to wet the packing in a complete and uniform manner. An inspection of Fig. 16 represents evidence favoring such an assumption and indicates the required water flow to be $10,000 \mathrm{lbs} . / \mathrm{hr} \cdot \mathrm{sq} \cdot \mathrm{ft}$. for security reasons: 
101

SUMMARY AND CONCLUSIONS 
The experimental procedure for this investigation was well established and straightforward; however, the data are reproducible only within the normal limits associated with determinations involving analytical sampling techniques. The results drawn from this experimental absorption study are consistent with respect to each other, and in excellent agreement with the theory advocated by the other published investigations:

An analysis of results leads to the following conclusions:

1. As a pacling, Fiberglas yields overall transfer coefficients which compare favorably with any small size. large surface area packings, such as Berl Saddles and Raschig Rings, but exceod those of the large size, low surface area packings, such as grids and spiral shapes:

2. Fiberglas can be safely expected to present H.E.T.P. and H.T.U. values amounting to 1.8 and 1.00 feet respectiveI7 If the prevailing liquor rate is sufficient in quantity to wet the Fiberglas in a complete and uniform manner.

3. The operating conditions of a Fiberglas packed column for gas absorption duty must allow an amply liquid rate exceeding 10,000 lbs./hr.sq.ft. If a high $\mathrm{K}_{\mathrm{g}} \mathrm{a}$ value together with a low H.T.U. value is necessary:

4. A Fiberglas packing can be utilized most advantageously for the stripping of a gas with a high solute concentration at a medium flow rate in conjunction with a high 
11quor throughput:

5. In the absorption of ammonia by water the effect of water flow rate on the overall transfer coefficlent is practically negligible if the existent water flow can completely wet the packing material: 
LITERATURE CITED 
(1) Badger, W.L., and MoCabe,W.L., "Elements of Chemical Engineering" 2nd edition, pp. 376-377, New York, McGraw-Hill Book Company, 1936

(2) Anon. "Fiberglas Tower Packing", pp.2-3. Owens-Corning Fiberglas Company

(3) Akell, R. B., M.Ch.E. Thesis in Chemical Engineering, University of Loulsville, 1946

(4) Perry, J.H.," "Chemical Engineers Handbook" 2nd edition, pp. 1200-1203. New York, McGraw-Hill Book Company, 1941

(5) Minard, G.W., Koffolt, J.H., and Withrow,J.T., Trans: Am. Inst. Chem.Engrs., 39,813 (1943)

(6) Colburn, A.P., Trans. Am.Inst.Chem.Engrs., 35,21I (1939)

(7) Herman, A., and Ka1ser, R०R•, Trans.Am.Inst.Chem.Engrs., 40,487 (1944)

(8) Whitman, W.G., and Davis, D.S., Ind. Eng. Chem., $16,1233(1924)$

(9) Moneweck, J.H., and Baker, E.M•, Trans.Am.Inst. Chem. Engrs:, 22,165 (1929)

(10) Hanks, W.V., and McAdams, W.H., Ind. Eng. Chem., 21,1034 (1929)

(II) Haslam, R.T., Hershey, R•I⿰, and Keen, R.H॰, Ind. Eng• Chem. 16.1224 (1924)

(12) Cogan, T.C., and Cogan, J.P., Thesis in Chem. Eng.. Mass.Inst.Tech.. 1932

(13) Hollings, H.: and Silver. I., Trans.Inst. Chem. Engrs. (London), 12.49 (1934) 
(14) Dwyer. O.E.. and Dodge B.F.. Ind. Eng. Chem.. 33.485 (1941)

(15) Kowalke, O.I., Hougen, O.A., and Watson, K.M., Bull.No.68, Eng.Exp.Sta., Univ. of Wisc., 1925

(16) Sherwood, T.K., and Kilgore, A.J., Ind.Eng.Chem.. 18,744 (1926)

(I7) Chilton, T.H., Duffey, H.R., and Vernon, H.C., Ind. Eng. Chem. 29,298 (1937)

(18) Sherwood, T.K., and Holloway, F.A.I,, Trans.Am.Inst. Chem. Engrs., 36,21 (1940)

(19) Borden, H.M., and Squires. W.. Jr., S.M. Thesis in Chem. Eng., Mass. Inst.Tec., 1937

(20) Doherty, T.B., and Johnson, S.C.. S.M. Thesis in Chem. Eng.. Mass. Inst. Tech.. 1938

(21) Molstad, M.C., McKinney, J.F., and Abbey, R.S., Trans. Am. Inst. Chem. Engrs., 39,605 (1943)

(22) Witman, W.G., Long I., and Wang, W.V., Ind. Eng. Chem. 18,363 (1926)

(23) Halta, S., Veda, T., and Baba, A., J.Soc. Chem. Ind. Japan, 37, Suppl. binding, 164 (1934)

(24) Johnstone, H.F., and Williams, G.C.. Ind. Eng. Chem.. 31,993 (1939)

(25) Hixson, A. W., and Scott, C.E., Ind. Eng. Chem., 27,307 (1935)

(26) Witman, W.G., Chem. Met. Eng., 29,147 (1923)

(27) Whitman, W.G., Ind. Eng. Chem., 16.1215 (1924) 
(28) Black, W.C., and Monroe, I.A., S.M. Thesis in Chemical Engineering, Mass. Inst. Tech., 1933

(29) Sherwood, T.K., "Absorption and Extraction" lst edition, pp. 26-27, New York, McGraw-Hill Book Company. 1937

(30) ibid., pp. 6I-69

(31) Walker, W.H.. Lewis, W.K., McAdams, W.H., and Gilliland, E.R., "Principles of Chemical Engineering" 3rd edition, pp. 473-483, New York, McGraw-Hill Book Company, 1937

(32) Sherwood, T.K., "Absorption and Extraction" Ist edition, pp. 69-79, New York, MeGraw-H1ll Book Compang, 1937.

(33) Peters, W.A.,Jr., Ind. Eng. Chem., 14,476 (1922)

(34) Sherwood. T.K.. "Absorption and Extraction" lst edition. pp. 89-93, New York. McGraw-Hill Book Company. 1937

(35) Chilton, T.H., and Colburn, A.P., Ind. Eng. Chem., 27,255 (1935)

(36) Bain, W.A., Jr., and Hougen, O. A., Trans.Am. Inst: Chem. Engrs., 40, 29 (1944)

(37) Rhodes. T.J.. "Industrial Instruments for Measurements and Control" lst edition, pp. 230-231 and 558, New York, McGraw-H1Il Book Company, 1941

(38) Lange, N.A., "Handbook of Chemistry" 4th edition, pp. 941, Sandusky, Oh1o, Handbook Publishing, Inc.,1941 
APPENDIX 


\section{NOMENC LATURE}

$A=$ area of interphase contact, surface and area of packing in square feet per cubic foot.

$B=$ density of glassused in forming fiber.

BI = Ras base factor dependent upon basis for $Q$ for orifice mea surements:

$C$ = apparent density of packing in pounds per cubic foot.

$C^{\prime}=$ coefficient of discharge for the orifice, no units:

$C_{A}=$ concentration of solute in liquid phase in pound mols per cublc foot:

$\mathrm{C}_{B}=$ concentration of solvent in liquid phase in pound mols per cubic foot:

$C_{B M}=\log$ mean of $C_{B}$ at film boundaries in pound mols per cubic foot:

$C_{\theta}=$ concentration of solute in liquid phase corresponding to equilibrium with gas in pound mols per cubic foot:

$C_{1}=$ solute concentration in the Ifquid at the interphase boundary in pound mols per cubic foot:

$C_{L}=$ solute concentration in the main body of the liquid in pound mols per cubic foot:

D = diffusion coefficlent for the solute through the gas phase in square feet per hour:

$D_{I}=$ diffusion coefficient for solute through the liquid. phase in square feet per hour:

$D_{p}=$ internal diameter of pipe in inches.

d a diameter of glass fiber in feet: 
$G=$ inert gas flow in pounds of solute-free gas per hour per square foot of column cross section.

$H=$ Henry's law constant $=C / p$

H' - square root of the maximum pressure differential in inches of rater under air.

H.E.T.P = height equivalent of a theoretical plate in feet.

H.T.U: = height of a transfer unit in feet.

$h=$ height of packing in feet.

$K_{g^{a}}=$ overall transfer coefficient expressed in pound mols per hour per cubic foot per atmosphere driving force, unless othervise specified:

$K_{L^{2}}=$ overall transfer coefficient expressed in pound mols per hour per cublc foot per unit overall concentration difference.

Ke $=$ overall transfer coefficient in pound mols per hour per square foot per atmosphere driving force.

$\mathrm{K}_{\mathbf{I}}=$ overall transfer coefficient in pound mols per hour per square foot per unit overall concentration différence:

$k_{g}=$ gas-film coefficlent in pound mols per hour per square foot per atmosphere driving force:

$k_{1}=$ liquid-film coefficlent. in pound mols per hour per square foot per unit overall concentration difference.

$I \quad=$ liquor rate in pounds of solute-free solvent per hour per square foot of column cross section.

$M=$ moisture correction for measured gas. 
$\mathrm{m}=$ slope of equilibrium curve:

$m^{\prime}=$ exponent depending on packing for I in empirical equation for $\mathrm{K}_{\mathrm{g}}{ }^{a}$.

$\mathrm{M}_{\mathrm{A}}=$ molecular welght of solute gas.

$\mathbf{M}_{\mathrm{B}}=$ molecular weight of inert gas.

$N_{A}=$ diffusion rate in pound moles per hour per square foot.

$n^{\prime}=$ exponent depending on packing for $G$ in empirical equation for $\mathrm{K}_{\mathrm{g}}$.

$\mathbf{P}=$ total pressure on system in atmospheres.

$P^{\prime}=$ pressure factor $=237.1 P_{0}$ where $P_{0}$ is the absolute operating pressures in inches of mercury.

$\mathrm{p}_{1}=$ partial pressure of solute in entering gas in atmospheres.

$p_{2}=$ partial prossure of solute in exiting gas in atmospheres.

$p_{\theta}=$ partial pressure of solute in equilibrium with concentration of main body of liquid in atmospheres:

pg = partial pressure of the solute in the main gas phase in atmospheres.

$p_{1}=$ partial pressure of the solute at the interface between gas and IIquid in atmospheres:

PBM $=$ log mean of inert gas pressures at f1lm boundaries in atmospheres.

Q - gas flow at specified temperature and pressure in cubic feet per hour:

$R=$ gas-law constant ( $=0.729$ in English units) expressed as (atmospheres) (Cu.Ft.) /(Ib.mol.)(OR). 
$S=$ cross-sectional area of column in square feet.

Si = specific gravity correction = square root of the reciprocal of the specific gravity of the gas using air as the reference gas.

T absolute temperature of system, in degrees Rankine.

T. - temperature factor = ratio of the square root of the absolute temperature of the gas at $60^{\circ} \mathrm{F}$ and under operating conditions:

$v=$ volume of packing column section in cubic feet.

$\mathrm{X}_{1}=$ solute concentration of liquid leaving column in pounds solute per pound solvent.

$x_{2}=$ solute concentration of liquid fed to column in pounds solute per pound of solvent:

$x_{g}=$ effective thickness of the gas film in feet:

$\mathrm{x}_{\mathrm{L}}=$ effective thickness of the liquid film in feet:

$Y_{1}=$ solute concentration of the gas entering the column in pounds solute per pound of inert gas.

$Y_{2}=$ solute concentration of the gas leaving the column in pounds solute per pound of inert gas.

$Y_{e}$ - solute concentration in gas corresponding to equilibrium with the concentration of the main body of the Ilquid in pound solute per pound in inert gas. $\alpha=\left(p-p_{\theta}\right) /\left(Y-Y_{\theta}\right)$

$\beta$ and $\gamma$ = constant of proportionality depending on packing in empirical equations for $\mathrm{K}_{\mathrm{g}}$ : 


\section{SAMPLE CALCULATIONS}

The sample calculations shown below are for Run 49, for which the experimental data were given on a sample data sheet included in the Experimental section.

Inlet Gas Sample:

Weight of Siphoned Water $=16$ Ibs.10 oz $=16,6251 \mathrm{bs}:$

Taking the density of water as $62.4 \mathrm{lbs} / \mathrm{ft}^{3}$.

Volume of inlet gas sample $=16.625 / 62.4=0.266$ cu.ft.

Bottle \#1

$$
\begin{aligned}
25(0.0968) & =2.420 \mathrm{~m} \cdot e_{0} \text { original } \\
16.95(0.0968) & =1.620 \mathrm{~m} \cdot \theta . \text { added }
\end{aligned}
$$

Bootle \#2

$$
\begin{aligned}
0.95(0.0123)= & \frac{0.012}{4.072} \text { m.e. added from 2nd Bottle } \\
2(0.30)(0.0123)= & \frac{0.008}{.0} \text { motal } \\
\text { Net } & 4.064 \mathrm{~m} . \theta \cdot \mathrm{NH} 3
\end{aligned}
$$

Outlet Gas Sample:

Weight of Siphoned Water $=26$ Ibs.10 $3 / 4$ oz. $=16.67 \mathrm{lbs}$.

Volume of outlet gas sample $=16.67 / 62.4=0.267 \mathrm{cu} . \mathrm{ft}$.

Bottle \#I $2.1(0.0123)=0.0258 \mathrm{~m} \cdot \theta \cdot$ added

$$
\begin{aligned}
0.3(0.0123) & =\frac{0.0036}{\mathrm{~m} \cdot \theta} \cdot \text { Titration Blank } \\
\text { Net } & 0.0022 \mathrm{~m} \cdot \theta_{0} \mathrm{NH}_{3}
\end{aligned}
$$

mitlet Water Sample:

Average Titer for discharge

liquor sample $=\frac{27.95+28.15}{2}=28.05 \mathrm{ml}$. 


$$
\begin{aligned}
28.05(0.0968) & =2.720 \mathrm{~m} \cdot \theta \cdot \begin{array}{l}
\text { required titer for } \\
\text { neutralization }
\end{array} \\
2.90(0.0123) & =\frac{0.036 \mathrm{~m} \cdot \theta \cdot \text { Titration Blank }}{\text { Net }} 2.684 \mathrm{~m} \cdot \theta \cdot \mathrm{NH}_{3}
\end{aligned}
$$

For an orifice differential pressure of $2.6 " \mathrm{H}_{2} \mathrm{O}$ on the $3^{\prime \prime}$ orffice, the corresponding air flow, as read from Fic. 7 is 262 C.F.M:

Total m.e: $\mathrm{NH}_{3}$ entering $=\frac{262(4.064)}{0.266}=4,000 \mathrm{~m} \cdot \theta_{0} \cdot \mathrm{NH}_{3}$ per minute

For a rotameter reading of 134.5 with the by-pass valve closed, the existing water rate, as determined from Fig: 8 is 10.00 g.p.m:

The conversion factor for converting gallons to cubic centimeters is 3785 .

Total m.e: $\mathrm{NH}_{3}$ leaving in exit water $=\frac{10(2.684)(3785)}{25}=$ $4060 \mathrm{~m} \cdot \theta_{0} \cdot \mathrm{NH}_{3}$ per minute

Total m.8: $\mathrm{NH}_{3}$ leaving in exiting gas stream $=\frac{(262)(0.0222)}{0.267}=$ $21.8 \mathrm{~m} \cdot \theta \cdot \mathrm{NH}_{3}$ per minute Total NH3 lesving $=4060+22=4082 \mathrm{~m} \cdot \theta \cdot \mathrm{NH} 3$ per minute.

The amount of ammonia entering in the gas stream in comparison with the total amonia leaving in both the exit gas and water was used as a check on the accuracy of the gas sampling technique. 
Inooming air was assumed to be completely saturated and at $70^{\circ} \mathrm{F}$. For saturated air at $70^{\circ} \mathrm{F}$ the corresponding saturated volume is $13.7 \mathrm{ft.} 3 / \mathrm{lb}$. dry air.

Inlet $\mathrm{NH}_{3}$ gas

$$
\begin{aligned}
\text { concentration } & =\frac{4082(17)(13.7)}{262(1000)(454)}=\frac{4082}{262}\left(5.14 \times 10^{-4}\right) \\
& =8.00 \times 10^{-3} 1 \mathrm{bs} . \mathrm{NH3} / 1 \mathrm{~b} . \mathrm{drg} \mathrm{alr} .
\end{aligned}
$$

outlet $\mathrm{NH}_{3}$ gas

$$
\begin{array}{r}
\text { concentration }=\frac{21.8}{262}\left(5.14 \times 10^{-4}\right)=4.28 \times 10^{-5} \\
1 \mathrm{bs} . \mathrm{NH}_{3} / 1 \mathrm{~b} . \mathrm{drv} \text { air. }
\end{array}
$$

$\mathrm{NH} 3$ concentration in

$$
\begin{aligned}
& \text { exit water }=\frac{4060(17)}{10(1000)(454)(8.34)}=1.83 \times 10^{-3} \\
& 1 \mathrm{bs} \cdot \mathrm{NH}_{3} / \mathrm{Ib} \cdot \mathrm{H}_{2} \mathrm{O}
\end{aligned}
$$

Pounds $\mathrm{NH}_{3}$ absorbed per minute $=\frac{4060(17)}{1000(454)}=0.1521 \mathrm{bs} . \mathrm{NH}_{3} / \mathrm{min}$ :

Barometric Pressuer

$=745 \mathrm{~mm} \cdot \mathrm{Hg}$.

Static pressure at base of column $=\frac{5.2(760)}{29.9(13.6)}=10 \mathrm{~mm}$. HR.

Absolute operating pressure at base

$=745+10=755 \mathrm{~mm} \cdot \mathrm{Hg}$

At $70^{\circ} \mathrm{F}, 100 \%$ saturated air base has a humidity of 0.016 Ibs. $\mathrm{H}_{2} \mathrm{O} / \mathrm{lb}$. dry air.

Dalton's law will be employed to determine the partial pressure of $\mathrm{NH}_{3}$ in the entering gas stream. 
Total Moles $=\frac{0.008}{17}+\frac{1}{29}+\frac{0.016}{18}=0.0359$ moles:

Partial Pressure of $\mathrm{NH}_{3}$ in entering gas stream $=\mathrm{p}_{1}$

$$
\begin{aligned}
& =\frac{0.000471}{0.0359}(755) \\
& =9.90 \mathrm{~mm} . \mathrm{Hg}
\end{aligned}
$$

To compute the resulting equilibrium partial pressure. of $\mathrm{NH}_{3}$ at the concentration conditions of the discharge liquor. the equation given by Kowalke. Hougen, a nd Watson (15) was used:

$$
\text { In } \frac{p_{\theta}}{m}=\frac{-4425}{T}+10.82
$$

where $T=$ absolute temperature of solution, $\left({ }^{\circ} \mathrm{K}\right)$.

$$
\begin{aligned}
p_{\ominus} & =\text { equilibrium partial pressure of amonia, (atm.) } \\
m & =\text { molality of aqueous solution, }
\end{aligned}
$$

the average temperature of the discharge liquor was $10^{\circ} \mathrm{C}$

$$
\begin{aligned}
& T=10+273=283{ }^{\circ} \mathrm{K} \\
& \mathrm{m}=\frac{1.83}{17}=0.1077 \mathrm{mols} \mathrm{NH}_{3} / 1000 \mathrm{gms} \cdot \mathrm{H}_{2} \mathrm{O} \\
& \text { In } \frac{p_{e}}{m}=\frac{-4425}{283}+10.82=-4.80 \\
& \text { or } \frac{p_{e}}{m}=c^{-4.80}=0.00826 \\
& \text { and } p_{\theta}=-0.00826 \mathrm{~m}=\left(8.26 \times 10^{-3}\right)\left(10.77 \times 10^{-2}\right)(760) \\
& =0.675 \mathrm{~mm} \text {. Hg: } \\
& \text { Then }\left(p-p_{e}\right)_{1}=9.90-0.67=9.23 \mathrm{~mm} \text {. Hg. } \\
& \text { Column pressure drop }=5.1(1.87)=10 \mathrm{~mm} \text {. Hg. }
\end{aligned}
$$


Operating pressure
at top of colum $=755-10=745 \mathrm{~mm} \cdot \mathrm{Hg}$.

The temperature of the outgoing gas was assumed to be the same as the temperature of the existing water.

The corresponding humidity for saturated air at $640 \mathrm{~F}$ is $0.013 \mathrm{Ibs} . \mathrm{H}_{2} \mathrm{O} / \mathrm{Ib}$. dry air.

Total moles $=\frac{4.28 \times 10^{-5}}{17}+\frac{1}{29}+\frac{0.013}{18}=0.0352$

Partial Pressure of $\mathrm{NH}_{3}$ in

$$
\begin{aligned}
\text { exiting gas streem } & =p_{2}=\frac{0.252 \times 10^{-5}}{0.0352}(745) \\
& =0.0533 \mathrm{~mm} . \mathrm{Hg}
\end{aligned}
$$

$p_{\theta}=0$ since fresh ter enters

Therefore, $\left(p-p_{\theta}\right)_{2}=0.0533 \mathrm{~mm}$. Hg:

By Eq. (19) $\left(p-p_{\theta}\right)_{\text {Qvg. }}=\left(p-p_{\theta}\right)_{1}-\left(p-p_{\theta}\right)_{2}$

$$
\ln \frac{\left(p-p_{\theta}\right)_{1}}{\left(p-p_{\theta}\right)_{2}}
$$

$$
\left(p-p_{\theta}\right)_{\text {avg. }}=\frac{9.23-0.0533}{\ln \frac{9.23}{0.0533}}=1.78 \mathrm{~mm} . \mathrm{Hg} \cdot
$$

According to Eq. (18) $K_{g} a=\frac{N_{d}}{V\left(p-p_{\theta}\right)_{a v g}}$

Since the height of packed section had been reduced to $6 \mathrm{ft}$,

$$
v=\frac{\pi(6)}{4}=4.71 \text { cu. ft. }
$$


$\mathrm{K}_{\mathrm{R}}^{\mathrm{a}}=\frac{0.252}{(1.78)(4.71)}=18.1 \times 10^{-3} \mathrm{Ibs.} \mathrm{NH}_{3} /(\mathrm{ft} .)^{3}(\min )(\mathrm{mm} . \mathrm{Hg})$

Calculating the H.E.T.P. by means of Eq. 23,

$$
\begin{aligned}
& \text { H.E.T.P. }=\frac{0.093}{\mathrm{~K}_{\mathrm{g}} \mathrm{a}\left[\frac{637}{\mathrm{C.F.M.}_{\bullet}}+\frac{1.56}{G_{. P . M . M .}}\right]} \\
& \text { H.E.T.P. }=\frac{0.093}{\left(18.1 \times 10^{-3}\right)\left[\frac{637}{262}+\frac{1.58}{10}\right]}=1.98 \mathrm{ft} \text {. }
\end{aligned}
$$

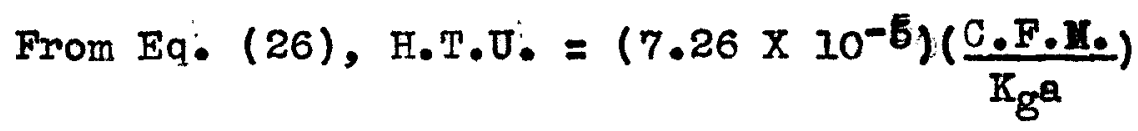

$$
\text { H.T.ण. }=\left(7.26 \times 10^{-5}\right) \frac{(262)}{\left(18.1 \times 10^{-3}\right.}=1.05 \mathrm{ft:}
$$


TABLE V - SUMMARY OF EX PERIMENTAL DATA

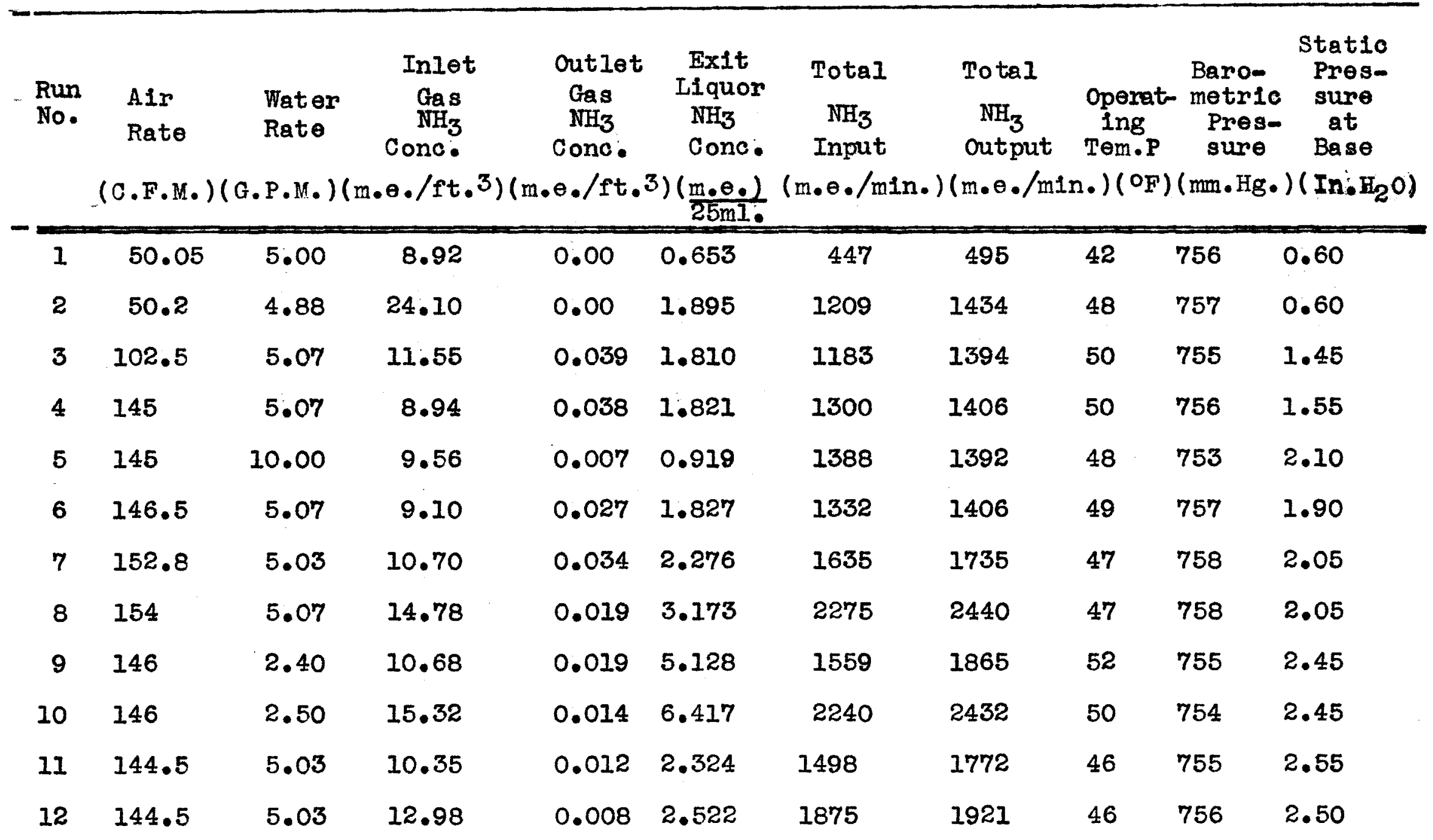


TABLE V (Cont Inued) - SUMMARY OF EXPERIMENTAL DATA

\begin{tabular}{|c|c|c|c|c|c|c|c|c|c|c|}
\hline $\begin{array}{l}\text { Run } \\
\text { No. }\end{array}$ & $\begin{array}{l}\text { A1r } \\
\text { Rato }\end{array}$ & $\begin{array}{l}\text { Water } \\
\text { Rato }\end{array}$ & $\begin{array}{c}\text { Inlet } \\
\mathrm{Gas} \\
\mathrm{NH}_{3} \\
\text { Conc. }\end{array}$ & $\begin{array}{l}\text { Outlet } \\
\text { Gas } \\
\mathrm{NH}_{3} \\
\text { Conc. }\end{array}$ & $\begin{array}{c}\text { Exit } \\
\text { Liquor } \\
\mathrm{NH}_{3} \\
\text { Conc. }\end{array}$ & $\begin{array}{c}\text { Total } \\
\mathrm{NH}_{3} \\
\text { Input }\end{array}$ & $\begin{array}{c}\text { Total } \\
\mathrm{NH}_{3} \\
\text { Output }\end{array}$ & $\begin{array}{l}\text { Operat- } \\
\text { Ing } \\
\text { Tem.P }\end{array}$ & $\begin{array}{l}\text { Baro- } \\
\text { metric } \\
\text { Pres- } \\
\text { sure }\end{array}$ & $\begin{array}{c}\text { Static } \\
\text { Pres- } \\
\text { sure } \\
\text { at } \\
\text { Base }\end{array}$ \\
\hline & C C.F.M & 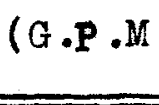 & $. e . / f t$ &.$\left.^{3}\right)(\mathrm{m} . \mathrm{e} \cdot \mathrm{ft}$ & ) $\frac{\left(\mathrm{m} \cdot \theta_{\cdot}\right)}{25 \mathrm{mI}}$ & $. \theta . / \mathrm{mi}$ & )$(\mathrm{m} \cdot \mathrm{e} \cdot \mathrm{mi}$ & $\left.{ }^{\circ} \mathrm{F}\right)(\mathrm{m}$ & $\mathrm{m} \cdot \mathrm{Hg} \cdot$ & ( In. $\mathrm{H} 2$ \\
\hline 13 & 144.5 & 2.50 & 12.50 & 0.002 & 5.220 & 1808 & 1978 & 52 & 756 & 2.50 \\
\hline 15 & 144.5 & 2.50 & 16.15 & 0.019 & 6.710 & 2340 & 2543 & 55 & 752 & 2.45 \\
\hline 16 & 50 & 2.50 & 22.05 & 0.014 & 5.358 & $1101 \%$ & 2031 & 52 & 753 & 0.60 \\
\hline 17 & 50 & 2.50 & 39.90 & 0.033 & 5.913 & 1994 & 2237 & 52 & 752 & 0.60 \\
\hline 18 & 50 & 2.50 & 46.75 & 0.014 & 7.513 & 2350 & 2706 & 54 & 754 & 0.60 \\
\hline 19 & 50 & 2.45 & 37.05 & 0.020 & 5.515 & 1852 & 2046 & 52 & 752 & 0.60 \\
\hline 20 & 50 & 5.00 & 41.25 & 0.030 & 3.028 & 2065 & 2297 & 48 & 753 & 0.65 \\
\hline 21 & 50 & 5.00 & 37.50 & 0.010 & 2.721 & 1872 & 2061 & 48 & 754 & 0.65 \\
\hline 22 & 170 & 2.50 & 12.40 & 0.032 & 6.007 & 2115 & 2284 & 54 & 755 & 3.30 \\
\hline \multirow[t]{2}{*}{24} & 170 & 2.50 & 15.55 & 0.037 & 7.260 & 2640 & 2746 & 59 & 757 & 3.30 \\
\hline & & & 2 & Sections of & Column $R$ & goved & & & & \\
\hline 25 & 177 & 2.50 & 14.68 & 0.565 & 6.969 & 2600 & 2740 & 59 & 754 & 2.60 \\
\hline
\end{tabular}


TABLE V (Continued) - SUMMARY OF EXPERTMENTAL DATA

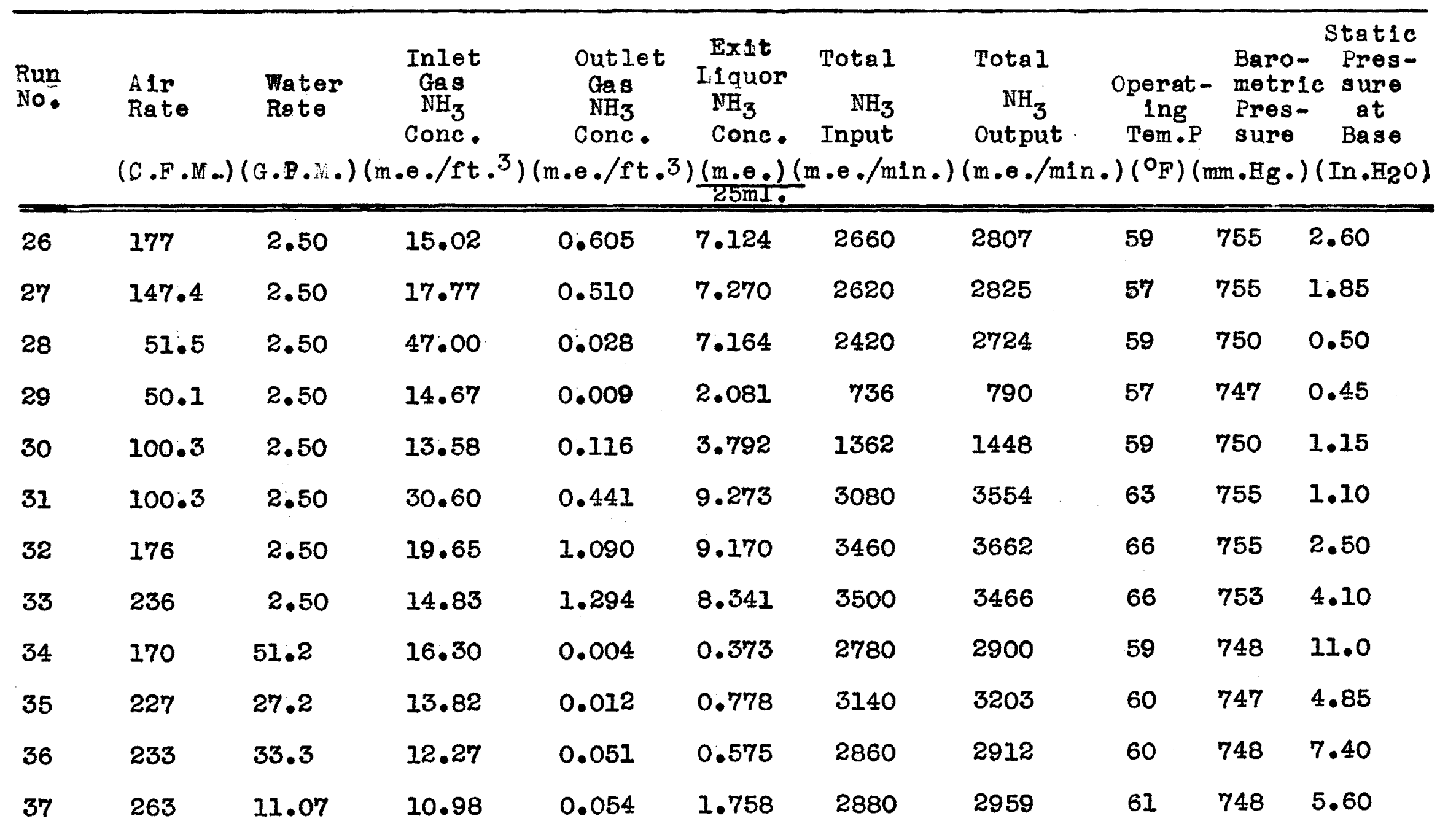


TABIE V - SCMMARY OF EXPERTMENTAL DATA

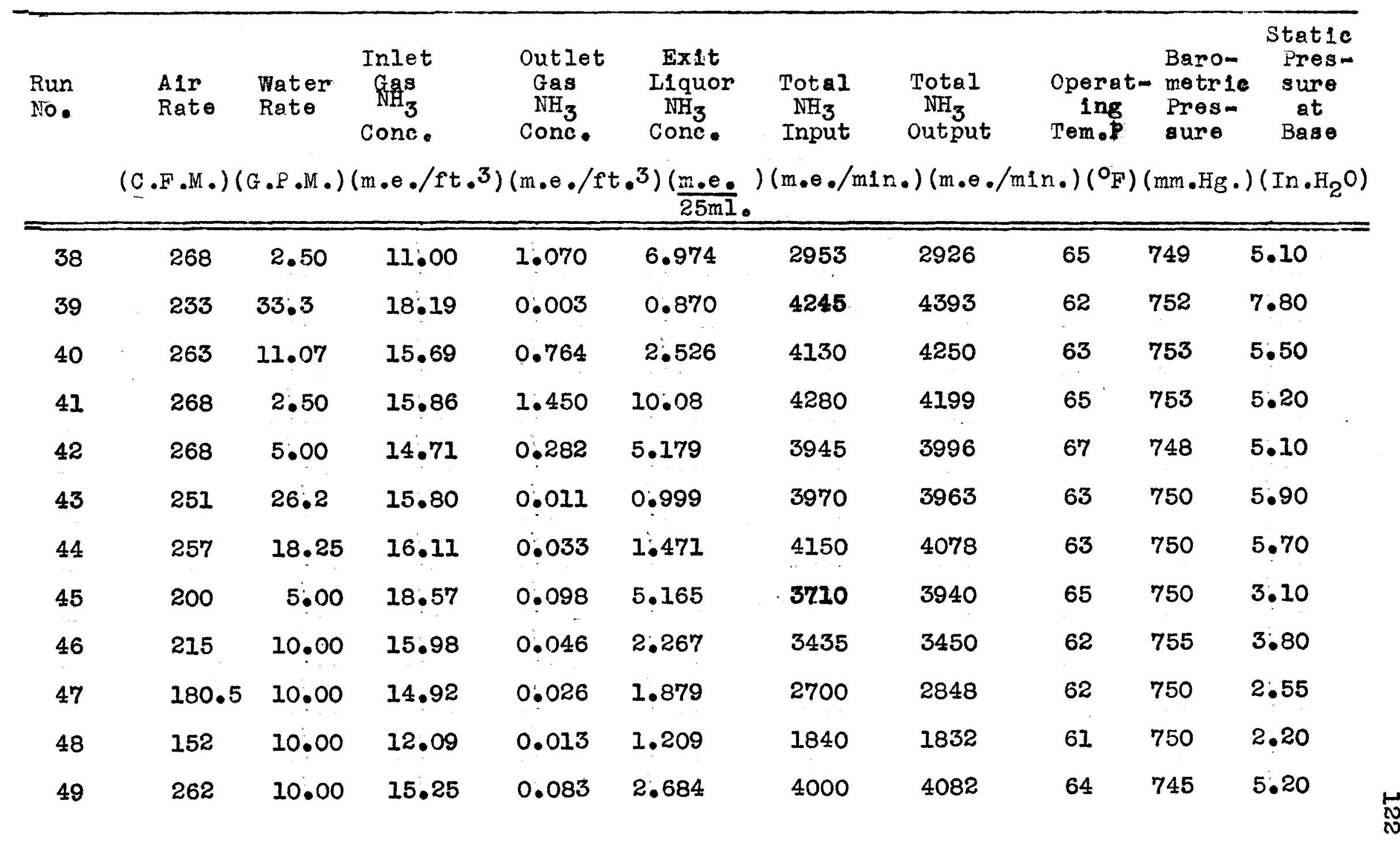


TABLE V (Continued) - SUMMARY OF EXPERIMENTAI DATA

\begin{tabular}{|c|c|c|c|c|c|c|c|c|c|c|}
\hline $\begin{array}{l}\text { Run } \\
\text { No: }\end{array}$ & $\begin{array}{l}\text { Air } \\
\text { Rate }\end{array}$ & $\begin{array}{l}\text { Water } \\
\text { Rate }\end{array}$ & $\begin{array}{c}\text { Inlet } \\
\text { Gas } \\
\mathrm{NH}_{3} \\
\text { Conc: }\end{array}$ & $\begin{array}{l}\text { Outlet } \\
\text { Gas } \\
\text { NHz: } \\
\text { Conk: }\end{array}$ & $\begin{array}{c}\text { Exit } \\
\text { Liquor } \\
\text { NHz } \\
\text { Cond. }\end{array}$ & $\begin{array}{c}\text { Total }_{\mathrm{NH}_{3}} \\
\text { Input }\end{array}$ & $\begin{array}{l}\text { Total }_{3} \\
\text { output }\end{array}$ & $\begin{array}{l}\text { Operat- } \\
\text { Ing } \\
\text { Tem.P }\end{array}$ & $\begin{array}{l}\text { Baro- } \\
\text { metrio } \\
\text { Pres- } \\
\text { sure }\end{array}$ & $\begin{array}{c}\text { Statio } \\
\text { Pres- } \\
\text { sure } \\
\text { at } \\
\text { Base }\end{array}$ \\
\hline & \multicolumn{10}{|c|}{ 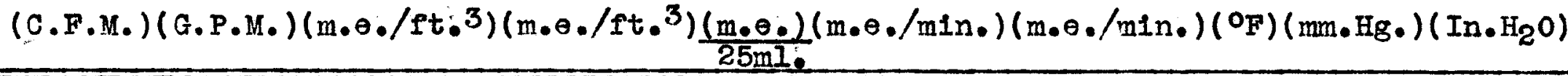 } \\
\hline 50 & 152 & 10.00 & 16.29 & 0.018 & 1.701 & 2475 & 2583 & 64 & 746 & 2.00 \\
\hline 51 & 262 & 10.00 & 11.65 & 0.037 & 1.983 & 3060 & 3010 & 63 & 752 & 5.30 \\
\hline 52 & 262 & 10.00 & 8.64 & 0.028 & 1.423 & 2260 & 2167 & 63 & 752 & 5.20 \\
\hline 53 & 180.5 & 26.25 & 14.70 & 0.021 & 0.722 & 2660 & 2873 & 60 & 752 & 3.25 \\
\hline 54 & 180.5 & 18.25 & 14.51 & 0.023 & $1: 043$ & 2625 & 2884 & 60 & 752 & 3.10 \\
\hline 55 & 180.5 & 5.00 & 15.40 & 0.056 & 3.783 & 2780 & 2880 & 62 & 752 & 2.70 \\
\hline
\end{tabular}




\section{TABIE VI - SUMMARY OF CALCULATED ABSORPTION DATA}

\begin{tabular}{|c|c|c|c|c|c|c|c|c|}
\hline \multirow[t]{3}{*}{$\begin{array}{l}\text { Run } \\
\text { No. }\end{array}$} & \multirow{3}{*}{$\frac{\text { lbs.dry alr }}{(\mathrm{hr} \cdot)(\mathrm{ft} .)^{2}}$} & \multirow{3}{*}{$\begin{array}{l}\begin{array}{l}\text { Water } \\
\text { Rate }\end{array} \\
\frac{\text { Ibs. }}{(\mathrm{hr} \cdot)\left(\text { ft. }_{\bullet}\right)^{2}}\end{array}$} & \multirow{2}{*}{$\begin{array}{l}\text { Inlet } \\
\text { Cone } \\
\times 10^{3} \\
1 \mathrm{~b} \cdot \mathrm{NH}_{3} \\
\end{array}$} & \multirow{2}{*}{$\begin{array}{l}\text { Outlet } \\
\text { Cone } \\
\times 10^{5} \\
\text { Ib.NH3 }\end{array}$} & \multirow{3}{*}{$\begin{array}{l}\mathrm{K}_{\mathrm{g} a} \\
\frac{\mathrm{lbs} \cdot \mathrm{NH}_{3}}{\left(\min _{(\min )(\mathrm{ft} \cdot)^{3}}\right)^{3}}\end{array}$} & \multirow{3}{*}{$\begin{array}{c}K_{g^{a}} \\
1 b \cdot m o 1 s \\
\left(h r_{\cdot}\right)\left(f t_{\cdot}\right)^{3} \\
\end{array}$} & \multirow[t]{2}{*}{$\mathrm{H} . \mathrm{E} . \mathrm{I}$} & \multirow{3}{*}{$\begin{array}{l}\cdot T \cdot P^{H \cdot T \cdot U} \\
(f t \cdot)(r t \cdot d\end{array}$} \\
\hline & & & & & & & & \\
\hline & & & lb.dry alr & $1 b . d x y$ alr & & & $(\operatorname{tm})$. & \\
\hline 1 & 280 & 3190 & 5.1 & 0 & - & - & - & - \\
\hline 2 & 280 & 3105 & 14.7 & 0 & - & - & - & - \\
\hline 3 & 571 & 3230 & 7.0 & 1.90 & 0.0046 & 12.6 & 3.09 & 1.61 \\
\hline 4 & 809 & 3230 & 4.9 & 1.50 & 0.0066 & 17.7 & 3.02 & 1.61 \\
\hline 5 & 809 & 6360 & 4.9 & 0.37 & 0.0078 & 21.8 & 2.61 & $1 \quad 1.34$ \\
\hline 6 & 817 & 3230 & 4.9 & 1.50 & 0.0067 & 17.9 & 3.02 & 1.61 \\
\hline$\eta$ & 852 & 3200 & 5.8 & 1.70 & 0.0069 & 18.7 & 2.99 & 1.60 \\
\hline 8 & 860 & 3230 & 8.1 & $1: 00$ & 0.0082 & 22.6 & 2.57 & 1.37 \\
\hline 9 & 815 & 1528 & 6.6 & 0.95 & 0.0081 & 21.7 & 2.29 & 1.31 \\
\hline 10 & 815 & 1590 & 8.5 & 0.72 & 0.0088 & 23.5 & 2.12 & 1.21 \\
\hline 11 & 806 & 3200 & 6.3 & 0.60 & 0.0079 & 21.1 & 2.50 & 1.33 \\
\hline 12 & 806 & 3200 & 6.8 & 0.43 & 0.0083 & 22.3 & 2.37 & 1.26 \\
\hline 13 & & & Erratic & Sondition, $F$ & Run Discarded & & & \\
\hline
\end{tabular}


TABHE VI (Continued) - SUMARY OF CALCULATED ABSORPTION DATA

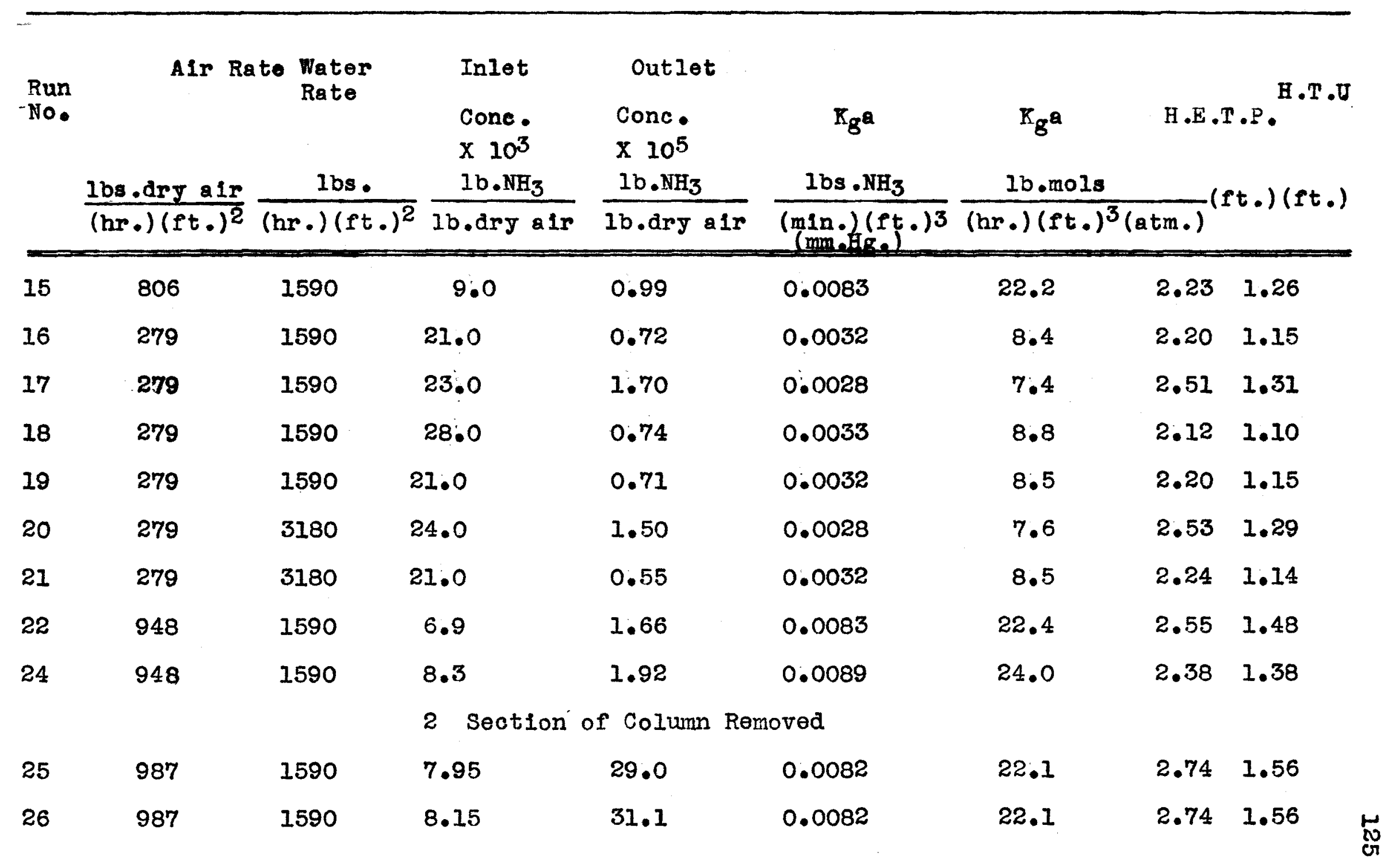


TABLE VI (Continued) - SUMMARY OF CALCULATED ABSORPTION DATA

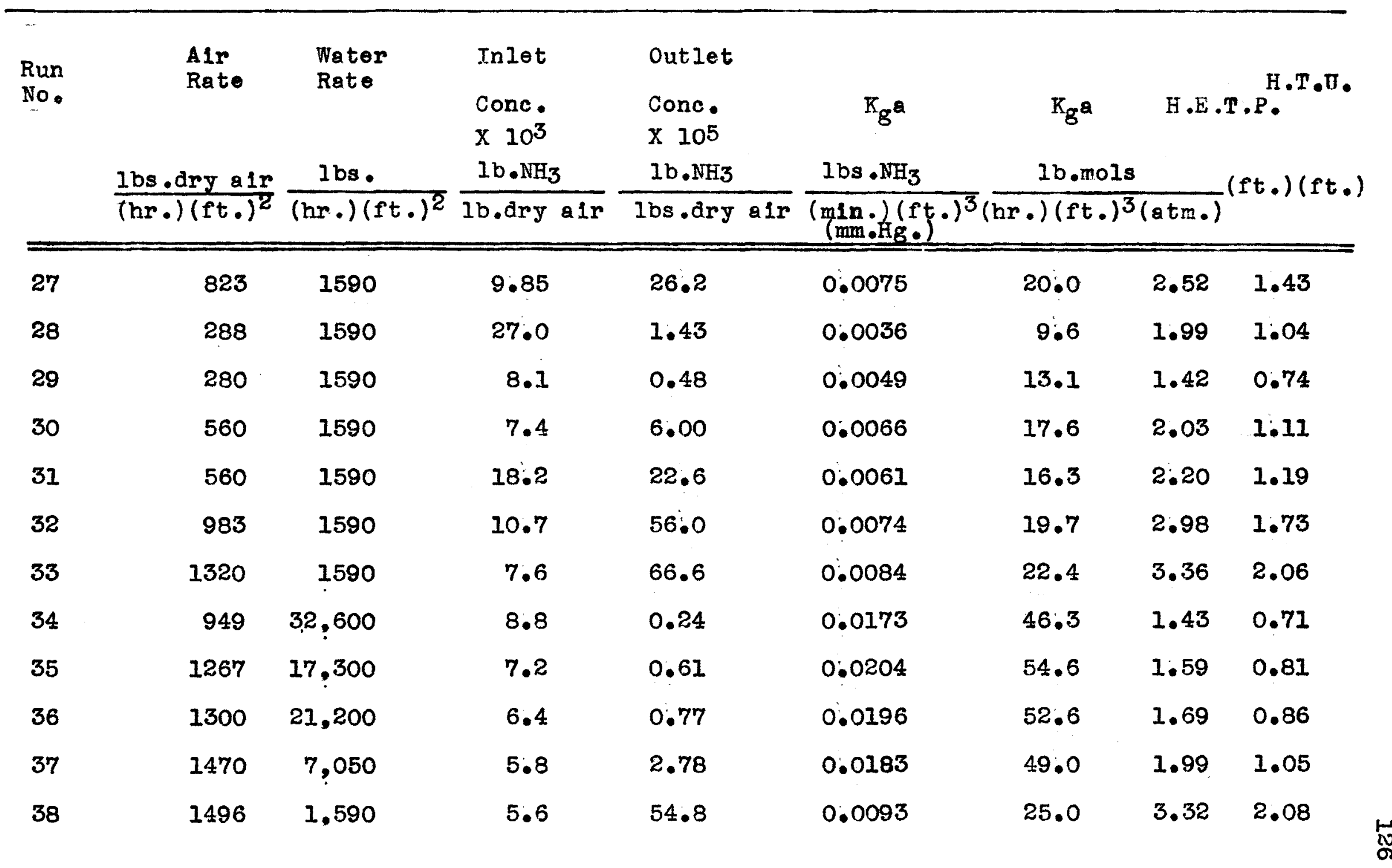




\section{TABIE VI (Continued) - SUMMARY OF CALCULATED ABSORPTION DATA}

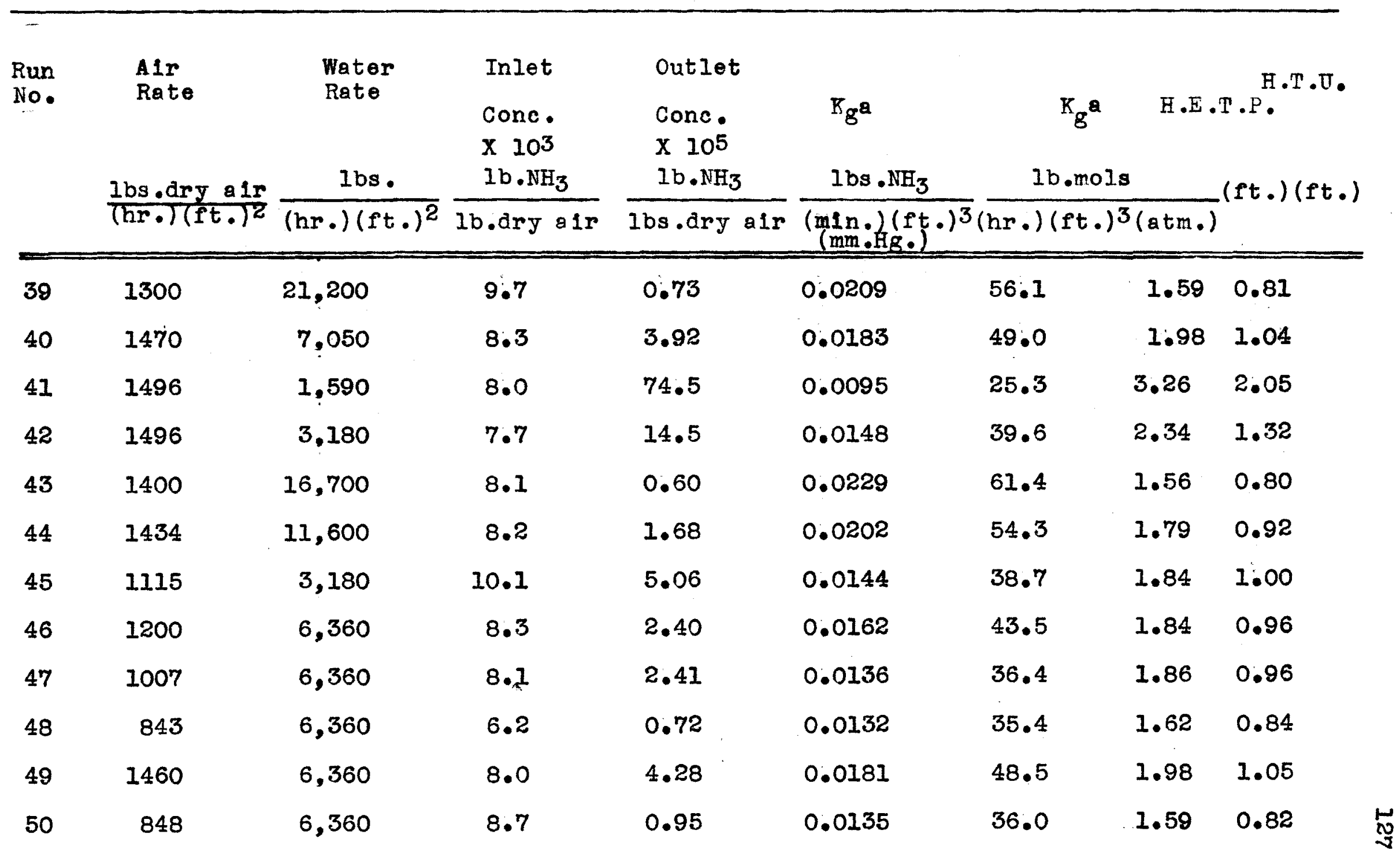


TABLE VI (Continued) - SUMMARY OF CALCULATED ABSORPTION DATA

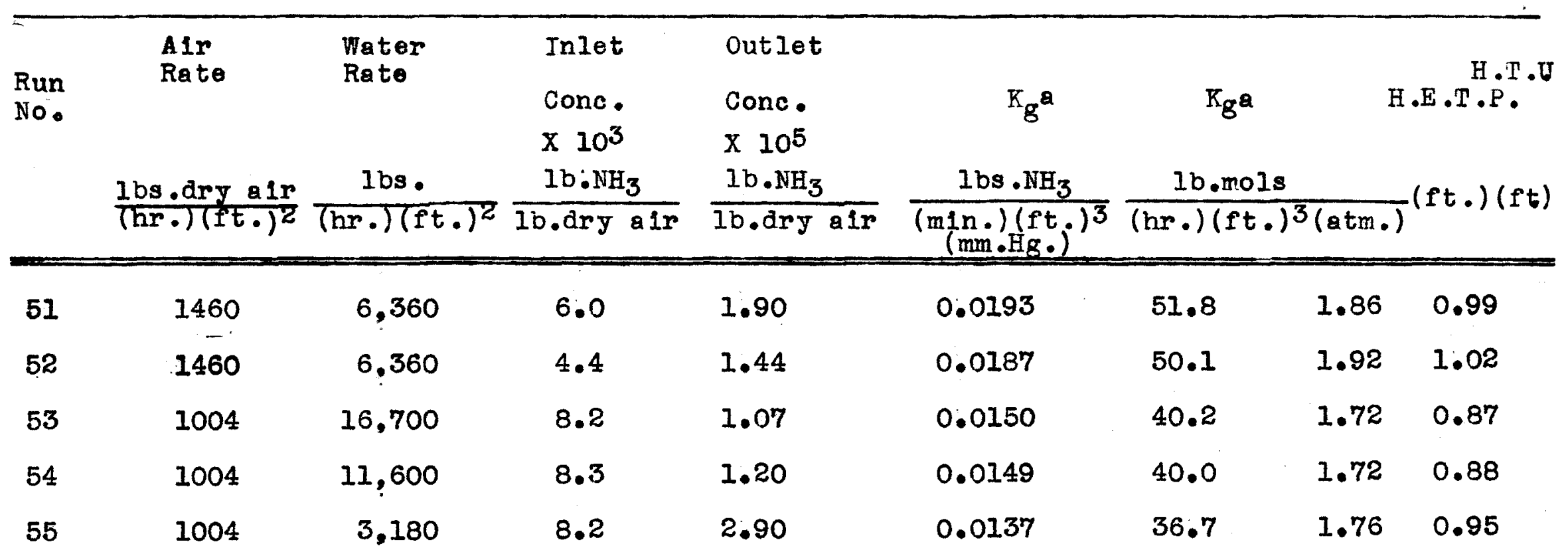


AC KNOWLEDGEMENT 
The author wishes to thank the Institute of Industrial Research of the University of Louisville for making this research avallable to him. He also wishes to thank the owens-Corning Fiberglas Corporation for supporting this project and for supplying the Fiberglas and other equipment. Appreciation is expressed to Mr. Robert B. Akell, a former graduate student, for his assistance in the experimental runs and calculations. 
131

VITA 
The author, Charles Philip Talbott, was born in Louisville, Kentucky, on Julv 6, 1923, the son of Charles William Talbott and Philomena Zehnder Talbott. He commenced his elementary education at the Sacred Heart Model School and transferred to St. James Parochial School where he completed his gramer-school education. He attended st. Xavier High School where he was graduated in June, 1942: In September of 1942, he enrolled in the University of Louisville and recelved his Bachelor of Chemical Engineering degree in June, 1945. He began his graduate studies at the University of Louisville in July, 1945, having been awarded an Industrial fellowship provided by the University of Louisville Institute of Industrial Research, and completed the requirements for a Master of Chemical Engineering degree in December of 1946 .

While pursuing his undergraduate studies at the University of Louisville, he was elected to Theta Chi Delta, a national honorary chemistry fraternity. He also was a member of the Student Chapter of the American Institute of Chemical Engineers, and served as the student council representative for this organization during his senior year: 